\title{
Strengthening the Reporting of Observational Studies in Epidemiology for Newborn Infection (STROBE-NI): An extension of the STROBE statement for neonatal infection research
}

\begin{abstract}
Dr Elizabeth J A Fitchett ${ }^{1}$ MBBCh, Dr Anna C Seale ${ }^{1,2}$ DPhil, Dr Stefania Vergnano ${ }^{3}$ FRCPCH, Professor Michael Sharland ${ }^{3}$ FRCPCH, Professor Paul T. Heath ${ }^{3}$ FRCPCH, Professor Samir Saha ${ }^{4}$ PhD, Dr Ramesh Agarwal ${ }^{5} \mathrm{PhD}$, Dr Adejumoke I. Ayede ${ }^{6} \mathrm{MBBS}$, Professor Zulfiqar A. Bhutta ${ }^{7}$ FRCPCH, Professor Robert Black ${ }^{8}$ $\mathrm{MD}$, Dr Kalifa Bojang ${ }^{9} \mathrm{PhD}$, Professor Harry Campbell ${ }^{10} \mathrm{MD}$, Professor Simon Cousens ${ }^{1}$ DipMathsStat, Professor Gary L. Darmstadt ${ }^{11}$ MD, Professor Shabir A. Madhi ${ }^{12}$ PhD, Dr Ajoke Sobanjo-ter Meulen ${ }^{13}$ MD, Professor Neena Modi ${ }^{14}$ FRCPCH, Dr Janna Patterson ${ }^{15}$ MD, Dr Shamim Qazi ${ }^{16}$ PhD, Dr Stephanie J Schrag ${ }^{17}$ DPhil, Professor Barbara J. Stoll ${ }^{18} \mathrm{MD}$, Dr Steve Wall ${ }^{19} \mathrm{MD}$, Professor Robinson Wammanda ${ }^{20} \mathrm{FWACP}$ Paed, Professor Joy E Lawn ${ }^{1}$ FRCPCH, on behalf of the SPRING (Strengthening Publications Reporting Infection in Newborns Globally) Group
\end{abstract}

Correspondence: Professor Joy E. Lawn ${ }^{1}$ : joy.lawn@Ishtm.ac.uk

${ }^{1}$ MARCH Centre, London School of Hygiene \& Tropical Medicine, London, UK

${ }^{2}$ The Farr Institute of Health Informatics Research, University College London, London, UK

${ }^{3}$ Paediatric Infectious Disease Research Group, St George's University of London, London, UK

${ }^{4}$ Child Health Research Foundation, Department of Microbiology, Dhaka Shishu Hospital, Dhaka, Bangladesh

${ }^{5}$ Department of Pediatrics, All India Institute of Medical Sciences, New Dehli, India

${ }^{6}$ Department of Paediatrics, College Of Medicine, University of Ibadan and University College Hospital, Ibadan, Nigeria ${ }^{7}$ Center of Excellence in Women and Child Health, The Aga Khan University, Karachi, Pakistan; Centre for Global Child Health, The Hospital for Sick Children, Toronto, Canada

${ }^{8}$ Institute for International Programs, Johns Hopkins Bloomberg School of Public Health, Baltimore, Maryland

${ }^{9}$ Medical Research Council, The Gambia Unit, Banjul, The Gambia

${ }^{10}$ Centre for Global Health Research, University of Edinburgh, Edinburgh, UK

${ }^{11}$ Department of Pediatrics, Stanford University School of Medicine, Stanford, CA, USA

${ }^{12}$ Medical Research Council: Respiratory and Meningeal Pathogens Research Unit \& DST/NRF Vaccine Preventable Diseases; Faculty Health Science, University of the Witwatersrand, Johannesburg, South Africa

${ }^{13}$ Vaccines, Bill \& Melinda Gates Foundation, Seattle, Washington

${ }^{14}$ Royal College of Paediatrics and Child Health, London, UK; Department of Medicine, Section of Neonatal Medicine, Imperial College London, London, UK

${ }^{15}$ Maternal, Newborn, and Child Health, Bill \& Melinda Gates Foundation, Seattle, Washington

${ }^{16}$ Department of Maternal Newborn Child and Adolescent Health, World Health Organization, Geneva, Switzerland

${ }^{17}$ Division of Bacterial Diseases, Centers for Disease Control and Prevention, Atlanta, Georgia

${ }^{18}$ Department of Pediatrics, Emory University School of Medicine and Children's Healthcare of Atlanta, Atlanta,

Georgia

${ }^{19}$ Saving Newborn Lives, Save the Children, Washington, DC

${ }^{20}$ Department of Paediatrics, Ahmadu Bello University Teaching Hospital, Ahmadu Bello University, Zaria, Nigeria

Funding: No specific funding was received for this work. Travel fellowships for experts attending the consensus meeting were provided by the Wellcome Trust, the World Health Organisation and the Bill and Melinda Gates Foundation through a grant to the Johns Hopkins Bloomberg School of Public Health. 


\begin{abstract}
Neonatal infections are estimated to account for a quarter of the $2 \cdot 8$ million annual neonatal deaths, as well as approximately $3 \%$ of all DALYs. Despite this burden, data are limited on incidence, aetiology and outcomes, particularly regarding impairment. We aimed to develop guidelines for improved scientific reporting of observational and interventional neonatal infection studies, to increase comparability and to strengthen research in this area. This statement, Strengthening the Reporting of Observational Studies in Epidemiology for Newborn Infection (STROBE-NI) is an extension of the Strengthening the Reporting of Observational Studies in Epidemiology (STROBE) checklist. STROBE-NI was developed following systematic reviews of published literature (1996-2015), compilation of over 130 potential reporting recommendations, and circulation of a survey to relevant professionals worldwide, eliciting responses from 147 professionals from 37 countries. An international consensus meeting of 18 participants (with expertise in infectious diseases, neonatology, microbiology, epidemiology and statistics) identified priority recommendations for reporting, additional to the STROBE statement. Implementation of these STROBE-NI recommendations, and linked checklist, aims to improve scientific reporting of neonatal infection studies, increasing data utility and allowing meta-analyses and pathogen-specific burden estimates to inform global policy and new interventions, including maternal vaccines.
\end{abstract}

Words: 188 


\section{Strengthening the Reporting of Observational Studies in Epidemiology for Newborn Infection (STROBE-NI): An extension of the STROBE statement for neonatal infection research}

\section{Background}

Progress in improving child survival has been one of the greatest successes in international development. ${ }^{1}$ However, there is an unfinished agenda, ${ }^{2}$ since the mortality reduction has been slowest for neonates. Almost half (44\%) of all child deaths now occur in the neonatal period (0-27 days), ${ }^{3}$ with a substantial burden of mortality in the first few days after birth. ${ }^{4}$ The "Every Newborn Action Plan" sets out a United Nations led platform, endorsed by all countries, to end preventable neonatal deaths, but requires data to implement and inform innovation. ${ }^{2,5}$

Estimates by the World Health Organisation (WHO), for 195 countries, suggest that infection accounts for around 680000 deaths - a quarter of all neonatal deaths annually; ${ }^{6}$ and half of all neonatal deaths in high neonatal mortality settings. ${ }^{2}$ The closely linked 2.6 million annual stillbirths have an as yet poorly quantified infection burden. ${ }^{7}$ Significant neurodevelopmental impairment affects approximately a quarter of neonates following meningitis, but impairment data are very limited worldwide, particularly for common infection syndromes such as sepsis and pneumonia. ${ }^{8,9}$

There are an estimated 6.9 million neonates with possible serious bacterial infection (pSBI) annually in SubSaharan Africa, South Asia and Latin America. ${ }^{8}$ Approximately $84 \%$ of neonatal deaths attributed to infections could be averted by increasing coverage of prevention and access to treatment, yet currently the gap is high, especially in the poorest countries. ${ }^{10}$ Recent large clinical trials have assessed the safety and efficacy of improving access to treatment through outpatient care, in cases where referral is not possible. ${ }^{11-13}$

Aetiology-specific data for neonatal infections are limited, and challenging to combine. Hospital-based studies suggest that Staphylococcus aureus, Escherichia coli, Klebsiella species and group B Streptococci (GBS) may be the most common pathogens globally. ${ }^{14}$ As yet there are no community-based aetiological studies from Africa, and few from South Asia, which together carry over $75 \%$ of the burden. Hence, there is an urgent need to improve data on incidence (especially in the first days following birth), aetiology (bacterial, viral and fungal), antimicrobial sensitivity, and outcomes. These data are essential to understand the burden and risk factors, refine treatment algorithms, support potential interventions (eg. maternal vaccines for respiratory syncytial virus and Group B Streptococcus), ${ }^{15-17}$ and mitigate antimicrobial resistance, which threatens current treatment strategies. ${ }^{18-20}$

Recording, reporting and interpreting neonatal infection data poses specific challenges. More than $95 \%$ of neonatal deaths occur in countries without adequate birth and death certification to capture cause-specific mortality, ${ }^{2,6}$ let alone pathogen-specific surveillance. Systematic clinical assessment, with investigations providing microbiological data, are also limited. ${ }^{8}$ Most available neonatal infection data are from tertiary referral hospitals, with recruitment bias, by missing those not accessing higher levels of care, or any care. ${ }^{21}$ In population-based studies, which are extremely few in high burden settings, ${ }^{22-24}$ even if women are recruited in pregnancy, the challenge remains that many newborns die within hours of birth before being assessed; meaning counting, investigations and treatment are missed. ${ }^{25}$ In a population-based Bangladeshi cohort, $62 \%$ of neonates who died were never clinically assessed, with $59 \%$ of deaths occurring within 48 hours of birth. ${ }^{22}$ Even when cases are captured in the numerator and denominator, case definitions are often inconsistent. Diagnosis is usually based on clinical expertise, or in settings with fewer health workers, on 
simplified clinical algorithms designed to be highly sensitive. For example, the most commonly used WHO young infant pSBI algorithm is very sensitive (85\%) and fairly specific (75\%). ${ }^{26-28}$ Additionally, unlike childhood infections, gestational age has a major effect on incidence, aetiology and outcomes of neonatal infections. Neonates of 25 and 35 week's gestation are both preterm, yet differentiation between the two is often missing in reported data, which is crucial for interpretation.

The Strengthening the Reporting of Observational Studies in Epidemiology (STROBE) ${ }^{29}$ and Consolidated Standards of Reporting Trials (CONSORT) ${ }^{30}$ statements were developed to improve scientific reporting. Several extensions of these statements have been published with additional recommendations for specialised fields of research, for example, the Strengthening the Reporting of Molecular Epidemiology for Infectious Diseases (STROME-ID) ${ }^{31}$ and the Outbreak Reports and Intervention Studies of Nosocomial Infection (ORION) ${ }^{32}$ statement. These extensions build on the principles of STROBE and CONSORT but explicitly address additional, problematic methods or settings. There are reporting guidelines under development which are specific to child health trials (SPIRIT-C; CONSORT-C), ${ }^{33}$ and for systematic reviews and meta-analyses (PRISMA-C; PRISMA-PC). ${ }^{34}$ This paper aims to address the specific challenges in reporting neonatal infections, using the $\mathrm{STROBE}^{29}$ model. If these recommendations are applied by upcoming epidemiological and interventional studies on neonatal infections, the value of new data will increase, avoiding "research waste". ${ }^{35}$

\section{Aims of STROBE-NI}

The purpose of these guidelines is to promote transparency, clarity and comparability of scientific reporting, specifically for neonatal infection research. We focus on observational studies (although many elements will be true for other study designs), and include detailed consideration of aetiological (bacterial, viral and fungal) data. Through improved reporting, we aim to facilitate reliable comparison of emerging newborn infection data across settings worldwide, and the synthesis of robust evidence to inform public health interventions. Our objectives were to assess current reporting components for neonatal infection in the literature, to list all potential reporting items, and to use an online survey and expert consensus process to develop the 'Strengthening Reporting of Observational Studies in Epidemiology for Newborn Infection (STROBE-NI)' checklist. The STROBE-NI checklist is intended to guide authors, reviewers, publishers and funders of neonatal infection studies. We focussed on parameters that are not included in STROBE, or other extensions.

\section{Development of the STROBE-NI checklist}

The STROBE-NI checklist was developed using recommended methods. ${ }^{36}$ The participants, processes and outputs are illustrated in Figure 1. Literature searches were undertaken to identify highly cited neonatal infection publications from different regions worldwide (1996-2015), and more recent (2011-2015) articles from high impact journals (see supplementary material for literature search criteria). Additional searches were carried out for reporting guidelines relevant to neonatal infections.

Through these reviews we identified a list of 133 reporting items, which was developed into an online survey (supplementary material). Respondents were asked to comment and/or rate the importance of each item in the list by selecting either 'unnecessary', 'sometimes useful', 'important for most studies', or 'essential for all studies'. Participants were also asked to identify definitions and classifications requiring discussion and clarification. The survey was disseminated to relevant investigator groups, corresponding authors of reviewed papers, and professional infectious disease and paediatrics networks worldwide (Figure 1). 147 experts replied, from 37 countries, with more than $41 \%$ from low/middle income counties (supplementary material). 
In June 2015, a group of 18 international, multi-disciplinary experts (epidemiologists, statisticians, microbiologists, paediatricians, neonatologists) met in London to examine the literature reviews, potential reporting items and survey results and to draft the structure and content of the recommendations. Recommendations were aligned with STROBE items in one draft checklist, as a topic-specific implementation $^{36}$ of the STROBE statement. The structural relationship between STROBE-NI and STROBE ${ }^{29}$ recommendations is illustrated in Figure 2.

The draft checklist was reviewed and revised by the expert group, disseminated to survey participants, and members of networks such as the Enhancing the Quality and Transparency of Health Research (EQUATOR) network, for further review and feedback, resulting in a final STROBE-NI Checklist (Table 1)

\section{STROBE-NI Standards}

The final STROBE-NI checklist is an extension of the 22 item STROBE list, with 28 additional parameters relating to neonatal infection. This includes a suggested flow diagram for both the recruitment and follow up of mothers and newborns, for which a template is provided in Figure 3. Below, we describe the additional recommendations for STROBE-NI that are not already outlined in detail in STROBE, or other extensions.

\section{Methods: Study design \\ Clinical case definitions (STROBE-NI 4.1 -4.4)}

The individual clinical signs used in clinical case definition algorithms should be detailed, (STROBE-NI 4.1), making clear whether case ascertainment was through physician diagnosis or a clinical algorithm (eg. Young Infants Clinical Signs Study Group algorithm for pSBI). Definitions of neonatal infection syndromes (pneumonia, meningitis and sepsis) are important for consistency and comparability, however, they cannot be distinguished on clinical grounds alone. Where authors are reporting case definitions of specific syndromes, microbiological and/or laboratory and/or radiological criteria for diagnosis should be stated (STROBE-NI 4.1), differentiating between probable and confirmed cases. For meningitis, the indications for lumbar puncture should be described (STROBE-NI 4-1). Case definitions should be aligned to international standards, when available and ideally be clinically validated. ${ }^{26}$ Clinical algorithms may introduce case ascertainment bias, and potential limitations of case definitions should be discussed.

Authors should state the criteria used to differentiate between new infection episodes and relapses (STROBENI 4-2). For example, new episodes may be considered when clinical signs develop more than 7 days after stopping treatment, versus a relapse, with reoccurrence of clinical signs within 7 days of stopping treatment. This is important for healthcare associated infections, and these should be explicitly differentiated from community-acquired infections, with reference to an international standard definition (STROBE-NI 4.3). ${ }^{37}$ Where relevant, specific hospital acquired infections such as ventilator associated pneumonia and central line associated bloodstream infection should be defined, and presented separately. ${ }^{37}$ Reporting whether the observed cases were part of an outbreak (see ORION statement) ${ }^{32}$ is essential, and the definition used for outbreaks (STROBE-NI 4.4).

\section{Microbiological sampling (STROBE-NI 4.5)}

The microbiological sampling strategy for infections should be presented (STROBE-NI 4.5), such as samples being taken from all participants, or a subset meeting a case-definition (eg pSBI). This is important given that the positive and negative predictive values of tests differ according to the prevalence in those sampled. For instance if few cases of pSBI have lumbar punctures, then cases of meningitis may not be captured. Numbers from whom samples were taken, and sample type, should be provided, including sample volume ranges for 
blood cultures, or minimum sample volume, as small volumes reduce sensitivity. It should be reported whether samples were taken prior to antimicrobial administration (which reduces sensitivity of testing) (STROBE-NI 4.5).

\section{Microbiological methods (STROBE-NI 4.6 - 4.8)}

Detailed reporting of laboratory methods is essential in order to assess implications and potential biases (STROBE-NI 4.6). To assess the extent of diagnostic investigation, a list of pathogens (or types of pathogen) being tested for, or likely to be identified by the methods used, should be available (including bacteria, viruses and fungi) (STROBE-NI 4.7). For diagnostic technologies using molecular methods, details of the assay should be given, describing any control samples used to determine clinical significance of detected organisms. ${ }^{38-40}$ Antimicrobial susceptibility testing methodology should be reported according to an international standard (eg. Clinical and Laboratory Standards Institute) reporting the susceptibilities tested, and the criteria used to determine susceptibility to each antimicrobial (STROBE-NI 4.8). For molecular analyses, methods ${ }^{41}$ should be explained (eg. for whole genome sequencing, details of mapping to reference genomes and quality assessment of sequences). Further details are in STROME-ID. ${ }^{31}$

\section{Methods: Setting}

\section{Context and denominator (STROBE-NI $5 \cdot 1$ - 5.2)}

Where possible, preterm, stillbirth, and neonatal mortality risks or rates at the study facility are helpful contextual information (STROBE-NI 5-1). This could be presented as the annual number of deaths, preterm births and stillbirths at the health facility, with live births (including the live birth definition used) or total births at the facility as the denominator.

When considering infection acquisition, stratification into 'inborn' or 'outborn' is not specific enough to be helpful, as multiple pathways to healthcare presentation exist; 'outborn' may reflect births at home or at another facility, and 'inborn' does not differentiate between those admitted from birth, and those returning to the facility following discharge. Alternative categories are 'admitted from birth at this facility', 'referred from another facility' or 'referred from home' (STROBE-NI 5-2). If specifying place of birth as a variable, similar categories of 'born at this facility', 'born at another facility' or 'born at home' could be used.

\section{Community studies (STROBE-NI 5.3)}

Community-based studies should report the surveillance strategy, including whether active or passive, and the methods used for defining and enumerating the population. Passive surveillance may underestimate disease, especially where care seeking is low (varying from 10 to $100 \%),{ }^{21}$ and an estimate of this should be made if possible. For active surveillance, if clinical algorithms are used by community health workers visiting homes, this should be documented, including visitation schedules. Active surveillance increases case ascertainment, particularly on days when visits are made. ${ }^{42}$ In view of variation in adherence to referral, details on referral (including time from first presentation to treatment) are necessary, as well as loss to follow-up (STROBE-NI 5·3). This could be presented in a flow diagram (Figure 3).

\section{Facility based studies (STROBE-NI 5.4 - 5.6)}

Levels of neonatal and obstetric care differ greatly. The obstetric care available ${ }^{43}$ including the percentage of births that occur in a facility (versus the community) and the incidence of operative delivery, should be described (STROBE-NI 5.4). Details about the level of neonatal care in place are essential, including availability of basic neonatal care (eg. resuscitation, breastfeeding practices) and if there is intensive neonatal care such as ventilation (eg. invasive, non-invasive, oxygen), indwelling catheters, intravenous fluids, staffing (eg. nurse 
to patient ratio), non-microbiological investigations (eg. biochemistry, radiology) and treatment (eg. antimicrobials available) (STROBE-NI 5.5). Where relevant, specific clinical infection control measures in place (and level of adherence), may be important contextual information to understand potential routes of infection acquisition and transmission.

The microbiology laboratory should be described, including location, facilities for different sample types and capacity for conventional and/or molecular microbiology. Laboratory quality control and quality assurance measures should be reported (STROBE-NI 5.6).

\section{Methods: Participants}

\section{Neonatal age groups (STROBE-NI 6.1)}

The 'neonatal' period is defined as $<28$ days (i.e. day 0 to 27.99 ) from birth. For babies born before 37 weeks gestation, noting gestational age at birth is essential to allow age correction. Disaggregating neonatal data from infants and children is important due to differing risk factors, aetiologies and outcomes (STROBE-NI 6.1). ${ }^{44}$ Timing is crucial for neonatal infections as incidence rates for pathogens, such as Group B Streptococcus, vary by day. ${ }^{45}$ The day of birth is best termed "day 0 ", as used in demographic work and most epidemiological studies (STROBE-NI 6-1). Time limits vary as to when 'day 0 ' becomes 'day 1' (eg. at midnight, or $24 \mathrm{~h}$ after birth), and the method used should be stated. ${ }^{4}$

\section{Methods: Variables}

\section{Clinical significance of pathogens (STROBE-NI 7-1)}

Authors should be explicit about the clinical significance of the organisms detected. This may vary across settings (particularly organisms associated with indwelling devices, eg. coagulase negative staphylococci) ${ }^{46}$ and the rationale for determining clinical significance should be stated, including control data, if available. ${ }^{38-}$

40 Publishing comprehensive lists of detected organisms, by sample type (eg. cerebrospinal fluid, blood), categorised as clinically significant, probably significant and clinically non-significant (the preferred term to "contaminant") are encouraged (STROBE-NI 7-1); as criteria for clinical significance may change over time.

\section{Results: Participants}

\section{Flow diagram (STROBE-NI 13.1)}

Figure 3 illustrates how the flow of eligibility, recruitment, sampling and diagnosis can be mapped in neonatal infection studies, including mothers and neonates (STROBE-NI 13·1).

\section{Results: Descriptive data (STROBE-NI 14.1 - 14.4)}

Maternal infections, and risk factors for infection, are important to report as maternal infections may result in vertical transmission and early onset neonatal infections, or stillbirth. ${ }^{47,48}$ Results of antenatal screening tests (eg. for GBS, syphilis, HIV) when done, and risk factors at delivery (eg. prolonged rupture of membranes (>18h) fever, maternal urinary tract infection) (STROBE-NI 14-1), are important for identifying high risk groups and informing interventions. ${ }^{49}$

Neonatal characteristics, including sex, postnatal and gestational age categories (e.g. $<28$ weeks; $28-<32$ weeks; $32-<37$ weeks; $\geq 37$ weeks) ${ }^{50}$, birth weight categories (e.g. <=1500 grams; 1501-2500 grams; >2500 grams), place of birth (see above) and mode of feeding should be described, with ranges and medians stated for each numeric variable (STROBE-NI 14.2). Co-morbidities (eg. neonatal encephalopathy) should be reported, including any exclusion from analysis (STROBE-NI 14-2). Reporting of individual clinical signs is 
encouraged (STROBE-NI 14.3), ${ }^{8}$ allowing comparison with other studies and may be helpful in refining diagnostic algorithms. ${ }^{2}$

Details of treatment given before and after enrolment are important (STROBE-NI 14.4). Serum antimicrobial testing has shown that parents under-report antimicrobial administration; ${ }^{22}$ and results of testing are preferable to report. Use of intrapartum antibiotic prophylaxis and its indication (eg. maternal risk factors versus positive GBS screening) ${ }^{51}$ should be reported to inform interpretation of culture results (STROBE-NI 14.4).

\section{Results: Outcome data}

\section{Microbiological results (STROBE-NI 15.1 - 15.2)}

Microbiological results should be reported in the context of participants recruited, and the number and type of samples taken (STROBE-NI 15-1-2). For example, the number of those meeting clinical criteria for diagnostic lumbar puncture should be provided, as well as the cerebrospinal fluid results. The number and proportion of microbiologically proven clinical infections should be given, and incorporated within a flow diagram (Figure 3) (STROBE-NI 15·2).

Reporting all organisms detected (eg. as an appendix), including those considered clinically non-significant, is helpful. For molecular assays in particular, reporting thresholds for detection and the organisms detected in control samples supports clinical case interpretation. ${ }^{38-40}$ Antimicrobial susceptibility data are essential to guide future antimicrobial policy development (STROBE-NI 15.1). It is helpful to provide raw antimicrobial susceptibility test result data (eg. minimum inhibitory concentrations), which can be analysed further in the future if international standards change.

\section{Timing of infection (STROBE-NI 15.3)}

Where categorisation into 'early-onset' (e.g. within 72 hours of birth) and 'late-onset' (e.g. after 72 hours of birth) disease is used, these terms should be clearly defined (STROBE-NI 15.3). Due to the changing aetiologies of neonatal disease, reporting infections by day, for the first week after birth (days 0-6) (STROBE$\mathrm{NI} 15 \cdot 3$ ) is more informative than dichotomous categories, and may improve understanding of early and late onset disease. $^{45}$

\section{Mortality (STROBE-NI 15.4) and long-term outcomes}

Mortality and other serious clinical outcomes should be reported (STROBE-NI 15.4), ideally by day (Figure 3). Sample size permitting, stratifying mortality by potential risk factors including sex, birthweight categories, gestational age groups, ${ }^{50}$ infection syndromes, individual pathogens or antimicrobial resistance profiles, may highlight intervention opportunities for high risk groups.

Where studies are reporting other long-term outcomes, such as neurological impairment, an international standard approach should be used, including the timing of follow up and assessment.

\section{Results: Main results}

\section{Incidence (STROBE-NI 16.1)}

For incidence, the selection and source of the denominator should be explained (see above). For neonates it is usual to calculate incidence risk per 1000 live births (STROBE-NI 16.1), as the time period (28 days) is short. 


\section{Discussion: Limitations}

\section{Bias (STROBE-NI 19.1)}

The first $12-48$ hours after birth are critical, as the survival curve is steep, ${ }^{4}$ and infectious aetiologies differ later after birth. These aetiologies may be systematically underestimated if there is recruitment bias arising from lack of access to care, or death before accessing care (STROBE-NI 19.1). ${ }^{44}$ Identifying possible causes of recruitment and other biases in studies is therefore essential in interpreting findings.

For all denominators used, authors should state the source (eg. hospital data or census / registration data), commenting on possible bias (STROBE-NI 19·1).

\section{Other information: Ethics (STROBE-NI 23.1)}

Because of ethical issues around recruitment, consent, and sampling in neonates, approaches taken must be reported, including processes for requesting consent from young mothers (minors) (STROBE-NI 23.1).52,53 If the time frame for sample collection and obtaining consent is limited (eg. during delivery), a staged process of consent may be appropriate, to avoid exclusion of emergency cases (and reduce recruitment bias). ${ }^{54}$

\section{Implications of STROBE-NI}

The STROBE-NI checklist provides a tool for researchers, funders, reviewers and publishers to improve neonatal infection data, which have specific, previously unaddressed, requirements for scientific reporting. Building on the $\mathrm{STROBE}^{29}$ statement and its related extensions, the checklist primarily targets observational studies. ${ }^{29}$ However, STROBE-NI checklist items should also be considered for randomised controlled trials, alongside other guideline extensions. ${ }^{33,34}$ To our knowledge, there are no other reporting guidelines specific to neonatal health research. ${ }^{34}$ Whilst neonatal infections are a priority starting point, future re-iterations should also address other aspects of neonatal research, as well as maternal, and stillbirth outcomes. Only recommendations for reporting acute outcomes of infection were included in this checklist. However we recognise that other important long-term outcomes, such as neurological impairment, are increasingly being assessed, and are important to include. ${ }^{55}$ Reporting guidance for impairment outcomes after neonatal infection as well as other common neonatal complications, such as preterm birth, ${ }^{56}$ is an area for future development.

The STROBE-NI checklist guides minimum standards for high quality reporting but is not exhaustive; and certain research objectives or contexts may necessitate other details. For instance, new technologies, such as molecular investigations, ${ }^{31,38}$ are likely to require additional descriptors.

This list was designed to be applicable to a wide range of settings, including those with limited resources and a high neonatal infection burden. To achieve this, we sought inputs from around the world through experts, and our online survey, as well as systematic literature reviews.

Uptake of the STROBE-NI checklist depends on dissemination through global research networks and meetings, and use by journals, funders and academics. Feedback and suggestions for improvement would be welcomed, as the STROBE-NI checklist will be updated periodically. Going forward, we intend to present 'explanation and elaboration' of this guidance (to build on that included in the supplementary material), develop abstract guidance for conference submissions, and evaluate the impact of STROBE-NI, as is recommended. ${ }^{36}$ The STROBE-NI checklist has been developed at a critical point in time for emerging opportunities in neonatal infection research. It is a demonstration of a new commitment towards reducing the unacceptable burden of mortality and morbidity from neonatal infection, and more broadly, as part of the movement to end preventable maternal and newborn deaths, and stillbirths..$^{5,57-59}$ 


\section{Author contributions:}

EJAF, ACS, SV, MS, PTH and JEL coordinated the expert group and planned the expert meeting. EJAF, ACS and SV conducted the literature reviews and compiled the initial list of potential reporting items. SV, ACS, EJAF and JEL developed the online survey. ACS, SV, MS, PTH, SS, RA, AIA, RB, KB, HC, SC, GLD, NM, JP, SQ, SW, RW and JEL participated in the expert meeting and developed the STROBE-NI checklist, chaired by MS, SS, RB, HC, SC, and JEL, and coordinated by EJAF. EJAF, ACS and JEL wrote the first draft of the manuscript. ACS, SS and JEL developed the flow diagram with feedback from RW, PTH, RA and SJS. SV, MS, PTH, RA, AIA, ZAB, RB, HC, SC, GLD, SAM, ASM, NM, JP, SQ, SJS and BJS edited and contributed to successive versions of the paper.

Conflicts of Interest: ASM was previously a salaried employee for Novartis Vaccines Research and Development (9/2012-10/2013). We declare no other conflicts of interest.

Acknowledgements: We thank the Royal Society of Medicine (Global Health Section) for hosting the expert consensus meeting. We also thank the SPRING (Strengthening Publications Reporting Infection In Newborns Globally) Group:

Ebunoluwa Aderonke Adejuyigbe, Ramesh Agarwal, ASM Nawshad Uddin Ahmed, Adejumoke I. Ayede, Sulagna Basu, Aisleen Bennett, Alberto Berardi, Chiara Bertaina, Zulfiqar A. Bhutta, Robert Black, Hannah Blencowe, Kalifa Bojang, Carl Bose, Harry Campbell, Aparna C Suman Chaurasia, Alleyna Claxton, Simon Cousens, Gary L. Darmstadt, Laura Davies, Sangappa Dhaded, Angela Dramowski, Simon B Drysdale, AbdelHady El-Gilany, Andrea Falaschi, Katy Fidler, Elizabeth J A Fitchett, Felipe Teixeira de Mello Freitas, Ana Garces, Bradford D. Gessner, Eric Giannoni, Despoina Gkentzi, Magdalena Goyheneix, Davidson H. Hamer, Paul T. Heath, Piotr Heczko, Pat Hibberd, David K Ho, Margaret Ip, Ashish Jain, Ashish KC, Korina Karachristou, Sonali Kochhar, Kirsty Le Doare, Edward A. Liechty, Suzanne Luck, Pagakrong Lumbiganon, Shabir A. Madhi, Ajoke Sobanjo-ter Meulen, Neena Modi, Janna Patterson, Shamim Qazi, Stephanie J Schrag, Barbara J. Stoll, Steve Wall, Robinson Wammanda, Joy E Lawn, Doug McMillan, Andre Ricardo Araujo Da Silva, Musa Mohammed, Sarah G. Moxon, Harish Nair, Indira Narayanan, Christina W. Obiero, James M Oleske, Santosh Pattnayak, William Rawlinson, Riccardo Pfister, Rashmi Ranjan Das, Bjarte Rogdo, Candice Romero, Manish Sadarangani , Samir Saha, M Jeeva Sankar, Anna C Seale, Michael Sharland, Tania Siahanidou, Eric A. F. Simões, Kevin B. Spicer, Claudia Turner, Stefania Vergnano, Rajlakshmi Viswanathan, Susannah Woodd, Erbu Yarci.

\section{References}

1 Lawn JE. The child survival revolution: what next? Lancet 2014; 384: 931-3.

2 Lawn JE, Blencowe H, Oza S, et al. Every Newborn 2: Progress, priorities, and potential beyond survival. 2015; 6736. DOI:10.1016/S0140-6736(14)60496-7.

3 You D, Hug L, Chen Y. Levels and Trends in Child Mortality (2014 Report): Estimates Developed by the UN Inter-agency Group for Child Mortality Estimation (UNIGME). 2014. countries in 2013: a vital-registration and modelling-based study. Lancet Glob Heal 2014; 2: e635-44. 1507448

6 Liu L, Oza S, Hogan D, et al. Global, regional, and national causes of child mortality in $2000-13$, with projections to inform post-2015 priorities: an updated systematic analysis. Lancet 2015; 6736. DOI:10.1016/S0140-6736(14)61698-6. 
Seale AC, Blencowe $H$, Manu AA, et al. Estimates of possible severe bacterial infection in neonates in subSaharan Africa, south Asia, and Latin America for 2012: a systematic review and meta-analysis. Lancet Infect Dis 2014; 14: 731-41.

Seale AC, Blencowe $\mathrm{H}$, Zaidi A, et al. Neonatal severe bacterial infection impairment estimates in South Asia, sub-Saharan Africa, and Latin America for 2010. Pediatr Res 2013; 74 Suppl 1: 73-85.

African Neonatal Sepsis Trial (AFRINEST) group. Baqui AH, Saha SK, Ahmed ASMNU, et al. Safety and efficacy of alternative antibiotic regimens compared with 7 day injectable procaine benzylpenicillin and gentamicin for outpatient treatment of neonates and young infants with clinical signs of severe infection when referral is not possible: a randomised, open-label, equivalence trial. Lancet 2015; 3: 279-87.

African Neonatal Sepsis Trial (AFRINEST) group. Tshefu A, Lokangaka A, Ngaima S, et al. Simplified antibiotic regimens compared with injectable procaine benzylpenicillin plus gentamicin for treatment of neonates and young infants with clinical signs of possible serious bacterial infection when referral is not possible: a randomised, open-label, equvalence trial. Lancet 2015; 385: 1767-76.

African Neonatal Sepsis Trial (AFRINEST) group. Tshefu A, Lokangaka A, Ngaima S, et al. Oral amoxicillin compared with injectable procaine benzylpenicillin plus gentamicin for treatment of neonates and young infants with fast breathing when referral is not possible: a randomised, open-label, equivalence trial. 2015; 385: 1758-1766.

Bhutta Z A, Das JK, Bahl R, et al. Can available interventions end preventable deaths in mothers, newborn babies, and stillbirths, and at what cost? Lancet 2014; 384: 347-70.

Darmstadt GL, Stoll BJ, Zaidi AKM. Neonatal Infections: A Global Perspective. Remington and Klein's Infectious Diseases of the Fetus and Newborn Infant. By Wilson C, Nizet V, Maldonado Y, Remington J, and Klein J. Philadelphia, PA. Elsevier/Saunders. (8 ${ }^{\text {th }}$ Edition) 2015; Chapter 2: 24-53.

Meulen AS, Abramson J, Mason E, et al. Path to impact: A report from the Bill and Melinda Gates Foundation convening on maternal immunization in resource-limited settings; Berlin - January 29-30, 2015. Vaccine 2015; 33: 6388-95.

Modjarrad K, Giersing B, Kaslow DC, Smith PG, Moorthy VS. WHO consultation on Respiratory Syncytial Virus Vaccine Development Report from a World Health Organization Meeting held on 23-24 March 2015. Vaccine 2015. DOI:10.1016/j.vaccine.2015.05.093.

Schrag SJ. Group B streptococcal vaccine for resource-poor countries. Lancet 2011; 378: 11-2.

Seale AC, Obiero C, Berkley JA. Rational development of guidelines for management of neonatal sepsis in developing countries. Curr Opin Infect Dis 2014; 28: 225-30.

Murray CJL, Vos T, Lozano R, et al. Disability-adjusted life years (DALYs) for 291 diseases and injuries in 21 regions, 1990-2010: A systematic analysis for the Global Burden of Disease Study 2010. Lancet 2012; 380: 2197-223.

WHO. Antimicrobial Resistance - Global Report on Surveillance. World Heal Organ 2014.

Herbert HK, Lee AC, Chandran A, Rudan I, Baqui AH. Care seeking for neonatal illness in low- and middleincome countries: A systematic review. PLoS Med 2012; 9(3): e1001183 DOI:10.1371/journal.pmed.1001183.

Darmstadt GL, Saha SK, Choi Y, et al. Population-Based Incidence and Etiology of Community-Acquired Neonatal Bacteremia in Mirzapur, Bangladesh: An Observational Study. J Infect Dis 2012; 127: 358-66.

Thaver D, Zaidi AK. Burden of Neonatal Infections in Developing Countries: A Review of Evidence From Community-Based Studies. Pediatr Infect Dis J 2009; 28: S3-9.

Farzin A, Saha S, Bacqui AH, et al. Population-based Incidence and Etiology of Community-acquired Neonatal Viral Infections in Bangladesh: A Community-based and Hospital-based Surveillance Study. Pediatr Infect Dis J 2015; 34: 706-11. 
The Young Infants Clinical Signs Study Group. Clinical signs that predict severe illness in children under age 2 months: a multicentre study. Lancet 2008; 371: 135-42.

The World Health Organization. Integrated Management of Childhood Illness: Chart Booklet. 2014.

Darmstadt GL, Baqui a. H, Choi Y, et al. Validation of a clinical algorithm to identify neonates with severe illness during routine household visits in rural Bangladesh. Arch Dis Child 2011; 96: 1140-6.

Elm E Von, Altman DG, Egger M, Pocock SJ, Gøtzsche C, Vandenbroucke JP. STrengthening the Reporting of Observational Studies in Epidemiology (STROBE) Statement: Guidelines for reporting observational studies. Bull World Health Organ 2007; 045120: 867-72.

Moher D, Jones a, Lepage L. Use of the CONSORT statement and quality of reports of randomized trials: a comparative before-and-after evaluation. JAMA 2001; 285: 1992-5.

Field N, Cohen T, Struelens MJ, et al. STrengthening the Reporting of Molecular Epidemiology for Infectious Diseases (STROME-ID): an extension of the STROBE statement. Lancet Infect Dis 2014; 14: 341-52.

Stone SP, Cooper BS, Kibbler CC, et al. The ORION statement: guidelines for transparent reporting of outbreak reports and intervention studies of nosocomial infection. Lancet Infect Dis 2007; 7: 282-8.

Saint-Raymond A, Hill S, Martines J, Bahl R, Fontaine O, Bero L. CONSORT 2010: Comments. Lancet. 2010; 376: 229-30.

Reporting Guidelines Under Development. EQUATOR Netw Enhancing Qual Transpar Heal Res http://www.equator-network.org/library/reporting-guidelines-under-development/.

Chalmers I, Glasziou P. Avoidable waste in the production and reporting of evidence. Lancet 2009; 374: 86-9.

Moher D, Schulz KF, Simera I, Altman DG. Guidance for developers of health research reporting guidelines. PLoS Med 2010; 7. DOI:10.1371/journal.pmed.1000217.

Folgori L, Bielicki J, Sharland M. A systematic review of strategies for reporting of neonatal hospital-acquired bloodstream infections. Arch Dis Child Fetal Neonatal Ed 2012; 98: F518-23.

Diaz MH, Waller JL, Napoliello R a., et al. Optimization of Multiple Pathogen Detection Using the TaqMan Array Card: Application for a Population-Based Study of Neonatal Infection. PLoS One 2013; 8. DOI:10.1371/journal.pone.0066183.

Levine OS, O’Brien KL, Deloria-Knoll M, et al. The pneumonia etiology research for child health project: A 21st century childhood pneumonia etiology study. Clin Infect Dis 2012; 54: 93-101.

Panchalingam S, Antonio M, Hossain A, et al. Diagnostic microbiologic methods in the GEMS-1 case/control study. Clin Infect Dis 2012; 55: 294-302.

Emmadi R, Boonyaratanakornkit JB, Selvarangan R, et al. Molecular methods and platforms for infectious diseases testing: A review of FDA-approved and cleared assays. J Mol Diagnostics 2011; 13: 583-604.

Baqui AH, Arifeen SE, Williams EK, et al. Effectiveness of home-based management of newborn infections by community health workers in rural Bangladesh. Pediatr Infect Dis J 2009; 28: 304-10.

Maine D, Bailey P, Lobis S, Fortney J, World Health Organization. Monitoring Emergency Obstetric Care. World Heal Organ 2009. DOI:10.3109/01443611003791730.

Seale AC, Mwaniki MK, Newton CR, Berkley JA. Maternal and early onset neonatal bacterial sepsis: burden and strategies for prevention in sub-Saharan Africa. Lancet Infect Dis 2009; 9: 428-38.

Heath PT, Balfour G, Weisner AM, et al. Group B Streptococcal Disease in UK and Irish Infants Younger Than 90 Days. Lancet 2004; 363: 292-4.

Rupp M, Archer G. Coagulase-negative staphylococci: pathogens associated with medical progress. Clin Infect Dis 1994; 19: 231-43.

Chan GJ, Lee AC, Baqui AH, Tan J, Black RE. Risk of Early-Onset Neonatal Infection with Maternal Infection or Colonization: A Global Systematic Review and Meta-Analysis. PLoS Med 2013; 10.

DOI:10.1371/journal.pmed.1001502. 
Schuchat A, Oxtoby M, Cochi S, et al. Population-based risk factors for neonatal group B streptococcal disease: results of a cohort study in metropolitan Atlanta. J Infect Dis 1990; 162: 672-7.

51 Blencowe $\mathrm{H}$, Cousens $\mathrm{S}$, Oestergaard $\mathrm{MZ}$, et al. National, regional, and worldwide estimates of preterm birth rates in the year 2010 with time trends since 1990 for selected countries: a systematic analysis and implications. Lancet 2012; 379: 2162-72.

52 Ohlsson A, Shah V. Intrapartum antibiotics for Group B streptococcal colonisation (Review). Cochrane Database Syst Rev 2009.

Modi N, Vohra J, Preston J, et al. Guidance on clinical research involving infants, children and young people: an update for researchers and research ethics committees. Arch Dis Child 2014; 99: 887-91.

Kaiser MM, Hays BJ. Recruiting and enrolling pregnant adolescents for research. Issues Compr Pediatr Nurs 2006; 29: 45-52.

Hassall O, Ngina L, Kongo W, et al. The acceptability to women in Mombasa, Kenya, of the donation and transfusion of umbilical cord blood for severe anaemia in young children. Vox Sang 2008; 94: 125-31.

Blencowe $\mathrm{H}, \operatorname{Vos} \mathrm{T}$, Lee $\mathrm{AC}$, et al. Estimates of neonatal morbidities and disabilities at regional and global levels for 2010: introduction, methods overview, and relevant findings from the Global Burden of Disease study.

Pediatr Res 2013; 74 Suppl 1: 4-16.

Blencowe H, Lee AC, Cousens S, et al. Preterm birth-associated neurodevelopmental impairment estimates at regional and global levels for 2010. Pediatr Res 2013; 74: 17-34.

57 Mason E, Mcdougall L, Lawn JE, et al. Every Newborn 5 From evidence to action to deliver a healthy start for the. 2015; 6736: 1-13. 9241508483 


\section{Figures}

Figure 1: Development process for the STROBE-NI checklist, showing participants, process and outputs

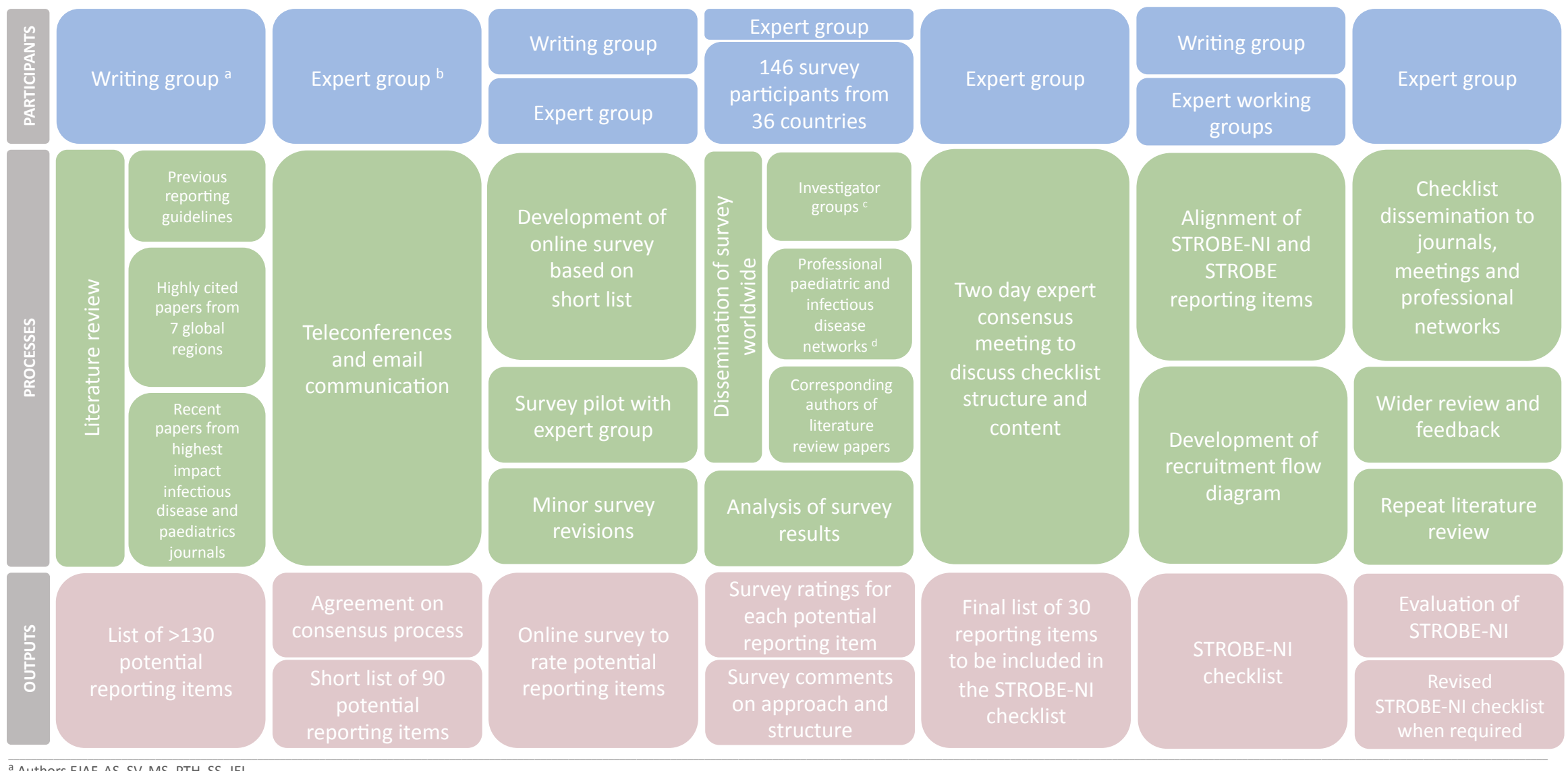

${ }^{a}$ Authors EJAF, AS, SV, MS, PTH, SS, JEL

${ }^{b}$ Authors AS, SV, MS, PTH, SS, RA, AIA, ZAB, RB, KB, HC, SC, GLD, SAM, ASM, NM, JP, SQ, SJS, BS, SW, RW, JEL

c Possible Serious Bacterial Infection (PSBI) investigator group; African Neonatal Sepsis Trial (AFRINEST) investigators
d Infectious Disease Research Network (IDRN); British Paediatric Allergy and Immunology Group (BPAIIG); Neonatal Infectious Disease Network (neonIN); UK Infection in Critical Care Quality Improvement Group; Australian and New Zealand Neonatal Adolescent, Reproductive and Child Health (MARCH) Centre 
Figure 2: Graphic showing structural relationship between STROBE ${ }^{28}$ and STROBE-NI checklist items

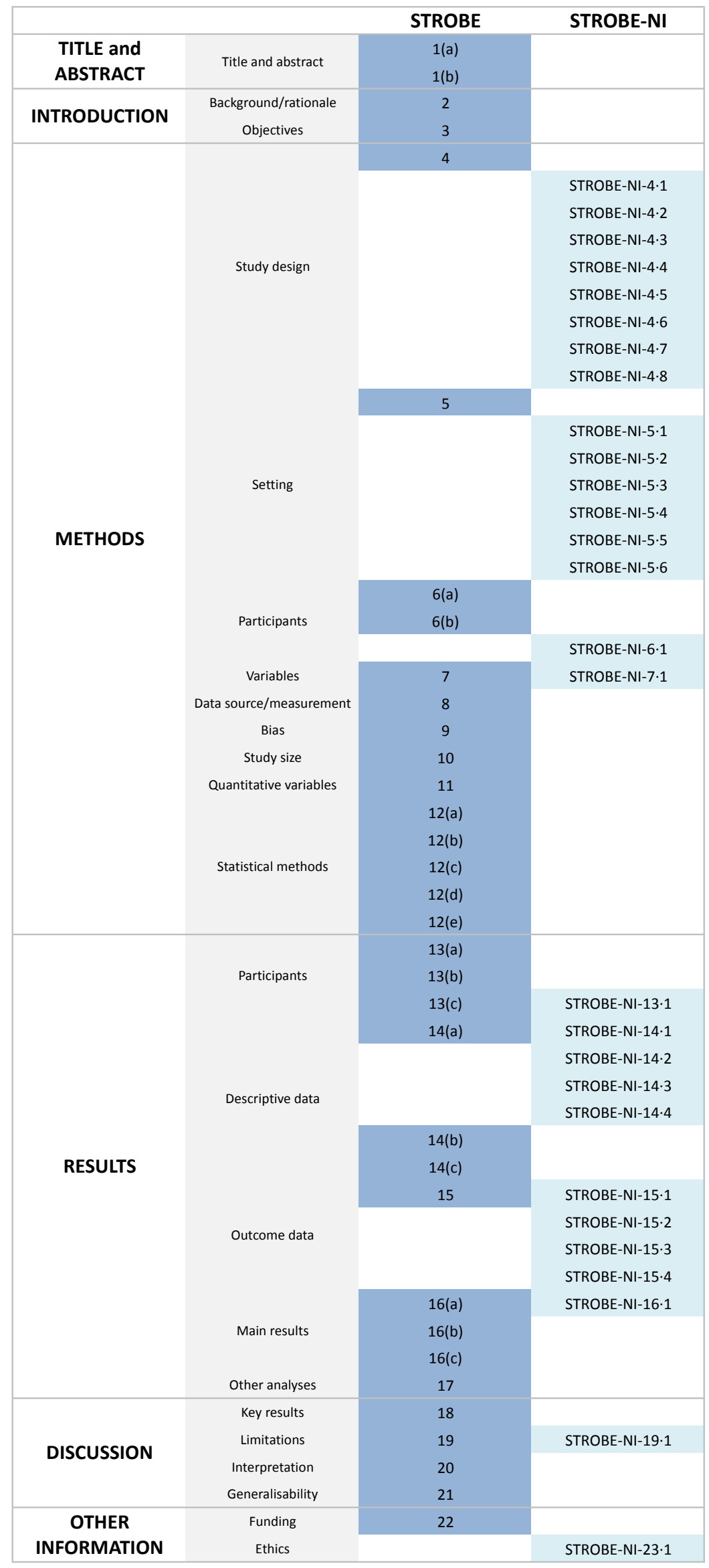


Figure 3: Strengthening Reporting of Observational Studies in Epidemiology for Newborn Infection (STROBE-NI) recommended flow chart showing recruitment and participation in the study

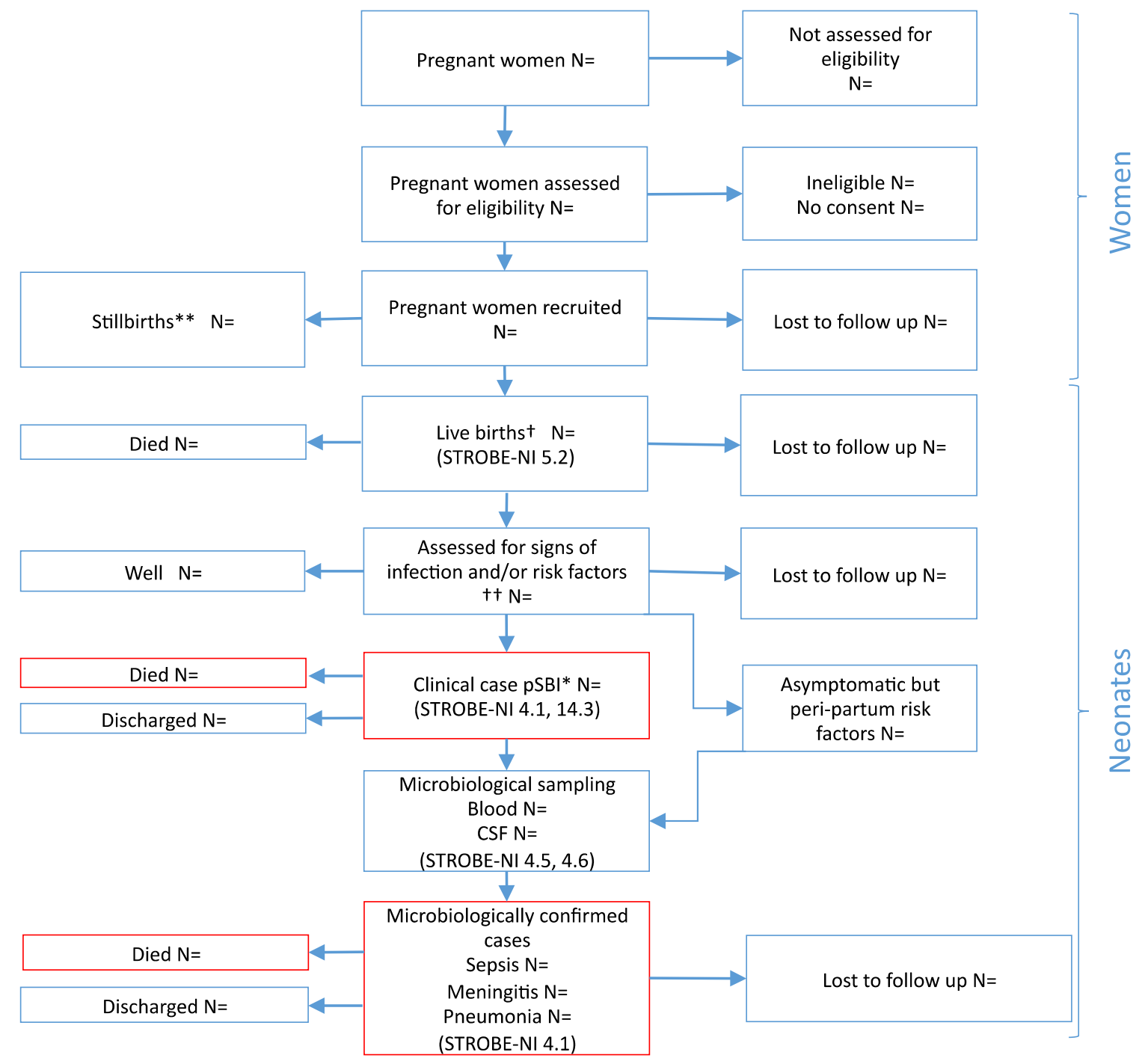

Give details by day where possible

*Give clinical algorithm used to define PSBI (STROBE-NI 4.1) and clinical signs for each neonate if possible (STROBE-NI 14.3)

** Give details of assessment, microbiological sampling if done.

tIf live births are assessed for eligibility (rather than pregnant women), give numbers of live births assessed for eligibility and then recruited after this box.

+†If neonates are assessed, for example at admission for care, give the numbers of neonates assessed and recruited. Differentiate between neonates born at home, at this facility or at another facility. 
Table 1: Strengthening Reporting of Observational Studies in Epidemiology for Newborn Infection (STROBE-NI) Checklist: An extension of the STROBE statement for neonatal infection research ${ }^{29}$

\begin{tabular}{lll}
\hline Section & Item No. & \multicolumn{1}{c}{ Recommendation } \\
\hline & $\begin{array}{l}\text { STROBE } \\
1(\mathrm{a}) \\
\text { STROBE } \\
1(\mathrm{~b})\end{array}$ & $\begin{array}{l}\text { Indicate the study's design with a commonly used term in the title or abstract } \\
\text { Provide in the abstract an informative and balanced summary of what was done and what } \\
\text { was found }\end{array}$ \\
$\begin{array}{l}\text { Background } \\
\text { / rationale } \\
\text { Objectives }\end{array}$ & $\begin{array}{l}\text { STROBE } \\
2\end{array}$ & $\begin{array}{l}\text { STROBE } \\
\text { STROin the scientific background and rationale for the investigation being reported }\end{array}$ \\
\hline
\end{tabular}

\section{METHODS}

\begin{tabular}{|c|c|c|}
\hline \multirow[t]{9}{*}{ Study design } & $\begin{array}{l}\text { STROBE } \\
4\end{array}$ & Present key elements of study design early in the paper \\
\hline & $\begin{array}{l}\text { STROBE-NI } \\
4.1\end{array}$ & $\begin{array}{l}\text { Clearly state case ascertainment methods (eg. physician diagnosis, clinical algorithm), } \\
\text { documenting individual clinical signs used for diagnosis of possible serious bacterial } \\
\text { infection. Give microbiological and/or laboratory and/or radiological criteria for other } \\
\text { infectious syndromes (eg. meningitis, sepsis, pneumonia). Include indications for clinical } \\
\text { investigations (eg. lumbar puncture) }\end{array}$ \\
\hline & $\begin{array}{l}\text { STROBE-NI } \\
4.2\end{array}$ & Give criteria used to differentiate between new infection episodes and relapses \\
\hline & $\begin{array}{l}\text { STROBE-NI } \\
4.3\end{array}$ & $\begin{array}{l}\text { For facility-based studies, indicate if the study is of community and/or hospital acquired } \\
\text { infections (HAI), defining HAl using an international standard and presenting specific HAI } \\
\text { clinical syndromes separately }\end{array}$ \\
\hline & $\begin{array}{l}\text { STROBE-NI } \\
4.4\end{array}$ & $\begin{array}{l}\text { State whether this is an outbreak study, and if so define an outbreak, with reference to an } \\
\text { international standard }\end{array}$ \\
\hline & $\begin{array}{l}\text { STROBE-NI } \\
4.5\end{array}$ & $\begin{array}{l}\text { Describe sampling strategy (eg. clinical indication vs. routine surveillance) and sampling } \\
\text { details, (eg. minimum volumes; timing in relation to antimicrobial administration) }\end{array}$ \\
\hline & $\begin{array}{l}\text { STROBE-NI } \\
4.6\end{array}$ & $\begin{array}{l}\text { Describe conventional and/or molecular microbiological methods used, with details (eg. } \\
\text { automation, enrichment steps), and the use of controls }\end{array}$ \\
\hline & $\begin{array}{l}\text { STROBE-NI } \\
4.7\end{array}$ & $\begin{array}{l}\text { List pathogens that are likely to be identified by microbiological methods used, and criteria } \\
\text { used to determine clinical significance }\end{array}$ \\
\hline & $\begin{array}{l}\text { STROBE-NI } \\
4.8\end{array}$ & $\begin{array}{l}\text { Describe antimicrobial susceptibility tests and thresholds used, with reference to an } \\
\text { international standard (eg. CLSI or EUCAST) }\end{array}$ \\
\hline \multirow[t]{7}{*}{ Setting } & $\begin{array}{l}\text { STROBE } \\
5\end{array}$ & $\begin{array}{l}\text { Describe the setting, locations, and relevant dates, including periods of recruitment, } \\
\text { exposure, follow-up, and data collection }\end{array}$ \\
\hline & $\begin{array}{l}\text { STROBE-NI } \\
5.1\end{array}$ & $\begin{array}{l}\text { Describe the study context in terms of incidence of neonatal mortality, stillbirth and preterm } \\
\text { birth. }\end{array}$ \\
\hline & $\begin{array}{l}\text { STROBE-NI } \\
5.2\end{array}$ & $\begin{array}{l}\text { Describe the population included eg. facility live births, referrals from home, referrals from } \\
\text { another facility }\end{array}$ \\
\hline & $\begin{array}{l}\text { STROBE-NI } \\
5.3\end{array}$ & For community-based studies, describe care-seeking and adherence and time to referral \\
\hline & $\begin{array}{l}\text { STROBE-NI } \\
5.4\end{array}$ & $\begin{array}{l}\text { For facility-based studies, describe obstetric care (basic or comprehensive), including } \\
\text { proportion of births by caesarean section. Report annual number of live births per facility } \\
\text { and state proportion of births in the study area that occur in hospital (vs. community) }\end{array}$ \\
\hline & $\begin{array}{l}\text { STROBE-NI } \\
5.5\end{array}$ & $\begin{array}{l}\text { For facility-based studies, indicate if the facility is public or private, and give the number of } \\
\text { health care staff and their training. Indicate the level of neonatal care available (eg. } \\
\text { ventilatory support, indwelling catheters) and investigations available (eg. biochemistry, } \\
\text { radiology). Report antimicrobial guidelines used for the empiric management of neonatal } \\
\text { sepsis. }\end{array}$ \\
\hline & $\begin{array}{l}\text { STROBE-NI } \\
5.6\end{array}$ & $\begin{array}{l}\text { State the laboratory location and capacity to process different sample types, and give quality } \\
\text { control and assurance measures in place. }\end{array}$ \\
\hline
\end{tabular}


Participants STROBE $6(a)$

STROBE

$6(\mathrm{~b})$

STROBE-NI 6.1

Variables

STROBE

7

STROBE-NI

7.1

Data sources measurement

Bias

Study size

Quantitative variables

Statistical methods
STROBE

STROBE

9

STROBE

10

STROBE

11

STROBE

12(a)

STROBE

12(b)

STROBE

12(c)

STROBE

12(d)

STROBE

12(e)
Cohort study-Give the eligibility criteria, and the sources and methods of selection of participants. Describe methods of follow-up

Case-control study-Give the eligibility criteria, and the sources and methods of case ascertainment and control selection. Give the rationale for the choice of cases and controls

Cross-sectional study-Give the eligibility criteria, and the sources and methods of selection of participants

Cohort study-For matched studies, give matching criteria and number of exposed and unexposed

Case-control study-For matched studies, give matching criteria and the number of controls per case

State age of participants (eg. 0-27 days defines neonates; 'day 0' as day of birth). Disaggregate neonatal data from that of older infants and from stillbirths

Clearly define all outcomes, exposures, predictors, potential confounders, and effect modifiers. Give diagnostic criteria, if applicable

State criteria used to define clinically significant organisms for each sample type

For each variable of interest, give sources of data and details of methods of assessment (measurement). Describe comparability of assessment methods if there is more than one group

Describe any efforts to address potential sources of bias

Explain how the study size was arrived at

Explain how quantitative variables were handled in the analyses. If applicable, describe which groupings were chosen and why

Describe all statistical methods, including those used to control for confounding

Describe any methods used to examine subgroups and interactions

Explain how missing data were addressed

Cohort study-If applicable, explain how loss to follow-up was addressed

Case-control study-If applicable, explain how matching of cases and controls was addressed Cross-sectional study-If applicable, describe analytical methods taking account of sampling strategy

Describe any sensitivity analyses

\section{RESULTS}

\begin{tabular}{|c|c|c|}
\hline \multirow[t]{4}{*}{ Participants } & $\begin{array}{l}\text { STROBE } \\
13(a)\end{array}$ & $\begin{array}{l}\text { Report numbers of individuals at each stage of study-eg. numbers potentially eligible, } \\
\text { examined for eligibility, confirmed eligible, included in the study, completing follow-up, and } \\
\text { analysed }\end{array}$ \\
\hline & $\begin{array}{l}\text { STROBE } \\
13(b)\end{array}$ & Give reasons for non-participation at each stage \\
\hline & $\begin{array}{l}\text { STROBE } \\
13(c)\end{array}$ & Consider use of a flow diagram \\
\hline & $\begin{array}{l}\text { STROBE-NI } \\
13.1\end{array}$ & See Figure 3 for suggested components of a flow diagram for neonatal infections \\
\hline \multirow[t]{3}{*}{$\begin{array}{l}\text { Descriptive } \\
\text { data }\end{array}$} & $\begin{array}{l}\text { STROBE } \\
14(a)\end{array}$ & $\begin{array}{l}\text { Give characteristics of study participants (eg. demographic, clinical, social) and information } \\
\text { on exposures and potential confounders }\end{array}$ \\
\hline & $\begin{array}{l}\text { STROBE-NI } \\
14.1\end{array}$ & $\begin{array}{l}\text { Describe maternal infections (clinical or on screening, eg. GBS or HIV) or risk factors for } \\
\text { infection (eg. PROM, peripartum fever). }\end{array}$ \\
\hline & $\begin{array}{l}\text { STROBE-NI } \\
14.2\end{array}$ & $\begin{array}{l}\text { Describe key neonatal characteristics, including sex, postnatal and gestational age categories } \\
\text { (range and median), birth weight categories (range and median), birth place, feeding (breast } \\
\text { milk or other) and comorbidities }\end{array}$ \\
\hline
\end{tabular}




\begin{tabular}{|c|c|c|}
\hline & $\begin{array}{l}\text { STROBE-NI } \\
14.3\end{array}$ & $\begin{array}{l}\text { Report data on occurrence of individual signs (eg. fast breathing), according to case } \\
\text { definitions }\end{array}$ \\
\hline & $\begin{array}{l}\text { STROBE-NI } \\
14.4\end{array}$ & $\begin{array}{l}\text { Give proportion of mothers and neonates with peripartum antibiotic exposure (+/- pre- } \\
\text { admission exposure for neonates). Report details of antimicrobials (or supportive care) given } \\
\text { during the study }\end{array}$ \\
\hline & $\begin{array}{l}\text { STROBE } \\
14(b)\end{array}$ & Indicate number of participants with missing data for each variable of interest \\
\hline & $\begin{array}{l}\text { STROBE } \\
14(c)\end{array}$ & Cohort study-Summarise follow-up time (eg. average and total amount) \\
\hline \multirow[t]{7}{*}{ Outcome data } & STROBE & Cohort study-Report numbers of outcome events or summary measures over time \\
\hline & & $\begin{array}{l}\text { Case-control study-Report numbers in each exposure category, or summary measures of } \\
\text { exposure }\end{array}$ \\
\hline & & Cross-sectional study-Report numbers of outcome events or summary measures \\
\hline & $\begin{array}{l}\text { STROBE-NI } \\
15.1\end{array}$ & $\begin{array}{l}\text { Report the number (+/- proportion) of samples microbiologically tested (including lumbar } \\
\text { punctures for meningitis cases); the number (+/-proportion) that were positive (including } \\
\text { thresholds for detection, where applicable); all isolates obtained (including clinically } \\
\text { significant and non-significant); and antimicrobial susceptibilities of pathogens, where done. }\end{array}$ \\
\hline & $\begin{array}{l}\text { STROBE-NI } \\
15.2\end{array}$ & $\begin{array}{l}\text { Report number (+/- proportion) of babies with microbiologically proven infection (and } \\
\text { number of infections per baby), and include this in the flow chart (see Figure } 3 \text { ). }\end{array}$ \\
\hline & $\begin{array}{l}\text { STROBE-NI } \\
15.3\end{array}$ & $\begin{array}{l}\text { Report infections by day, for days } 0-6 \text {. State age categories, if used, defining 'early-onset' and } \\
\text { 'late-onset' infection (eg. }<72 \text { hours and } \geq 72 \text { hours respectively). }\end{array}$ \\
\hline & $\begin{array}{l}\text { STROBE-NI } \\
15.4\end{array}$ & Report deaths and any sub-analyses by risk groups \\
\hline \multirow[t]{4}{*}{ Main results } & $\begin{array}{l}\text { STROBE } \\
16(a)\end{array}$ & $\begin{array}{l}\text { Give unadjusted estimates and, if applicable, confounder-adjusted estimates and their } \\
\text { precision (eg. } 95 \% \text { confidence interval). Make clear which confounders were adjusted for and } \\
\text { why they were included }\end{array}$ \\
\hline & $\begin{array}{l}\text { STROBE } \\
16(\mathrm{~b})\end{array}$ & Report category boundaries when continuous variables were categorized \\
\hline & $\begin{array}{l}\text { STROBE } \\
16(c)\end{array}$ & $\begin{array}{l}\text { If relevant, consider translating estimates of relative risk into absolute risk for a meaningful } \\
\text { time period }\end{array}$ \\
\hline & $\begin{array}{l}\text { STROBE-NI } \\
16.1\end{array}$ & $\begin{array}{l}\text { For incidence, give risk per } 1000 \text { live births, or if alternative denominator used (eg. total } \\
\text { births or bed days), define this clearly }\end{array}$ \\
\hline Other analyses & $\begin{array}{l}\text { STROBE } \\
17\end{array}$ & $\begin{array}{l}\text { Report other analyses done-eg. analyses of subgroups and interactions, and sensitivity } \\
\text { analyses }\end{array}$ \\
\hline
\end{tabular}

\section{DISCUSSION}

\begin{tabular}{|c|c|c|}
\hline Key results & $\begin{array}{l}\text { STROBE } \\
18\end{array}$ & Summarise key results with reference to study objectives \\
\hline \multirow[t]{2}{*}{ Limitations } & $\begin{array}{l}\text { STROBE } \\
19\end{array}$ & $\begin{array}{l}\text { Discuss limitations of the study, taking into account sources of potential bias or imprecision. } \\
\text { Discuss both direction and magnitude of any potential bias }\end{array}$ \\
\hline & $\begin{array}{l}\text { STROBE-NI } \\
19.1\end{array}$ & $\begin{array}{l}\text { Discuss sources of recruitment bias, particularly regarding the period of time shortly after } \\
\text { birth. State source of denominator data and discuss possible related biases }\end{array}$ \\
\hline Interpretation & $\begin{array}{l}\text { STROBE } \\
20\end{array}$ & $\begin{array}{l}\text { Give a cautious overall interpretation of results considering objectives, limitations, } \\
\text { multiplicity of analyses, results from similar studies, and other relevant evidence }\end{array}$ \\
\hline Generalisability & $\begin{array}{l}\text { STROBE } \\
21\end{array}$ & Discuss the generalisability (external validity) of the study results \\
\hline \multicolumn{3}{|r|}{ OTHER INFORMATION } \\
\hline Funding & $\begin{array}{l}\text { STROBE } \\
22\end{array}$ & $\begin{array}{l}\text { Give the source of funding and the role of the funders for the present study and, if } \\
\text { applicable, for the original study on which the present article is based }\end{array}$ \\
\hline Ethics & $\begin{array}{l}\text { STROBE-NI } \\
23.1\end{array}$ & $\begin{array}{l}\text { Report any ethical considerations, including the recruitment of young mothers (minors), and } \\
\text { the consent process for early recruitment of neonates after delivery. Provide details of } \\
\text { research ethics approval. }\end{array}$ \\
\hline
\end{tabular}




\section{SUPPLEMENTARY MATERIAL}

Strengthening Reporting of Observational Studies in Epidemiology for Newborn Infection (STROBE-NI): An extension of the STROBE statement for neonatal infection research

\section{Contents}

SECTION 1: Literature review and preliminary list

2

A. Search strategy 2

B. Search results (reviewed papers) 3

1. Neonatal infection literature from seven global regions (Table 1) 3

2. Literature from high impact infectious disease and paediatric journals (Table 2) 5

C. Preliminary list of potential reporting items (Table 3) 6

SECTION 2: Survey to rate potential reporting items $\quad 9$

A. Countries of survey respondents (Table 4) 9

B. Survey tool 11

C. Survey results (pie charts) $\quad 24$

SECTION 3: Figure 2b 50

A. The structural relationship between STROBE ${ }^{29}$, STROME-ID ${ }^{31}$, and STROBE-NI 50 
SECTION 1: Literature Review and Preliminary List

1.A. Search strategy and selection criteria for neonatal infection articles

\section{Search terms:}

[All Fields] neonat* OR newborn* OR newborn infant* OR young infant* AND

[All Fields] infect* OR sepsis OR meningitis OR pneumonia OR tetanus OR omphalitis

Inclusion criteria:

- Papers presenting primary microbiological data on infections in neonates ( $0-27$ days), including studies of infections in children who present separate neonatal data

\section{Exclusion criteria:}

- Studies with data only from very high risk neonatal populations (eg. very low birth weight, extremely premature)

- Studies focussing on HIV, TB, syphilis, malaria or other congenital infections

\section{Search 1: Literature from seven Global Burden of Disease region}

- SCOPUS database (which gives citation data)

- 1996 to February 2015 (last search $27^{\text {th }}$ February 2015)

- Searches for literature with author affiliations to institutions in countries within each of seven Global Burden of Disease Regions ${ }^{1}$ and presenting primary data from a country in that region

i. Central Europe, Eastern Europe, and Central Asia

ii. Latin American and Caribbean

iii. North Africa and Middle East

iv. South Asia

v. Southeast Asia, East Asia and Oceania

vi. Sub-Saharan Africa

vii. High income countries - Asia-Pacific, North America, Western Europe, Australasia,

viii. Southern Latin America

- All studies from each region ranked by number of citations per year

- Three studies, from each region, with the highest number of citations per year selected for review

\section{Search 2: Recent literature from high impact infectious diseases and paediatric journals}

(excluding journals not publishing neonatal infection articles eg. Journal of the American Academy of Child \& Adolescent Psychiatry)

- Pubmed database

- 2011 to March 2015 (last search 15 ${ }^{\text {th }}$ March 15)

- Highest impact infectious disease journals searched:

i. Lancet Infectious Diseases

ii. Clinical Infectious Diseases

iii. Emerging Infectious Diseases

iv. Journal of Infectious Diseases

- Highest impact paediatric journals searched:

i. Pediatrics

ii. Archives of Pediatrics \& Adolescent Medicine

iii. Archives of Disease in Childhood - Fetal and Neonatal Edition

iv. Journal of Pediatrics

\section{Reference:}

1 Global Burden of Disease Study 2013 Collaborators. Global, regional, and national incidence, prevalence, and years lived with disability for 301 acute and chronic diseases and injuries in 188 countries, 1990-2013: a systematic analysis for the Global Burden of Disease Study 2013. Lancet 2015; 6736. DOI:10.1016/S0140-6736(15)60692-4. 


\section{B. Search results - papers selected for review}

\section{Table 1: Neonatal infection literature from seven global regions}

\begin{tabular}{|c|c|c|c|c|c|c|}
\hline $\begin{array}{l}\text { Super-GBD } \\
\text { Region }\end{array}$ & Title & Country & Authors & Year & Journal & $\begin{array}{l}\text { Citations } \\
\text { per year }\end{array}$ \\
\hline & $\begin{array}{l}\text { Population-Based Incidence and Etiology of Community- } \\
\text { Acquired Neonatal Bacteremia in Mirzapur, Bangladesh: An } \\
\text { Observational Study }\end{array}$ & Bangladesh & $\begin{array}{l}\text { Darmstadt G.L., Saha S.K., Choi Y., Arifeen S.E., Ahmed N.U., Bari S., } \\
\text { Rahman S.M., Mannan I., Crook D., Fatima K., Winch P.J., Seraji H.R., Begum } \\
\text { N., Rahman N., Islam M., Rahman A., Black R.E., Santosham M., Sacks E., } \\
\text { Baqui A.H. }\end{array}$ & 2009 & $\begin{array}{l}\text { Journal of Infectious } \\
\text { Diseases }\end{array}$ & 4.8 \\
\hline \multirow[t]{3}{*}{ South Asia } & Multidrug resistant neonatal sepsis in Peshawar, Pakistan & Pakistan & Rahman S., Hameed A., Roghani M.T., Ullah Z. & 2002 & $\begin{array}{l}\text { Archives of Disease in } \\
\text { Childhood: } \\
\text { Fetal and Neonatal Edition }\end{array}$ & 4.0 \\
\hline & Early onset neonatal sepsis & India & Chacko B., Sohi I. & 2005 & Indian Journal of Pediatrics & 3.9 \\
\hline & $\begin{array}{l}\text { A } 10 \text {-year prospective surveillance of nosocomial infections } \\
\text { in neonatal intensive care units }\end{array}$ & Brazil & $\begin{array}{l}\text { Couto R.C., Carvalho E.A.A., Pedrosa T.M.G., Pedroso E.R., Neto M.C., } \\
\text { Biscione F.M. }\end{array}$ & 2007 & $\begin{array}{l}\text { American Journal of } \\
\text { Infection Control }\end{array}$ & 9.1 \\
\hline \multirow{3}{*}{$\begin{array}{l}\text { Latin America \& } \\
\text { The Caribbean }\end{array}$} & $\begin{array}{l}\text { Nosocomial infections in a neonatal intensive care unit: } \\
\text { Incidence and risk factors }\end{array}$ & Brazil & Nagata E., Brito A.S.J., Matsuo T. & 2002 & $\begin{array}{l}\text { American Journal of } \\
\text { Infection Control }\end{array}$ & 5.3 \\
\hline & $\begin{array}{l}\text { Reduction in colonization and nosocomial infection by } \\
\text { multiresistant bacteria in a neonatal unit after institution of } \\
\text { educational measures and restriction in the use of } \\
\text { cephalosporins }\end{array}$ & Brazil & Calil R., Marba S.T.M., von Nowakonski A., Tresoldi A.T. & 2001 & $\begin{array}{l}\text { American Journal of } \\
\text { Infection Control }\end{array}$ & 4.1 \\
\hline & $\begin{array}{l}\text { Neonatal nosocomial sepsis in a level-III NICU: Evaluation } \\
\text { of the causative agents and antimicrobial susceptibilities }\end{array}$ & Turkey & Yalaz M., Cetin H., Akisu M., Aydemir S., Tunger A., Kultursay N. & 2006 & $\begin{array}{l}\text { Turkish Journal of } \\
\text { Pediatrics }\end{array}$ & 3.3 \\
\hline \multirow[t]{3}{*}{$\begin{array}{l}\text { North Africa \& } \\
\text { The Middle East }\end{array}$} & Changing spectrum of neonatal omphalitis & Oman & Sawardekar K.P. & 2004 & $\begin{array}{l}\text { Pediatric Infectious } \\
\text { Disease Journal }\end{array}$ & 3.0 \\
\hline & $\begin{array}{l}\text { A case control study of neonatal sepsis: Experience from } \\
\text { Saudi Arabia }\end{array}$ & Saudi Arabia & Dawodu A., Al Umran K., Twum-Danso K. & 1997 & $\begin{array}{l}\text { Journal of Tropical } \\
\text { Pediatrics }\end{array}$ & 1.4 \\
\hline & $\begin{array}{l}\text { Nosocomial infection in a neonatal intensive care unit: A } \\
\text { prospective study in Taiwan }\end{array}$ & Taiwan & Su B.-H., Hsieh H.-Y., Chiu H.-Y., Lin H.-C., Lin H.-C. & 2007 & $\begin{array}{l}\text { American Journal of } \\
\text { Infection Control }\end{array}$ & 4.9 \\
\hline
\end{tabular}




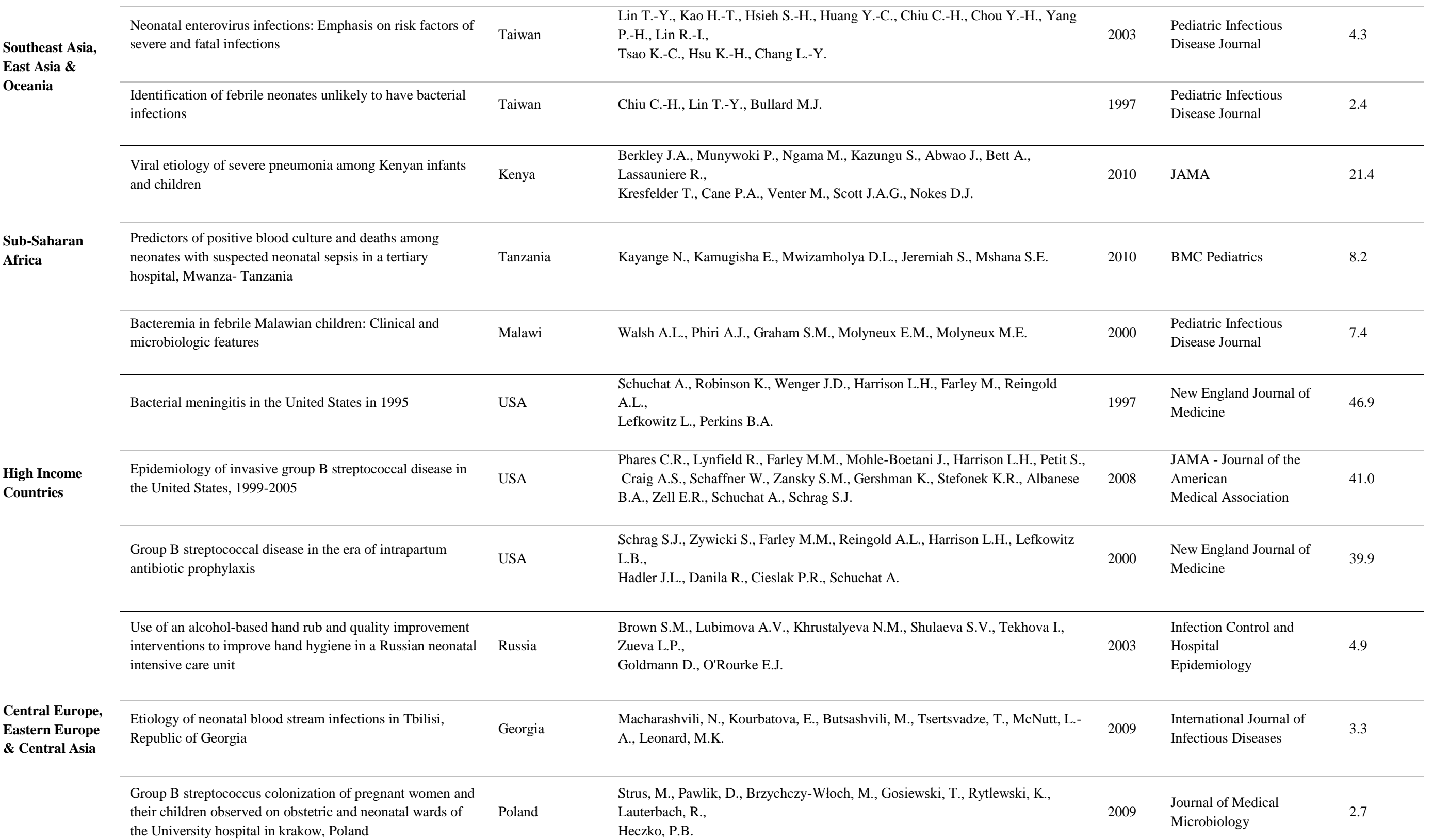




\section{Table 2: Recent literature from high impact journals}

\begin{tabular}{|c|c|c|c|c|c|}
\hline & Title & Authors & Year & Journal & $\begin{array}{l}\text { Journal } \\
\text { Impact } \\
\text { Factor }\end{array}$ \\
\hline \multirow{4}{*}{ 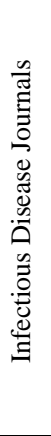 } & $\begin{array}{l}\text { Incidence of invasive group B streptococcal disease } \\
\text { and pathogen genotype distribution in newborn babies } \\
\text { in the Netherlands }\end{array}$ & Bekker V., Bijlsma M.W., van de Beek D., Kuijpers T.W., van der Ende A. & 2014 & Lancet ID & 19.446 \\
\hline & $\begin{array}{l}\text { Neonatal invasive haemophilus influenzae disease in } \\
\text { England and Wales: Epidemiology, clinical } \\
\text { characteristics, and outcome }\end{array}$ & Collins S., Litt D.J., Flynn S., Ramsay M.E., Slack M.P.E., Ladhani S.N. & 2015 & $\begin{array}{l}\text { Clinical Infectious } \\
\text { Diseases }\end{array}$ & 9.416 \\
\hline & $\begin{array}{l}\text { Incidence, etiology, and outcome of bacterial } \\
\text { meningitis in infants aged <90 days in the United }\end{array}$ & & & & \\
\hline & $\begin{array}{l}\text { Kingdom and Republic of Ireland: Prospective, } \\
\text { enhanced, national population-based surveillance }\end{array}$ & $\begin{array}{l}\text { Okike I.O., Johnson A.P., Henderson K.L., Blackburn R.M., } \\
\text { Muller-Pebody B., Ladhani S.N., Anthony M., Ninis N., Heath P.T. }\end{array}$ & 2014 & $\begin{array}{l}\text { Clinical Infectious } \\
\text { Diseases }\end{array}$ & 7.327 \\
\hline \multirow{8}{*}{ 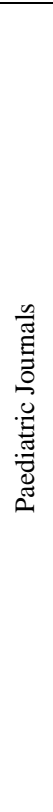 } & $\begin{array}{l}\text { Early onset neonatal sepsis: The burden of group B } \\
\text { streptococcal and E. coli diseases continues }\end{array}$ & $\begin{array}{l}\text { Stoll B., Hansen N.I., Sanchez P.J., Faix R.G., Poindexter B.B., Van Meurs K.P., Bizzaro M.J., Goldberg R.N., } \\
\text { Frantz I.D., Hale E.C., Shankaran S., Kennedy K., Carlo W.A., Watterberg K.L., Bell E.F., Walsh M.C., } \\
\text { Schibler K., Laptook A.R., Shane A.L., Schrag S.J., Das A., Higgins R.D. }\end{array}$ & 2011 & Pediatrics & 5.297 \\
\hline & Group B streptococcus late-onset disease: 2003-2010 & $\begin{array}{l}\text { Beradi A., Rossi C., Lugli L., Creti R., Reggiani M.L.B., Lanari M., } \\
\text { Memo L., Pedna M.F., Venturelli C., Perrone E., Ciccia M., Tridapalli E., Piepoli M., Contiero R., Ferrari F. }\end{array}$ & 2013 & Pediatrics & 5.297 \\
\hline & $\begin{array}{l}\text { Trends in candida central line-associated bloodstream } \\
\text { infections among NICUs, 1999-2009 }\end{array}$ & Chitnis A.S., Magill S.S., Edwards J.R., Chiller T.M., Fridkin S.K., Lessa F.C. & 2012 & Pediatrics & 5.297 \\
\hline & $\begin{array}{l}\text { Changing epidemiology of bacteremia in infants aged } 1 \\
\text { week to } 3 \text { months }\end{array}$ & Greenhow T.L., Hung Y-Y., Herz A.M & 2012 & Pediatrics & 5.297 \\
\hline & $\begin{array}{l}\text { Neonatal infections in China, Malaysia, Hong Kong } \\
\text { and Thailand }\end{array}$ & Al-Taiar A., Hammoud M.S., Cuiqing L., Lee J.K., Lui K.M., Nakwan N., Isaacs D. & 2013 & $\begin{array}{l}\text { Arch Dis Child: Fe Neonat } \\
\text { Ed }\end{array}$ & 3.861 \\
\hline & $\begin{array}{l}\text { Seasonal variations in healthcare-associated infection } \\
\text { in neonates in Canada. }\end{array}$ & Shah P.S., Yoon W., Kalapesi Z., Bassil K., Dunn M., Lee S.K. & 2013 & $\begin{array}{l}\text { Arch Dis Child: Fe Neonat } \\
\text { Ed }\end{array}$ & 3.861 \\
\hline & $\begin{array}{l}\text { Multi-drug resistant gram negative bacilli causing early } \\
\text { neonatal sepsis in India }\end{array}$ & Viswanathan R., Singh A.K., Basu S., Chatterjee S., Sardar S., Isaacs D. & 2012 & $\begin{array}{l}\text { Arch Dis Child: Fe Neonat } \\
\text { Ed }\end{array}$ & 3.861 \\
\hline & $\begin{array}{l}\text { Neonatal infections in England: The NeonIN } \\
\text { surveillance network }\end{array}$ & $\begin{array}{l}\text { Vergnano S, Menson E, Kennea N, Embleton N, Russell AB, Watts T, Robinson MJ, } \\
\text { Collinson A, Heath PT }\end{array}$ & 2011 & $\begin{array}{l}\text { Archives of Disease in } \\
\text { Childhood: } \\
\text { Fetal and Neonatal Ed. }\end{array}$ & 3.861 \\
\hline
\end{tabular}




\section{C. Preliminary ist of potential reporting items}

Table 3. List of 133 potential reporting items derived from literature review

\begin{tabular}{|c|c|c|c|}
\hline \multirow{4}{*}{$\begin{array}{c}\text { Study } \\
\text { Overview }\end{array}$} & $\begin{array}{c}1 . \\
\text { Study purpose }\end{array}$ & $\begin{array}{l}\text { a. Aim } \\
\text { b. Contribution to existing research } \\
\text { c. Primary outcomes } \\
\text { d. Secondary outcomes }\end{array}$ & \\
\hline & $\begin{array}{c}2 . \\
\text { Study design }\end{array}$ & $\begin{array}{l}\text { a. Study type or description of surveillance network } \\
\text { b. Prospective vs. retrospective } \\
\text { c. Data collection dates (day, month, year) } \\
\text { d. Sample size calculations } \\
\text { e. Inclusion criteria } \\
\text { f. Exclusion criteria } \\
\text { g. Case finding method } \\
\text { h. Method of randomisation } \\
\text { i. Ethical approval (name of board (s)/institution(s)) } \\
\text { j. Funding source(s) } \\
\text { k. Source of demographic data }\end{array}$ & $\begin{array}{l}\text { (eg. systematic screening; active vs. passive } \\
\text { surveillance) }\end{array}$ \\
\hline & $\begin{array}{l}3 . \\
\text { Recruitment }\end{array}$ & $\begin{array}{l}\text { a. Number of eligible subjects } \\
\text { b. Number of subjects enrolled } \\
\text { c. Number of excluded subjects } \\
\text { d. Proportion of study subjects sampled } \\
\text { e. Description of comparison groups } \\
\text { f. Consent process }\end{array}$ & 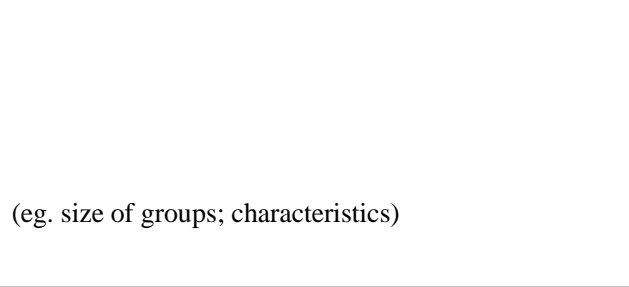 \\
\hline & $\begin{array}{c}4 . \\
\text { Statistical } \\
\text { Methods }\end{array}$ & $\begin{array}{l}\text { a. Software used } \\
\text { b. Descriptive statistics methods } \\
\text { c. Modelling methods }\end{array}$ & \\
\hline \multirow[t]{2}{*}{ Setting } & $\begin{array}{c}5 . \\
\text { Study site context }\end{array}$ & $\begin{array}{l}\text { a. Facility or community based } \\
\text { b. Size of study site (catchment area or total population) } \\
\text { c. Annual number of live births in study catchment area } \\
\text { d. Neonatal mortality risk (per } 1000 \text { live births) in study area } \\
\text { e. Stillbirth risk (per } 1000 \text { births) in study area } \\
\text { f. Source of population denominator } \\
\text { g. Climate or seasonal change, where relevant } \\
\text { h. Healthcare staff (grade/qualification) looking after study patients } \\
\text { i. Training (study specific) conducted } \\
\text { j. Geographical location } \\
\text { k. Endemic diseases } \\
\text { 1. HIV testing strategy } \\
\text { m. Vaccination schedule } \\
\text { n. Vaccination coverage } \\
\text { o. Climate }\end{array}$ & $\begin{array}{l}\text { (eg. vital registration or census data) } \\
\text { (eg. Community Health Workers, clinical officers, } \\
\text { medical officers, paediatricians) } \\
\text { (eg. clinical algorithm to diagnose clinical possible } \\
\text { severe bacterial infection) } \\
\text { (eg. malaria) } \\
\text { (eg. seasonal rainfall) }\end{array}$ \\
\hline & $\begin{array}{c}6 . \\
\text { Health facility } \\
\text { (where applicable) }\end{array}$ & $\begin{array}{l}\text { a. Type of facility and which ward(s)/unit(s) included } \\
\text { b. Criteria for admission (+/- ward) } \\
\text { c. Annual admissions (+/- ward) } \\
\text { d. Level of care available } \\
\text { e. Patients requiring ventilation, central lines, TPN and surgery, } \\
\text { expressed as patient days (where relevant) } \\
\text { f. Cot occupancy } \\
\text { g. Infection control measures, availability of local guidelines, and } \\
\text { adherence } \\
\text { h. Availability and use of kangaroo mother care } \\
\text { i. Size of health facility } \\
\text { j. Annual number of live births at the health facility } \\
\text { k. Annual number of admissions at the health facility }\end{array}$ & $\begin{array}{l}\text { (eg. First level health facility, district, referral hospital; } \\
\text { neonatal intensive care unit, paediatric ward) } \\
\text { (eg. Level of respiratory support available: invasive } \\
\text { ventilation, CPAP, oxygen, nil) } \\
\text { (eg. total central-line days) } \\
\text { (eg. space between cots, hand washing) }\end{array}$ \\
\hline
\end{tabular}



time of data collection)

b. Parity

7.

Maternal demographic and clinical information

Newborn demographic and clinical information c. Mode of delivery

d. Complications during pregnancy / birth

e. Recent maternal illness

f. Maternal co-morbidities

g. Definitions used for maternal co-morbidities

h. Antenatal screening for infections

a. Sex

b. Postnatal age range (and mean / median) of study participants

c. Time between admission/birth and infection

d. Gestational age range (and median) of study participants, including method of assessment and criteria used to define 'preterm' / 'very preterm'

e. Birth weight range (and mean / median) of study participants, including criteria used to define "low birth weight' / 'very low birth weight'

f. Place of birth, defining terms such as 'inborn' and 'outborn'

g. Newborn comorbidities

h. Definitions used for newborn comorbidities

i. Prognostic scores

10.

Sampling

strategy

9.

Clinical

assessment

a. Physical examination and whether consistent

b. Blood tests other than culture

c. Measurement of vital signs

d. Radiological investigations

e. Method of documentation of case reports

a. Indication for sample collection

b. Sample collection method

c. Number of samples collected (from each subject)

d. Volume of sample collected

e. Methods for transfer/storage of clinical samples

11.

a. General case management

b. Local empirical antimicrobial policy

Treatment

c. Antimicrobial point prevalence survey data

a. Infectious syndromes definitions

b. Culture-proven infection definitions

12.

Definitions of

cases and

denominators

Antimicrobial use

14.

Context c. HAI cases and outbreaks, definitions and duration of episode

d. 'Early-onset' and 'late-onset' infection definitions

e. Denominator for incidence / mortality

f. Stillbirth definitions, including subgroups

g. Morbidity or long-term impairment definitions

a. Prior administration of antimicrobial (or anti-fungal) agents in the

newborn, including type and timing and whether serum testing was

done

b. Prior maternal use of antimicrobials (recent antenatal or

intrapartum), including type and timing and whether for treatment or prophylaxis

c. Indications / rationale for antimicrobial use

d. Number (+/- proportion) of study subjects who received

antimicrobials, and type

e. Route, dose (per kg per day) and durations of antimicrobial administration

a. Location, description, and any accreditation of laboratory

b. Samples taken for culture, including number, type and collection

methods (eg. vaginal vs. elective caesarean vs. emergency caesarean)

(eg. Prolonged Rupture Of Membranes)

(eg. fever, UTI)

(eg. Anaemia, malaria)

(eg. GBS, HIV, syphilis, Hep B)

(in hours or days)

(eg. congenital malformations, HIV)

(eg. 10 minute Apgar score, CRIB score)

(eg. FBC)

(eg. pulse oximetry, temperature)

(eg. CXR)

(eg. standard data collection forms)

(eg. clinically indicated vs. routine surveillance)

(eg. whether aseptic technique used; clean catch vs. catheter for urine collection)

(eg. admission, IV fluid administration)

(eg. sepsis, pneumonia, meningitis);

(eg. criteria for HABSI, CLABSI);

(eg. patient days, live births, admissions)

(eg. intrapartum (fresh) or Antepartum (macerated) stillbirth

(eg. neurodisability)

(eg. empirical antibiotic policy)

(eg. proportion who received gentamicin or meropenem)

(eg. oral, intramuscular, intravenous) 
c. Isolates defined as contaminants

d. Quality control and validation

a. Process for dealing with polymicrobial cultures

b. Conventional or molecular

c. Broth or direct plating

15.

Microbiological methods

16.

Antimicrobial susceptibility testing

17.

Microbiological results

Results \& Outcomes

d. Gram staining or other method used methods, automated or manual

a. Antimicrobial susceptibility testing methods

b. Antimicrobial testing standards

c. Drugs tested

d. Mechanisms of resistance tested for

a. Number (+/- proportion(s)) of positive cultures resistant to each antimicrobial gram negatives

f. Time between admission and positive culture criteria e. Method(s) of pathogen identification, including culture/sub-culture

f. Methods of DNA extraction, PCR and whole genome sequencing, including manufacturer of equipment used (where applicable))

g. Whether point of care tests were used and the type/brand

Whether point of care tests were used and the type/brand

b. Number (+/- proportion(s)) of isolates/pathogens

c. Number (+/-proportion(s)) of isolates susceptible, intermediate or

d. Number (+/- proportion) of isolates classified as contaminants

e. Number (+/- proportions(s)) of isolates that were gram positive vs.

a. Number (+/- proportion) of babies meeting clinical case definition

b. Number (+/- proportion) of babies with culture-proven infection

c. Number (+/- proportion(s)) of babies meeting criteria for hospitalacquired infection

18.

Clinical results

d. Incidence of infection cases (as per defined clinical and/or microbiological criteria)

e. Number (+/- proportion(s)) and/or incidence of cases by risk factors

f. Trends in incidence risk

a. Overall mortality and/or case fatality risk, including timing

19.

Mortality and morbidity

20.

Other

g. Morality trends

a. Estimates of burden

b. Cost analysis

c. Sources of recruitment bias

d. Sources of information bias (eg. whether any samples were externally validated; sensitivity or specificity of testing)

(eg. biochemical testing, VITEK)

(eg. quantitative, real-time, multiplex, 16s/18s, high throughput genome sequencing)

(eg. disc diffusion, e-test, MIC)

(eg. EUCAST/CLSI)

(eg. group B strep., klebsiella sp.)

(eg. PACCS, drug/bug combinations)

(eg. number with pSBI, pneumonia, meningitis)

(eg. HABSI, CLABSI)

(eg. per 1000 patient days, live births, admissions)

(eg. by gestational age, postnatal age, birth weight)

(eg. at 7 and 28 days)

(eg. GBS, E.Coli; resistant vs. sensitive)

(eg. sepsis vs. meningitis)

(eg. by postnatal / gestational age, birth weight)

(eg. of intrapartum vs antepartum stillbirths)

(eg. long term neurological impairment)

(eg. over months, years)

e. Factors affecting generalizability of results 
SECTION 2: Survey to rate potential reporting items

2.A Countries of survey respondents

Table 4.

n

$\%$ of total

\begin{tabular}{|c|c|c|c|c|}
\hline \multirow{9}{*}{ Africa } & Kenya & & 5 & $3.6 \%$ \\
\hline & Nigeria & & 3 & $2.1 \%$ \\
\hline & Ethiopia & & 2 & $1.4 \%$ \\
\hline & Mozambique & & 1 & $0.7 \%$ \\
\hline & Malawi & & 3 & $2.1 \%$ \\
\hline & South Africa & & 4 & $2.9 \%$ \\
\hline & Gambia & & 1 & $0.7 \%$ \\
\hline & Egypt & & 1 & $0.7 \%$ \\
\hline & Republic of Congo & & 1 & $0.7 \%$ \\
\hline \multirow{8}{*}{ Asia } & & Sub Total & 21 & $15.0 \%$ \\
\hline & Cambodia & & 1 & $0.7 \%$ \\
\hline & Bangladesh & & 2 & $1.4 \%$ \\
\hline & India & & 22 & $15.7 \%$ \\
\hline & Pakistan & & 2 & $1.4 \%$ \\
\hline & Thailand & & 1 & $0.7 \%$ \\
\hline & Hong Kong & & 1 & $0.7 \%$ \\
\hline & Nepal & & 1 & $0.7 \%$ \\
\hline \multirow{3}{*}{ North America } & & Sub Total & 30 & $21.4 \%$ \\
\hline & USA (see list of states) & & 27 & $19.3 \%$ \\
\hline & Canada & & 1 & $0.7 \%$ \\
\hline \multirow{9}{*}{ Europe } & & Sub Total & 28 & $20.0 \%$ \\
\hline & France & & 4 & $2.9 \%$ \\
\hline & UK & & 29 & $20.7 \%$ \\
\hline & Switzerland & & 4 & $2.9 \%$ \\
\hline & Greece & & 4 & $2.9 \%$ \\
\hline & Italy & & 3 & $2.1 \%$ \\
\hline & Poland & & 1 & $0.7 \%$ \\
\hline & Estonia & & 2 & $1.4 \%$ \\
\hline & Netherlands & & 1 & $0.7 \%$ \\
\hline \multirow{5}{*}{ Middle East } & & Sub Total & 48 & $34.3 \%$ \\
\hline & Qatar & & 1 & $0.7 \%$ \\
\hline & UAE & & 1 & $0.7 \%$ \\
\hline & Turkey & & 1 & $0.7 \%$ \\
\hline & Oman & & 1 & $0.7 \%$ \\
\hline \multirow{7}{*}{ Latin America } & & Sub Total & 4 & $2.9 \%$ \\
\hline & Peru & & 1 & $0.7 \%$ \\
\hline & Venezuela & & 1 & $0.7 \%$ \\
\hline & Guatemala & & 1 & $0.7 \%$ \\
\hline & Brazil & & 2 & $1.4 \%$ \\
\hline & Argentina & & 1 & $0.7 \%$ \\
\hline & & Sub Total & 5 & $4.3 \%$ \\
\hline
\end{tabular}




\begin{tabular}{|c|c|c|c|}
\hline Australasia & $\begin{array}{l}\text { Australia } \\
\text { New Zealand }\end{array}$ & $\begin{array}{l}3 \\
1 \\
\end{array}$ & $\begin{array}{l}2.1 \% \\
0.7 \% \\
\end{array}$ \\
\hline \multirow{21}{*}{ (USA states) } & Sub Total & 4 & $2.9 \%$ \\
\hline & Washington DC & 4 & $2.9 \%$ \\
\hline & Washington State & 1 & $0.7 \%$ \\
\hline & Massachusetts & 4 & $2.9 \%$ \\
\hline & New York & 1 & $0.7 \%$ \\
\hline & Indiana & 1 & $0.7 \%$ \\
\hline & Maryland & 2 & $1.4 \%$ \\
\hline & Georgia (US) & 2 & $1.4 \%$ \\
\hline & North Carolina & 3 & $2.1 \%$ \\
\hline & New Jersey & 1 & $0.7 \%$ \\
\hline & Ohio & 2 & $1.4 \%$ \\
\hline & Texas & 2 & $1.4 \%$ \\
\hline & Missouri & 1 & $0.7 \%$ \\
\hline & Philadelphia & 1 & $0.7 \%$ \\
\hline & Colorado & 1 & $0.7 \%$ \\
\hline & California & 1 & $0.7 \%$ \\
\hline & Sub Total & 27 & $19.3 \%$ \\
\hline & Number with country data & 141 & \\
\hline & Number without country data & 6 & \\
\hline & Total respondents & 147 & \\
\hline & Total countries & 37 & \\
\hline
\end{tabular}


2.B. Survey Tool

\section{Expert online survey to inform new guidance for reporting neonatal infection research}

$6 \%$ complete

\section{Page 2: Contents}

1. Setting: Study Site

Setting: Health Facility

3. Clinical Information: Maternal

5. Clinical Information: Antimicrobial Use

6. Microbiology: Context

6. Microbiology: Context

8. Microbiology: Antimicrobial Susceptibility Testing

9. Results and Outcomes: Clinical

10. Results and Outcomes: Microbiologica

11. Results and Outcomes: Mortality and Morbidity

11. Resiltitions

$<$ Previous

Bristol Online Surveys: www.onlinesurveys.ac.uk 


\section{Q1 - Setting: Study Site}

(1) How important is it to report the following items in neonatal infection studies?

Please don't select more than 1 answer(s) per row.

Please select at least 9 answer(s).

Having trouble with the format of this question? View in tableless mode

\begin{tabular}{|c|c|c|c|c|c|}
\hline & Unnecessary & Sometimes useful & Important for most studies & Essential for all studies & \\
\hline Facility or community based study & $\square$ & $\square$ & • & • & - \\
\hline $\begin{array}{r}\text { Size of study site catchment area or } \\
\text { total population }\end{array}$ & $\square$ & $\square$ & $\square$ & $\square$ & - \\
\hline $\begin{array}{r}\text { Annual number of live births in study } \\
\text { catchment area }\end{array}$ & $\bullet$ & $\square$ & $\square$ & $\square$ & - \\
\hline Neonatal mortality rate in study area & $\square$ & $\square$ & $\square$ & $\square$ & - \\
\hline Preterm birth rate in study area & • & $\square$ & - & $\square$ & - \\
\hline Stillbirth rate in study area & $\bullet$ & $\square$ & • & $\square$ & - \\
\hline Source of population denominator & $\square$ & $\square$ & $\square$ & • & eg. source of vital registration or survey data \\
\hline $\begin{array}{r}\text { Climate or seasonal change during } \\
\text { study, where relevant }\end{array}$ & $\bullet$ & $\square$ & $\square$ & 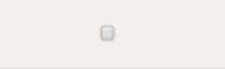 & - \\
\hline $\begin{array}{r}\text { Type / grade and number of } \\
\text { healthcare staff looking after study } \\
\text { patients }\end{array}$ & $\square$ & $\square$ & $\square$ & $\square$ & $\begin{array}{l}\text { eg. community health workers, neonatal nurses, paediatricians; nurse to } \\
\text { patient ratio }\end{array}$ \\
\hline Study specific training conducted & ○ & $\square$ & $\square$ & $\square$ & eg. clinical algorithm to diagnose possible bacterial infections \\
\hline Obstetric care provided & $\square$ & $\square$ & $\square$ & $\square$ & $\begin{array}{l}\text { eg. trained or untrained birth attendant; obstetric practices, infection } \\
\text { control practices in the delivery room, availability of antenatal steroids }\end{array}$ \\
\hline
\end{tabular}

a Comments

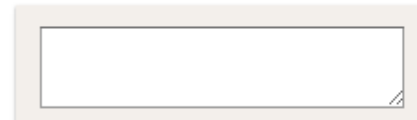


Q2 - Setting: Health Facility

2 How important is it to report the following items in neonatal infection studies?

Please don't select more than 1 answer(s) per row.

Please select at least 8 answer(s).

Having trouble with the format of this question? View in tableless mode

\begin{tabular}{|c|c|c|c|c|c|}
\hline & Unnecessary & Sometimes useful & Important for most studies & Essential for all studies & \\
\hline Type of facility and which ward(s)/unit(s) included & • & • & • & ○ & $\begin{array}{l}\text { eg. first level health centres, district hospitals, referral } \\
\text { hospital; neonatal intensive care unit, paediatric ward; } \\
\text { private, public }\end{array}$ \\
\hline Criteria for admission to the health facility ( + - ward) & ㅁ & ㅁ & ㅁ & $\square$ & - \\
\hline $\begin{array}{r}\text { Annual number of admissions to health facility }(+/- \\
\text { ward) }\end{array}$ & $\square$ & • & $\square$ & $\square$ & - \\
\hline Level of neonatal care available & ○ & 0 & ๑ & 0 & $\begin{array}{l}\text { eg. level of respiratory support offered: mechanical } \\
\text { ventilation, continuous positive airway pressure, } \\
\text { oxygen, none }\end{array}$ \\
\hline $\begin{array}{r}\text { Number of patients requiring interventions such as } \\
\text { ventilation, central lines, TPN and surgery, expressed } \\
\text { as patient days }\end{array}$ & $\square$ & $\square$ & $\square$ & $\square$ & - \\
\hline Average cot occupancy rates & • & • & ㅁ & ㅁ & - \\
\hline $\begin{array}{r}\text { Infection control measures and adherence (including } \\
\text { the delivery room) }\end{array}$ & $\square$ & $\bullet$ & $\bullet$ & $\square$ & eg. space between cots, audit data on hand washing \\
\hline Availability and use of kangaroo mother care & • & - & ㅁ & $\square$ & - \\
\hline
\end{tabular}

a Comments

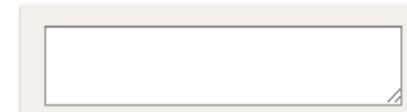


Q3 - Clinical Information: Maternal

3 How important is it to report the following items in neonatal infection studies?

Please don't select more than 1 answer(s) per row.

Please select at least 7 answer(s).

Having trouble with the format of this question? View in tableless mode

\begin{tabular}{|c|c|c|c|c|c|}
\hline & Unnecessary & Sometimes useful & Important for most studies & Essential for all studies & \\
\hline Maternal age & $\square$ & $\square$ & $\square$ & a & _- \\
\hline Parity & ㅁ & $\square$ & $\square$ & $\square$ & - \\
\hline Mode of delivery & $\square$ & 口 & 口 & a & eg. vaginal vs. elective caesarean vs. emergency caesarean \\
\hline Complications during pregnancy / delivery & $\square$ & $\square$ & $\square$ & $\square$ & eg. prolonged or preterm rupture of membranes \\
\hline Recent maternal illness & $\square$ & $\square$ & $\square$ & $\square$ & eg. fever, urinary tract infection \\
\hline List of maternal comorbidities & ㅁ & ㅁ & $\square$ & $\square$ & eg. anaemia, malaria \\
\hline Antenatal screening for infections & • & 口 & 口 & a & eg. GBS, HIV, syphilis, Hep B \\
\hline
\end{tabular}

a Comments

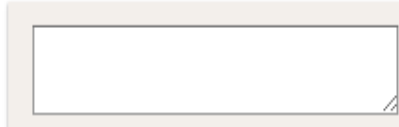




\section{Q4 - Clinical Information: Newborn}

\section{How important is it to report the following items in neonatal infection studies?}

Please don't select more than 1 answer(s) per row.

Please select at least 10 answer(s)

Having trouble with the format of this question? View in tableless mode

\begin{tabular}{|c|c|c|c|c|c|}
\hline & Unnecessary & Sometimes useful & Important for most studies & Essential for all studies & \\
\hline Sex & 口 & ○ & e & $\square$ & _ \\
\hline $\begin{array}{r}\text { Postnatal age range (and mean / median) of study participants (in hours } \\
\text { or days) }\end{array}$ & - & $\square$ & $\square$ & $\square$ & - \\
\hline $\begin{array}{r}\text { Timing of infection, including proportion of cases occurring on the first day } \\
\text { of life that were captured }\end{array}$ & ㅁ & • & ○ & 0 & - \\
\hline $\begin{array}{r}\text { Gestational age range (and median) of study participants, including } \\
\text { method of assessment }\end{array}$ & ㅁ & • & 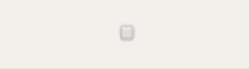 & $\square$ & - \\
\hline Birth weight range (and mean / median) of study participants & • & ㅂ & e & • & - \\
\hline Place of birth & ¿ & - & $\square$ & 口 & $\begin{array}{l}\text { eg. facility vs. home births; 'inborn' } \\
\text { or 'outborn' }\end{array}$ \\
\hline List of comorbidities & • & ○ & • & a & eg. congenital malformations, HIV \\
\hline Prognostic scores & • & a & 口 & • & $\begin{array}{l}\text { eg. } 10 \text { minute Apgar score, CRIB } \\
\text { score }\end{array}$ \\
\hline $\begin{array}{l}\text { Methods of clinical assessment including examination performed, vital } \\
\text { signs, blood tests (other than culture) and radiological investigations }\end{array}$ & - & $\square$ & $\square$ & • & eg. FBC, inflammatory markers \\
\hline Supportive care available & $\bullet$ & • & • & $\bullet$ & $\begin{array}{l}\text { eg. intravenous fluid administration, } \\
\text { nasogastric feeds, phototherapy }\end{array}$ \\
\hline Follow up period & $\square$ & D & D & 0 & eg. to discharge, to 28 days \\
\hline
\end{tabular}

\section{a Comments}

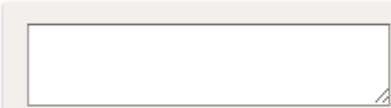


Q5 - Clinical Information: Antimicrobial Use

(6) How important is it to report the following items in neonatal infection studies?

Please don't select more than 1 answer(s) per row.

Please select at least 5 answer(s.

Having trouble with the format of this question? View in tableless mode

\begin{tabular}{|c|c|c|c|c|c|}
\hline & Unnecessary & Sometimes useful & Important for most studies & Essential for all studies & \\
\hline $\begin{array}{l}\text { Prior administration of antimicrobials to the newborn, including } \\
\text { type and timing }\end{array}$ & ๑ & • & • & 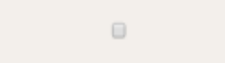 & - \\
\hline Use of maternal intrapartum antibiotic prophylaxis & $\square$ & 口 & $\square$ & ㅁ & _ \\
\hline Indications / rationale for antimicrobial use & $\square$ & - & $\square$ & $\square$ & $\begin{array}{l}\text { eg. empirical antibiotic policy or criteria for } \\
\text { starting antibiotics }\end{array}$ \\
\hline $\begin{array}{r}\text { Number (+l-proportion) of study subjects who received } \\
\text { antimicrobials, and type }\end{array}$ & • & 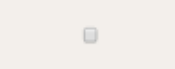 & 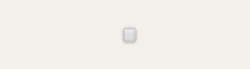 & $\square$ & $\begin{array}{l}\text { eg. proportion who received gentamicin or } \\
\text { meropenem }\end{array}$ \\
\hline Route, dose and duration of antimicrobial administration & ㅁ & ㅁ & 口 & • & eg. oral, intramuscular, intravenous \\
\hline
\end{tabular}

a Comments

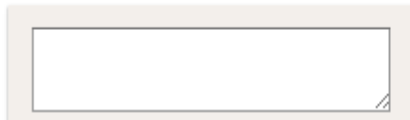


Q6 - Microbiology: Context

0 How important is it to report the following items in neonatal infection studies?

Please don't select more than 1 answer(s) per row.

Please select at least 3 answer(s)

Having trouble with the format of this question? View in tableless mode

\begin{tabular}{|c|c|c|c|c|c|}
\hline & Unnecessary & Sometimes useful & Important for most studies & Essential for all studies & \\
\hline $\begin{array}{r}\text { Location and description, any accreditation of } \\
\text { laboratory }\end{array}$ & • & $\square$ & • & $\square$ & - \\
\hline $\begin{array}{l}\text { Samples taken for culture, including type and } \\
\text { collection methods }\end{array}$ & • & $\square$ & - & $\square$ & $\begin{array}{l}\text { eg. blood or CSF; number and volume taken from each } \\
\text { baby }\end{array}$ \\
\hline Reason for sample collection & $\square$ & ㅁ & • & $\square$ & $\begin{array}{l}\text { eg. routine surveillance, study requirement, clinical } \\
\text { indication }\end{array}$ \\
\hline $\begin{array}{r}\text { Timing of sample collection in relation to } \\
\text { antimicrobial administration }\end{array}$ & • & $\square$ & 0 & - & eg. samples taken before or after starting antibiotics \\
\hline Quality control and validation & • & 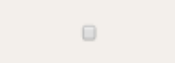 & • & • & $\begin{array}{l}\text { eg. whether samples were externally validated; sensitivity or } \\
\text { specificity of testing }\end{array}$ \\
\hline
\end{tabular}

a Comments

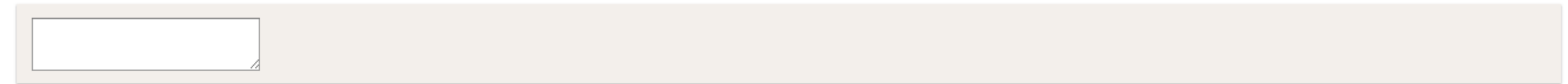


Q7 - Microbiology: Culture Methods

(7) How important is it to report the following items in neonatal infection studies?

Please don't select more than 1 answer(s) per row.

Please select at least 5 answer(s).

Having trouble with the format of this question? View in tableless mode

\begin{tabular}{|c|c|c|c|c|c|}
\hline & Unnecessary & Sometimes useful & Important for most studies & Essential for all studies & \\
\hline Whether conventional or molecular methods used & $\square$ & ㅁ & • & $\square$ & _ \\
\hline Culture incubation & a & a & a & a & e.g BACTEC \\
\hline Gram staining or other method used for early diagnosis & $\square$ & $\square$ & • & D & _ \\
\hline $\begin{array}{r}\text { Method(s) of pathogen identification, including culture/sub-culture } \\
\text { methods }\end{array}$ & $\square$ & $\square$ & $\square$ & $\square$ & $\begin{array}{l}\text { eg. automated or manual, biochemical } \\
\text { testing, VITEK }\end{array}$ \\
\hline $\begin{array}{l}\text { Methods of DNA extraction, PCR and whole genome sequencing, } \\
\text { including manufacturer of equipment used, where applicable }\end{array}$ & $\square$ & $\square$ & $\square$ & $\square$ & $\begin{array}{l}\text { eg. quantitative, real-time, multiplex, } \\
16 \text { s/18s, high throughput genome } \\
\text { sequencing }\end{array}$ \\
\hline
\end{tabular}

a Comments

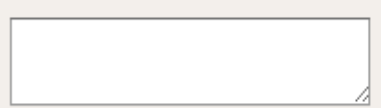

Q8 - Microbiology: Antimicrobial Susceptibility Testing

(3) How important is it to report the following items in neonatal infection studies?

Please don't select more than 1 answeris) per row.

Please select at least 2 answer(s).

Having trouble with the format of this question? View in tableless mode

\begin{tabular}{|c|c|c|c|c|c|}
\hline & Unnecessary & Sometimes useful & Important for most studies & Essential for all studies & \\
\hline $\begin{array}{r}\text { Antimicrobial susceptibility testing methods, including whether } \\
\text { automated or manual }\end{array}$ & $\square$ & $\square$ & $\square$ & D & $\begin{array}{l}\text { eg. disc diffusion, e-test, minimum inhibitory } \\
\text { concentration (MIC) }\end{array}$ \\
\hline Antimicrobial testing policy & $\square$ & a & ㅁ & a & eg. EUCAST/CLSI \\
\hline
\end{tabular}

a Comments

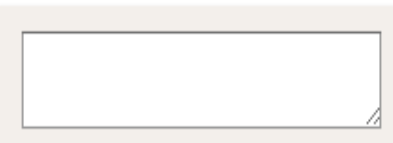


Q9 - Results and Outcomes: Clinical

How important is it to report the following items in neonatal infection studies?

Please don's select more than 1 answer(s) per row.

Having trouble with the format of this question? View in tableless mode

\begin{tabular}{|c|c|c|c|c|c|}
\hline & Unnecessary & Sometimes useful & Important for most studies & Essential for all studies & \\
\hline $\begin{array}{r}\text { Number ( }+/ \text { - proportion) of babies meeting clinical case } \\
\text { definition criteria }\end{array}$ & $\square$ & ○ & 0 & 0 & $\begin{array}{l}\text { eg. number with blood stream infections (BSI), } \\
\text { pneumonia, meningitis }\end{array}$ \\
\hline $\begin{array}{r}\text { Number (+l- proportion) of babies with culture-proven } \\
\text { infection }\end{array}$ & $\square$ & • & ㅁ & - & - \\
\hline $\begin{array}{l}\text { Number (+/- proportion) of babies meeting criteria for hospital } \\
\text { acquired infection }\end{array}$ & 口 & a & 0 & - & - \\
\hline $\begin{array}{l}\text { Incidence of infection cases (as defined by clinical and/or } \\
\text { microbiological criteria) }\end{array}$ & • & ㅁ & • & $\square$ & eg. per 1000 patient days, live births, admissions \\
\hline $\begin{array}{r}\text { Number (+/- proportion) and/or incidence of cases by } \\
\text { perinatal and postnatal risk factors }\end{array}$ & $\square$ & $\square$ & ㅁ & - & $\begin{array}{l}\text { eg. by gestational age, postnatal age, birth } \\
\text { weight }\end{array}$ \\
\hline
\end{tabular}

Q10 - Results and Outcomes: Microbiological

(10) How important is it to report the following items in neonatal infection studies?

Please don't select more than 1 answer(s) per row.

Please select at least 4 answer(s).

Having trouble with the format of this guestion? View in tableless mode

\begin{tabular}{|c|c|c|c|c|c|}
\hline & Unnecessary & Sometimes useful & Important for most studies & Essential for all studies & \\
\hline Number (+l- proportion) of positive cultures & ๑ & 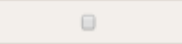 & • & $\square$ & _ \\
\hline Number (+l- proportion) of isolates/pathogens & 口 & • & $\square$ & $\square$ & $\begin{array}{l}\text { eg. group B strep., klebsiella } \\
\text { pn. }\end{array}$ \\
\hline $\begin{array}{r}\text { Number (+/-proportion) of isolates susceptible, intermediate or resistant to each } \\
\text { antimicrobial }\end{array}$ & • & • & • & $\bullet$ & $\begin{array}{l}\text { eg. PACCS, druglbug } \\
\text { combinations }\end{array}$ \\
\hline Number ( +1 - proportion) of isolates classified as contaminants & D & D & 口 & $\square$ & _ \\
\hline
\end{tabular}

a Comments

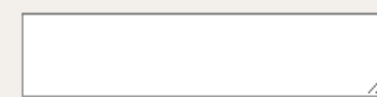




\section{Q11 - Results and Outcomes: Mortality and Morbidity}

(11) How important is it to report the following items in neonatal infection studies (as applicable)?

Please don't select more than 1 answer(s) per row.

Please select at least 7 answer(s).

Having trouble with the format of this question? View in tableless mode

\begin{tabular}{|c|c|c|c|c|c|}
\hline & Unnecessary & Sometimes useful & Important for most studies & Essential for all studies & \\
\hline $\begin{array}{r}\text { Overall mortality and/or case fatality risk (CFR), } \\
\text { including timing }\end{array}$ & $\square$ & $\square$ & $\square$ & $\square$ & eg. at 7 and 28 days \\
\hline Subgroup mortality or CFR analysis by pathogen & $\square$ & $\square$ & $\square$ & $\square$ & eg. group B strep., E.Coli; resistant vs. sensitive \\
\hline $\begin{array}{r}\text { Subgroup mortality of CFR analysis by infection } \\
\text { syndrome }\end{array}$ & ○ & $\square$ & $\square$ & $\square$ & eg. blood stream infection vs. meningitis \\
\hline Subgroup mortality or CFR analysis by risk group & $\square$ & $\square$ & $\square$ & $\square$ & eg. by post-natal age, gestational age, birth weight \\
\hline $\begin{array}{r}\text { Number (+/-proportion) of still births (+/- subgroup } \\
\text { analysis) }\end{array}$ & $\square$ & $\square$ & $\square$ & $\square$ & eg. antepartum or intrapartum stillbirths \\
\hline Mortality trends, where possible & $\square$ & $\square$ & $\square$ & $\square$ & eg. over months, seasons, years \\
\hline Morbidity outcomes & $\square$ & $\square$ & $\square$ & $\square$ & $\begin{array}{l}\text { eg. number ( }+l \text { - proportion) with long term neurological } \\
\text { impairment }\end{array}$ \\
\hline
\end{tabular}

a Comments

$+1$ 
Q12 - Definitions

(12) Clinical presentation and infection syndromes: How important is it that authors report their definitions or criteria for the following?

Please don't select more than 1 answer(s) per row.

Please select at least 11 answer(s).

Having trouble with the format of this question? View in tableless mode

\begin{tabular}{|c|c|c|c|c|}
\hline & Unnecessary & Sometimes useful & Important for most studies & Essential for all studies \\
\hline Possible severe bacterial infection (pSBI) & ○ & • & $\square$ & ○ \\
\hline Confirmed bloodstream infection (BSI) & • & • & $\square$ & a \\
\hline Meningitis & • & • & $\square$ & e \\
\hline Pneumonia (including VAP) & • & • & • & • \\
\hline Hospital acquired infection & • & • & • & 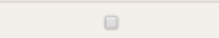 \\
\hline Central line associated infection & $\square$ & $\square$ & • & $\square$ \\
\hline Outbreak & • & • & • & 0 \\
\hline Contaminant isolate & e & • & • & • \\
\hline Coagulase negative staphylococcus infection & • & $\square$ & • & • \\
\hline Stillbirth & • & • & • & e \\
\hline Onset of infection (eg. timing of eariy and late onset infection) & • & • & a & e \\
\hline Duration of infection episode & • & • & • & • \\
\hline Long term impairment (eg. neurodisability) & e & • & a & • \\
\hline
\end{tabular}

13 Study population: How important is it that authors report their definitions or criteria for the following?

Please don't select more than 1 answer(s) per row.

Please select at least 5 answer(s).

Having trouble with the format of this question? View in tableless mode

\begin{tabular}{|c|c|c|c|c|}
\hline & Unnecessary & Sometimes useful & Important for most studies & Essential for all studies \\
\hline Neonatal population & $\square$ & $\square$ & $\square$ & $\square$ \\
\hline First day of life & $\square$ & $\square$ & $\square$ & ( \\
\hline Birth weight categories & • & • & • & $\square$ \\
\hline Gestational age categories & e & $\square$ & $\square$ & $\square$ \\
\hline Denominator & • & $\square$ & $\square$ & 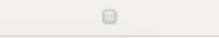 \\
\hline
\end{tabular}

eg. $0-28$ days vs. admissions to NICU

eg. day 0 , day 1

eg. VLBW, LBW

eg. late preterm, very preterm

eg. 1000 live births, 1000 patient days, 1000 admissions 
(13) Study population: How important is it that authors report their definitions or criteria for the following?

Please don't select more than 1 answer(s) per row.

Please select at least 5 answer(s).

Having trouble with the format of this question? View in tableless mode

\begin{tabular}{|c|c|c|c|c|c|}
\hline & Unnecessary & Sometimes useful & Important for most studies & Essential for all studies & \\
\hline Neonatal population & ○ & ๑ & • & • & eg. $0-28$ days vs. admissions to NICU \\
\hline First day of life & $\square$ & $\square$ & $\square$ & $\bullet$ & eg. day 0 , day 1 \\
\hline Birth weight categories & • & • & $\square$ & ○ & eg. VLBW, LBW \\
\hline Gestational age categories & ○ & ○ & ○ & D & eg. late preterm, very preterm \\
\hline Denominator & e & ๑ & ○ & e & eg. 1000 live births, 1000 patient days, 1000 admissions \\
\hline
\end{tabular}

10 Setting: How important is it that authors report their definitions and criteria for the following?

Please don't select more than 1 answer(s) per row.

Please select at least 2 answer(s).

Having trouble with the format of this question? View in tableless mode

\begin{tabular}{r|c|c|c|c|c|} 
& Unnecessary & Sometimes useful & Important for most studies & Essential for all studies & (eg. inborn vs. outbom) \\
\hline Place of birth & $\square$ & - & $\square$ & (eg. NICU I-III or SCBU, NHDU) \\
\hline Level of care & $\square$ & - & $\square$
\end{tabular}

(15) Comments

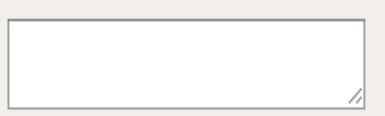


(16) Would reporting of neonatal infections be improved if the following had an agreed / recommended definition? Please don't select more than 1 answer(s) per row.

Please select at least 18 answer(s).

Having trouble with the format of this question? View in tableless mode

\begin{tabular}{rr}
\hline Possible severe bacterial infection (PSBI) \\
Confirmed blood stream infection (BSI) \\
Meningitis \\
\hline Pneumonia (including VAP) \\
Hospital acquired infection \\
Outbreak \\
\hline Contaminant isolate \\
\hline Coagulase negative stapylococcus infection \\
Stillbirth \\
\hline Onset of infection \\
\hline Duration of infection episode \\
Long-term impairment \\
Neonatal population \\
First day of life \\
\hline Birth weight categories \\
\hline Gestational age categories \\
\hline Denominator \\
\hline Place of bith \\
Level of care
\end{tabular}

(17) Comments

\begin{tabular}{l|c} 
Yes - but beyond the remit of SPRING & $\begin{array}{c}\text { Yes - should be prioritised at the } \\
\text { SPRING expert consensus meeting }\end{array}$
\end{tabular}

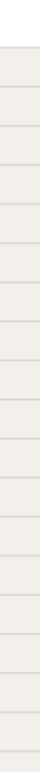

\begin{tabular}{|c|c|}
\hline 0 & घ \\
\hline • & घ \\
\hline • & e \\
\hline • & घ \\
\hline D & घ \\
\hline$\bullet$ & e \\
\hline$\bullet$ & e \\
\hline • & • \\
\hline 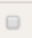 & a \\
\hline$\square$ & 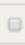 \\
\hline • & e \\
\hline 口 & a \\
\hline • & $\square$ \\
\hline 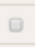 & $\square$ \\
\hline • & e \\
\hline • & a \\
\hline • & 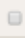 \\
\hline • & • \\
\hline • & • \\
\hline
\end{tabular}

\begin{tabular}{|l}
- \\
- \\
- \\
- \\
- \\
- \\
- \\
\hline- \\
\hline eg. antepartum and intrapartum \\
\hline eg. timing of early and late onset infection \\
\hline- \\
\hline eg. neurodisability \\
\hline eg. 0 -28 days vs. admissions to NICU \\
\hline eg. day 0 , day 1 \\
\hline eg. VLBW, LBW \\
\hline eg. late preterm, very preterm \\
\hline eg. live births, patient days, admissions \\
\hline- \\
\hline
\end{tabular}



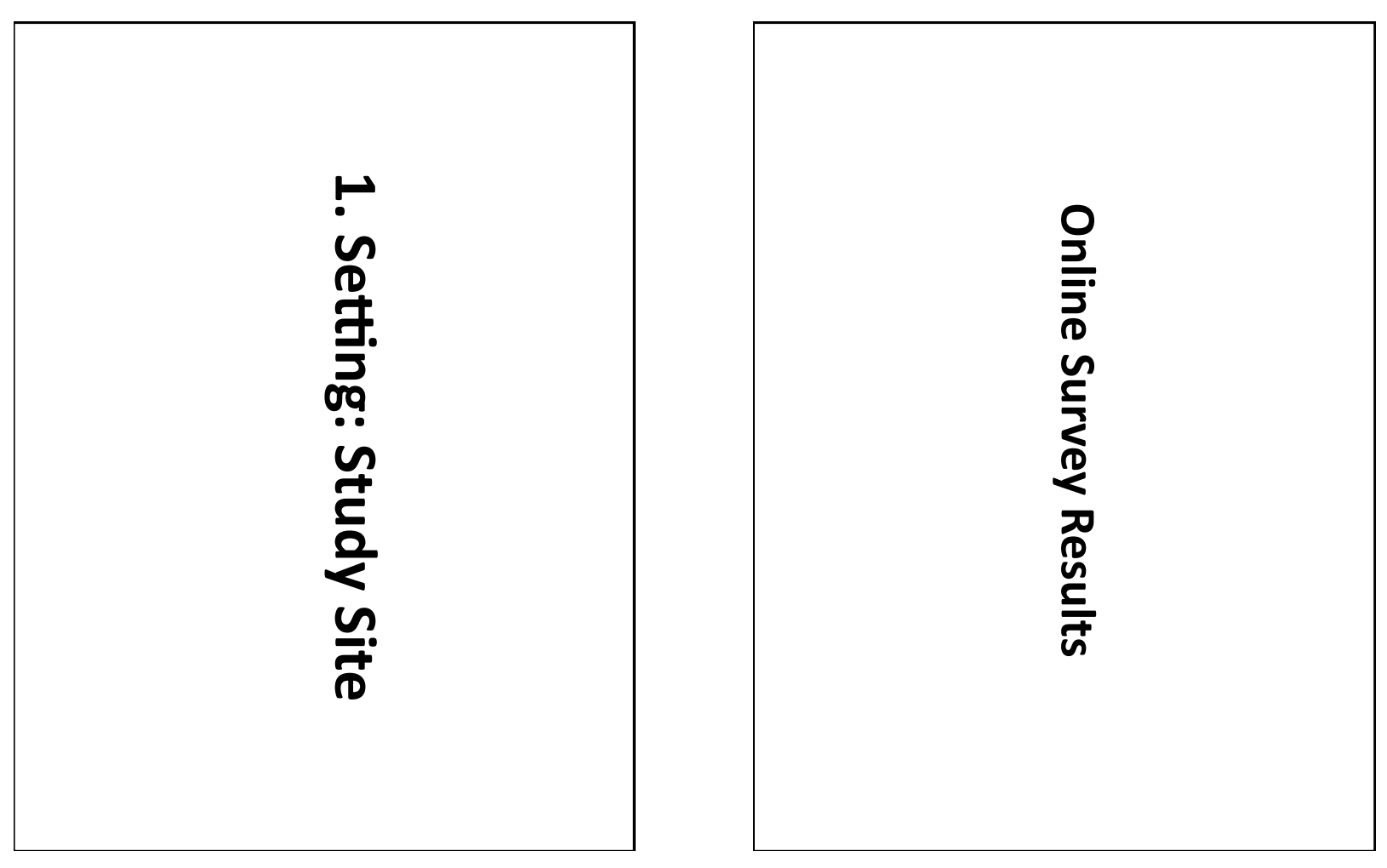

$\tilde{D}$
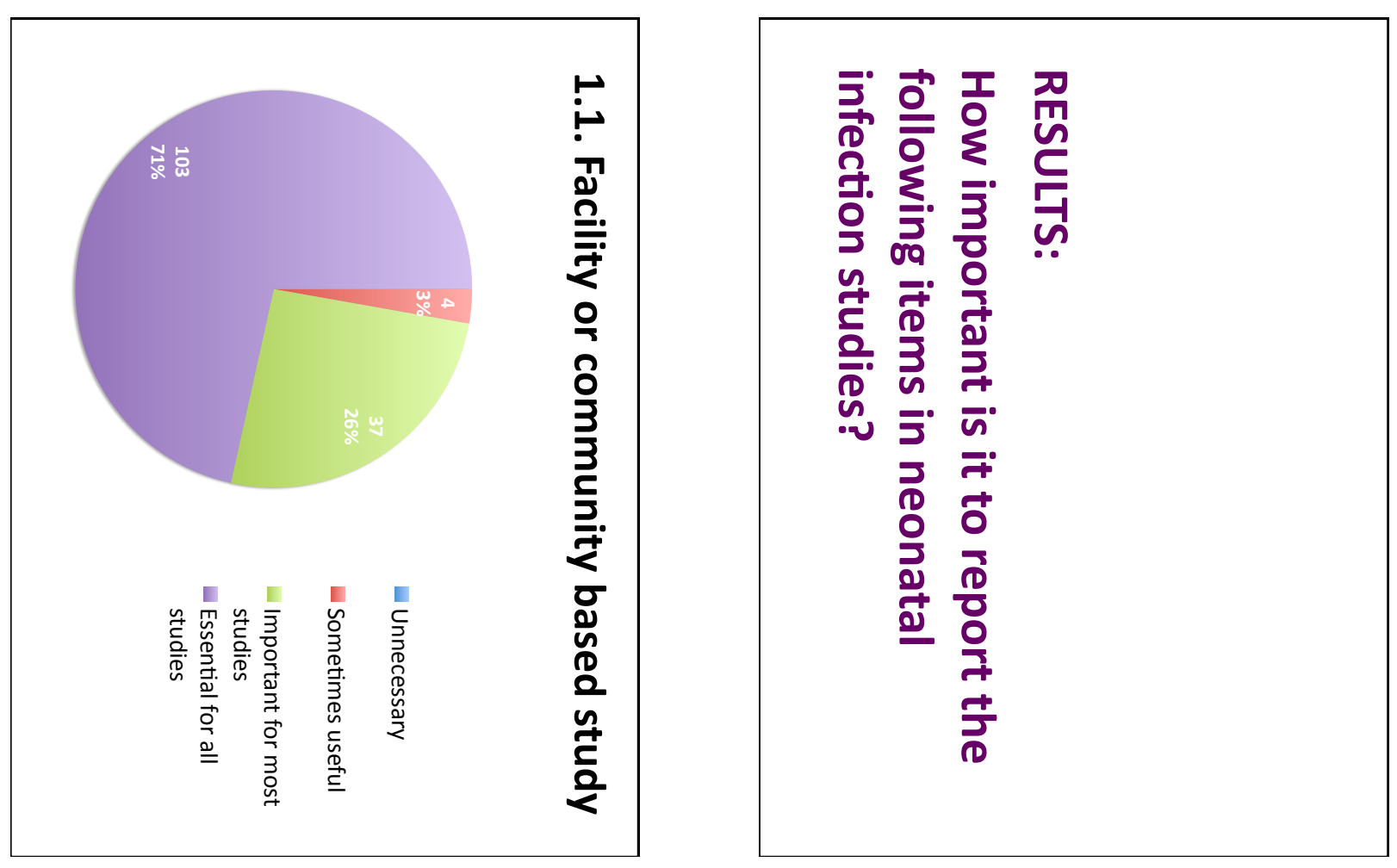

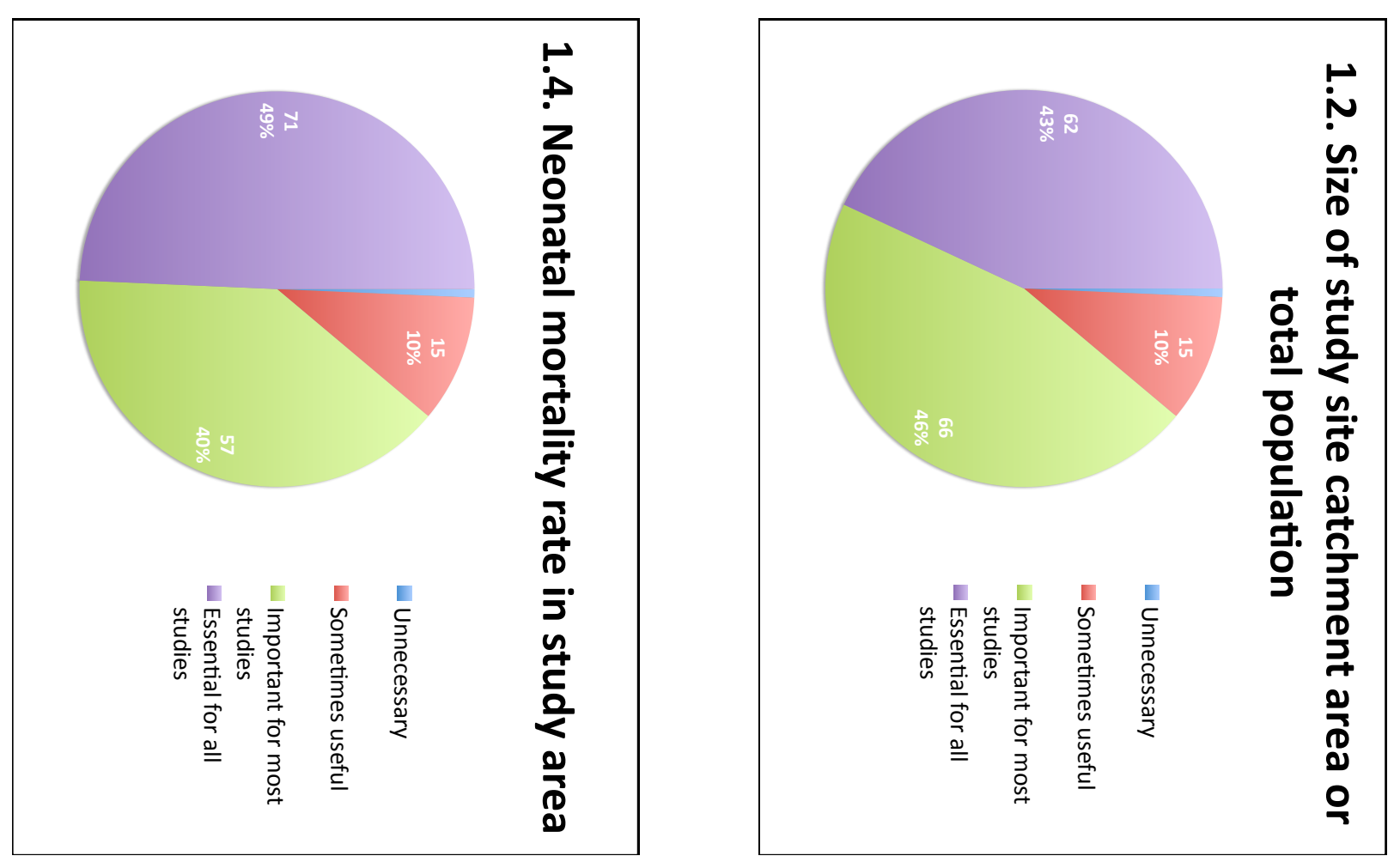

N
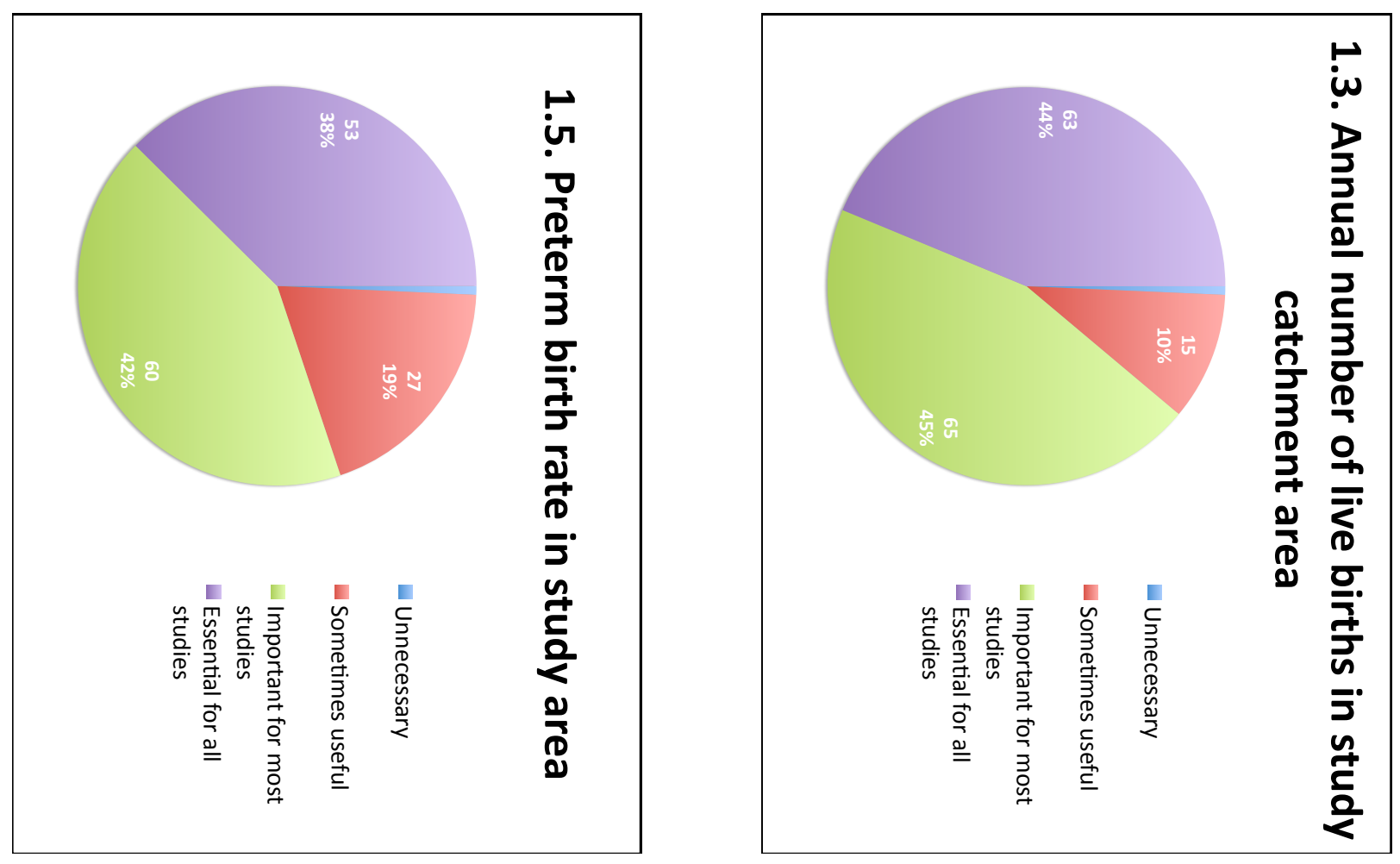

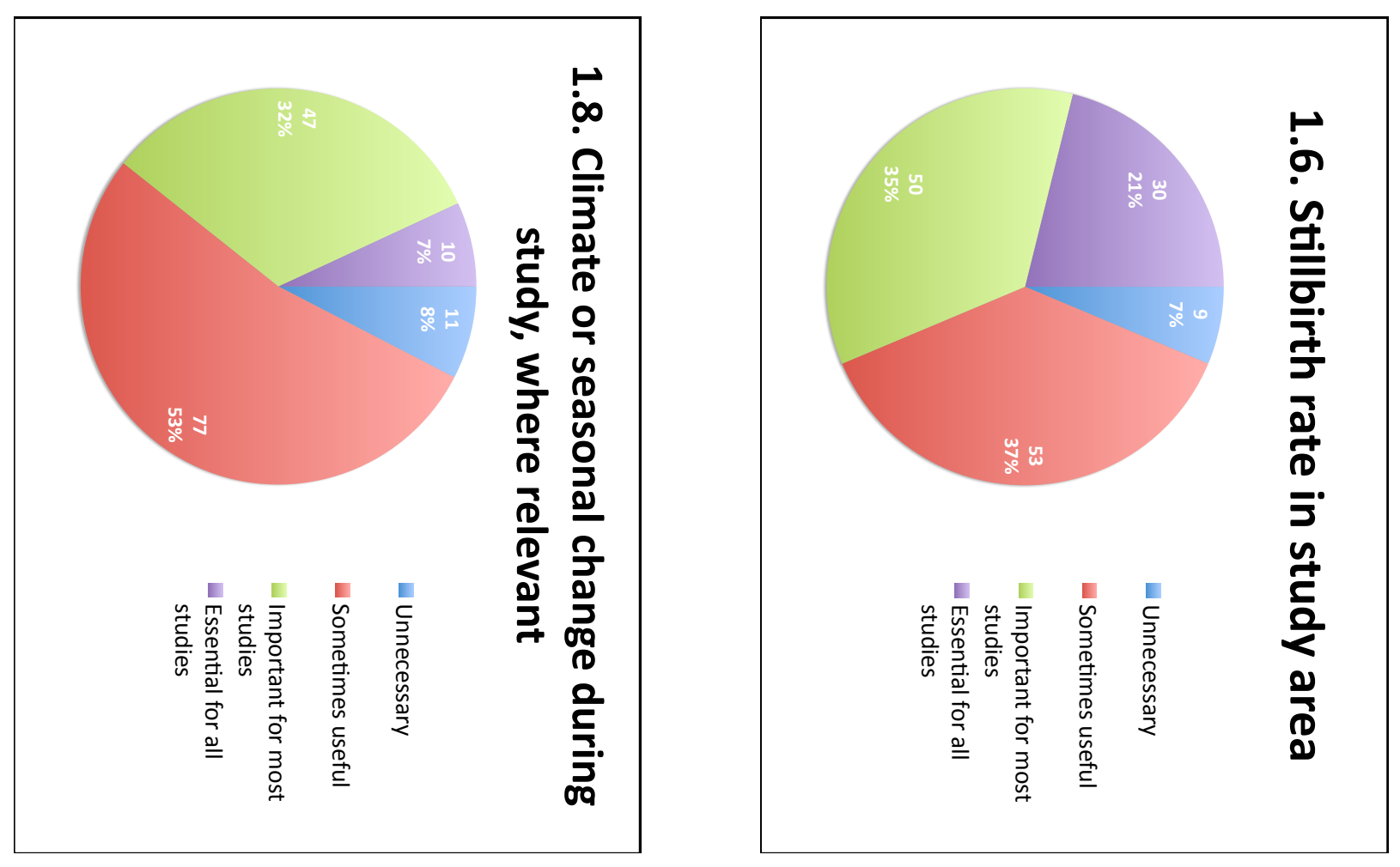

ก
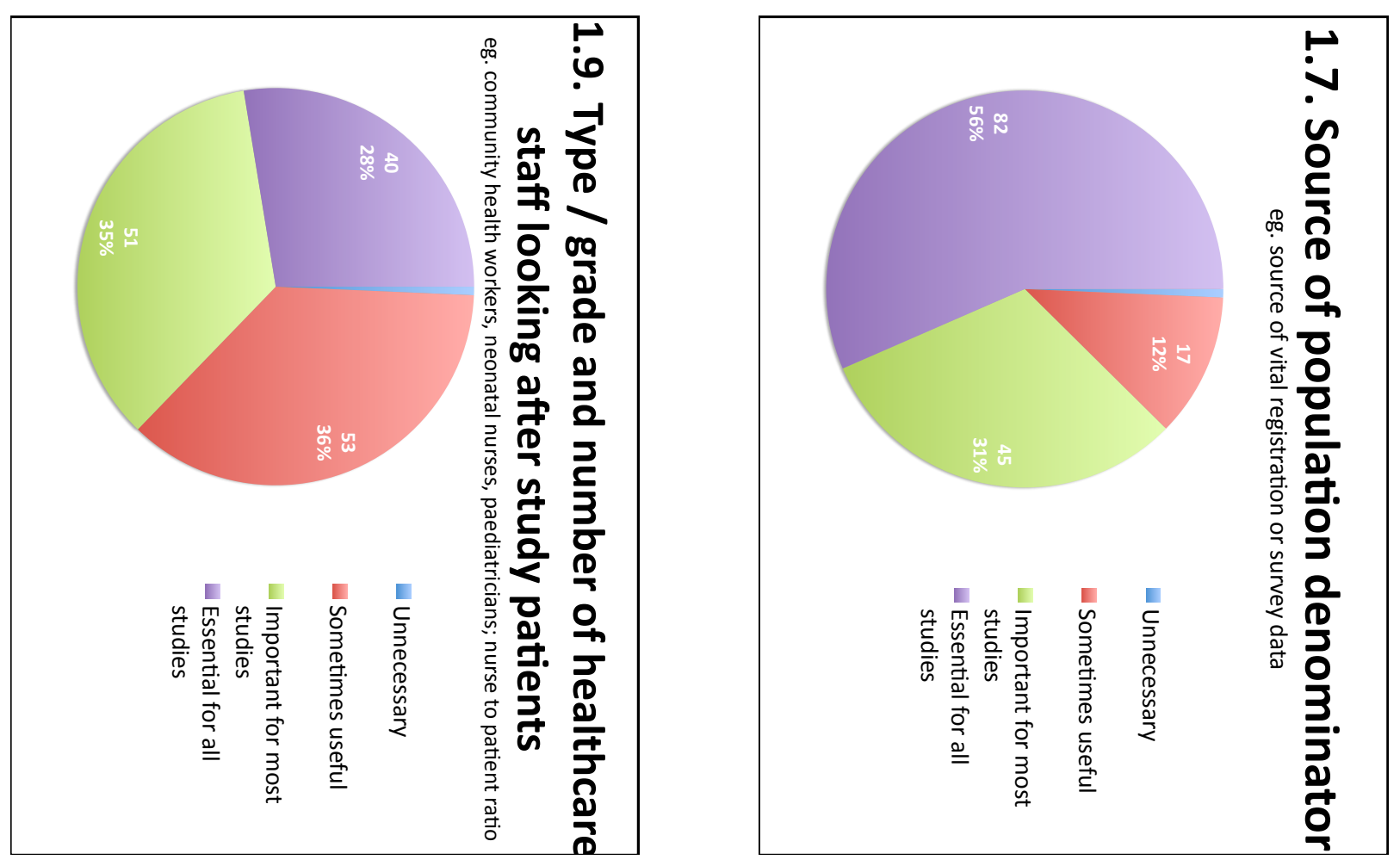

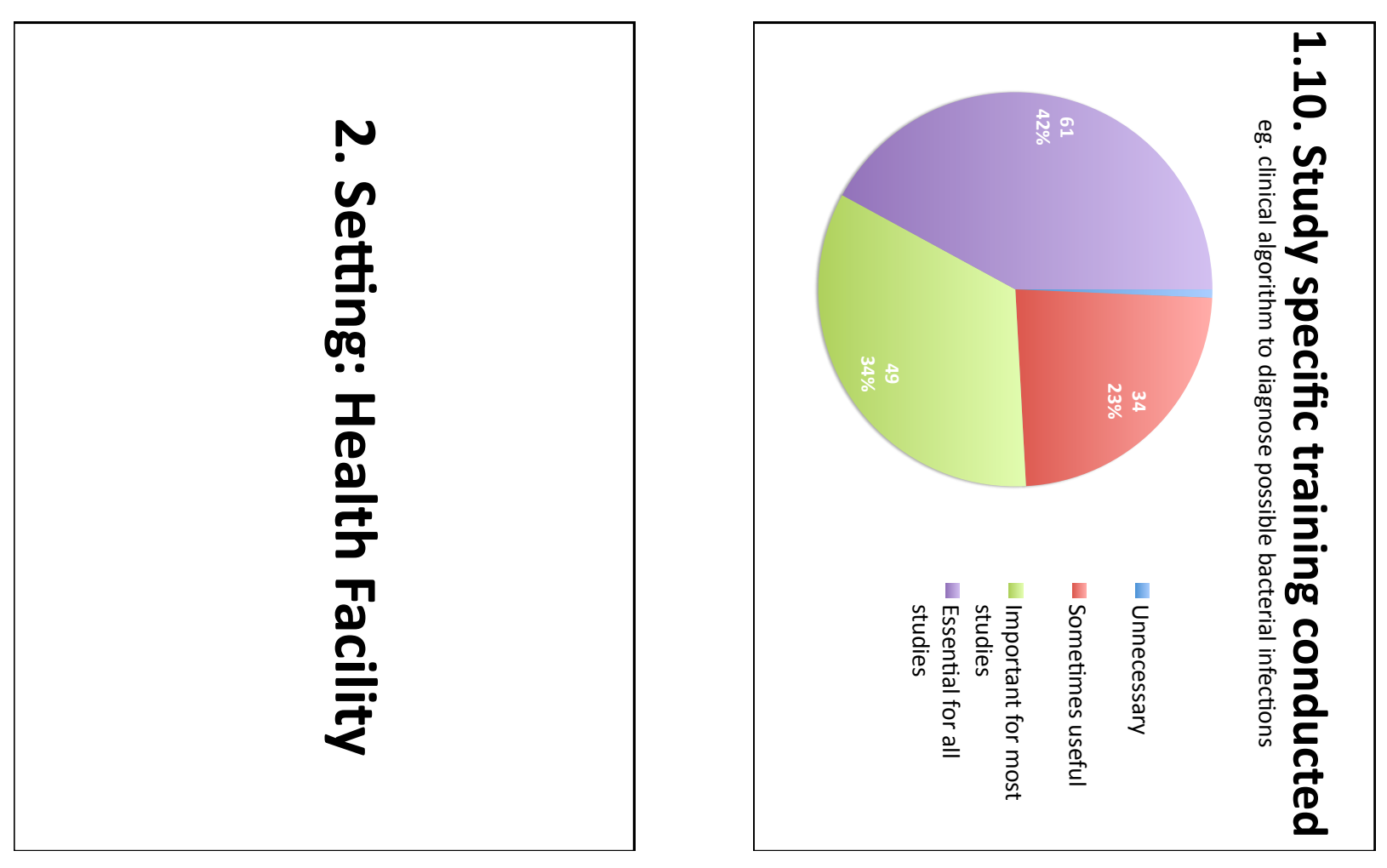

V
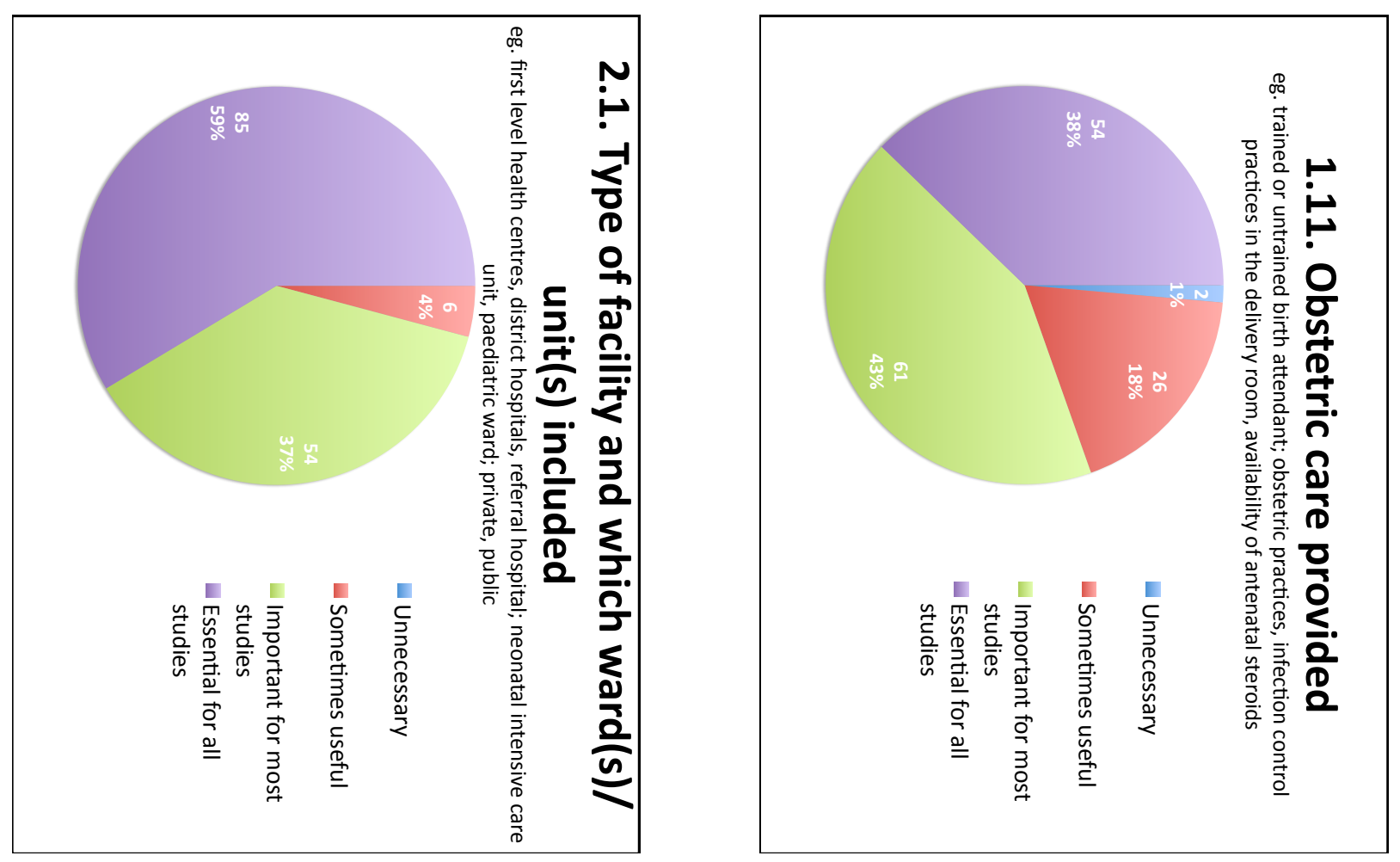

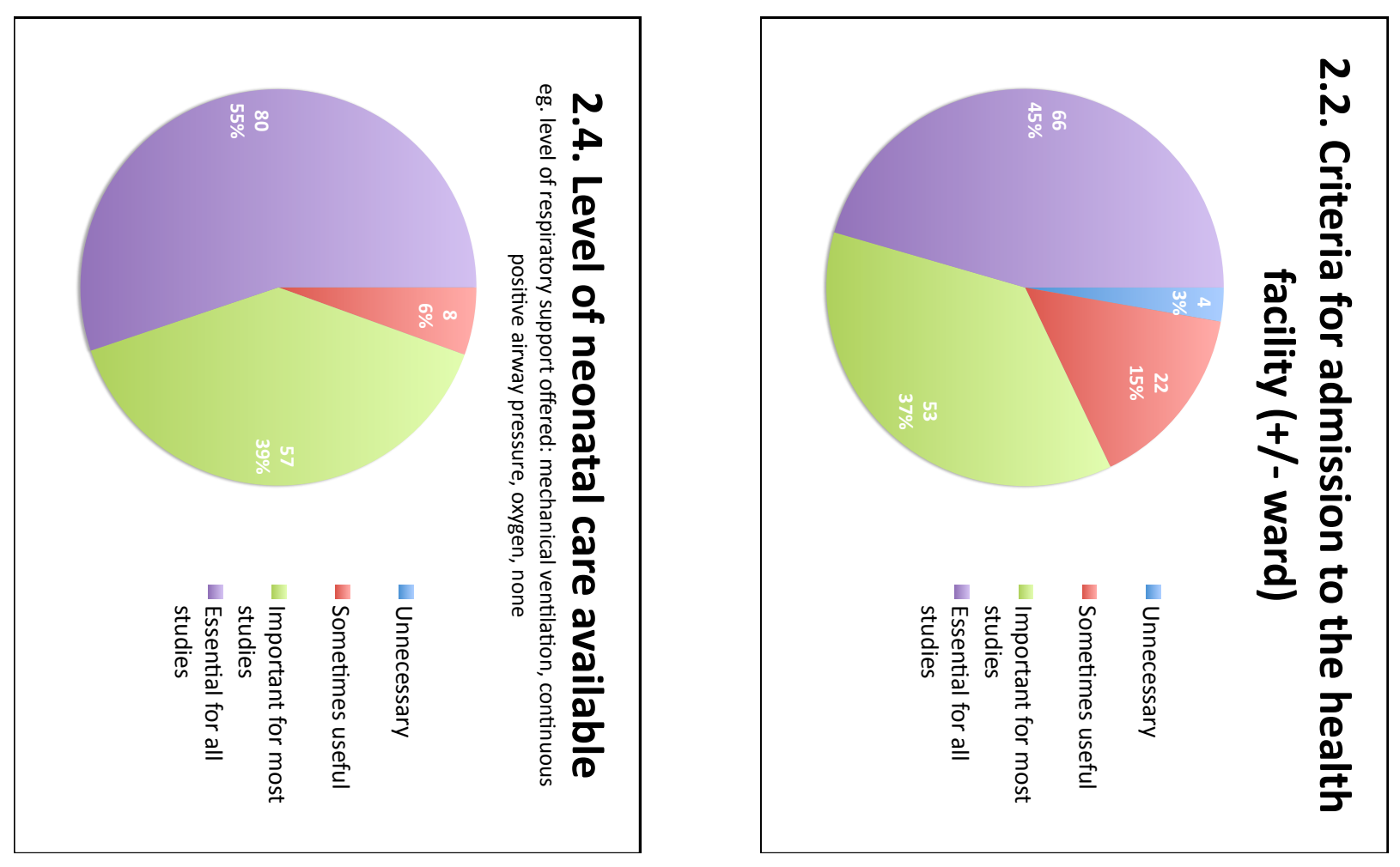

N
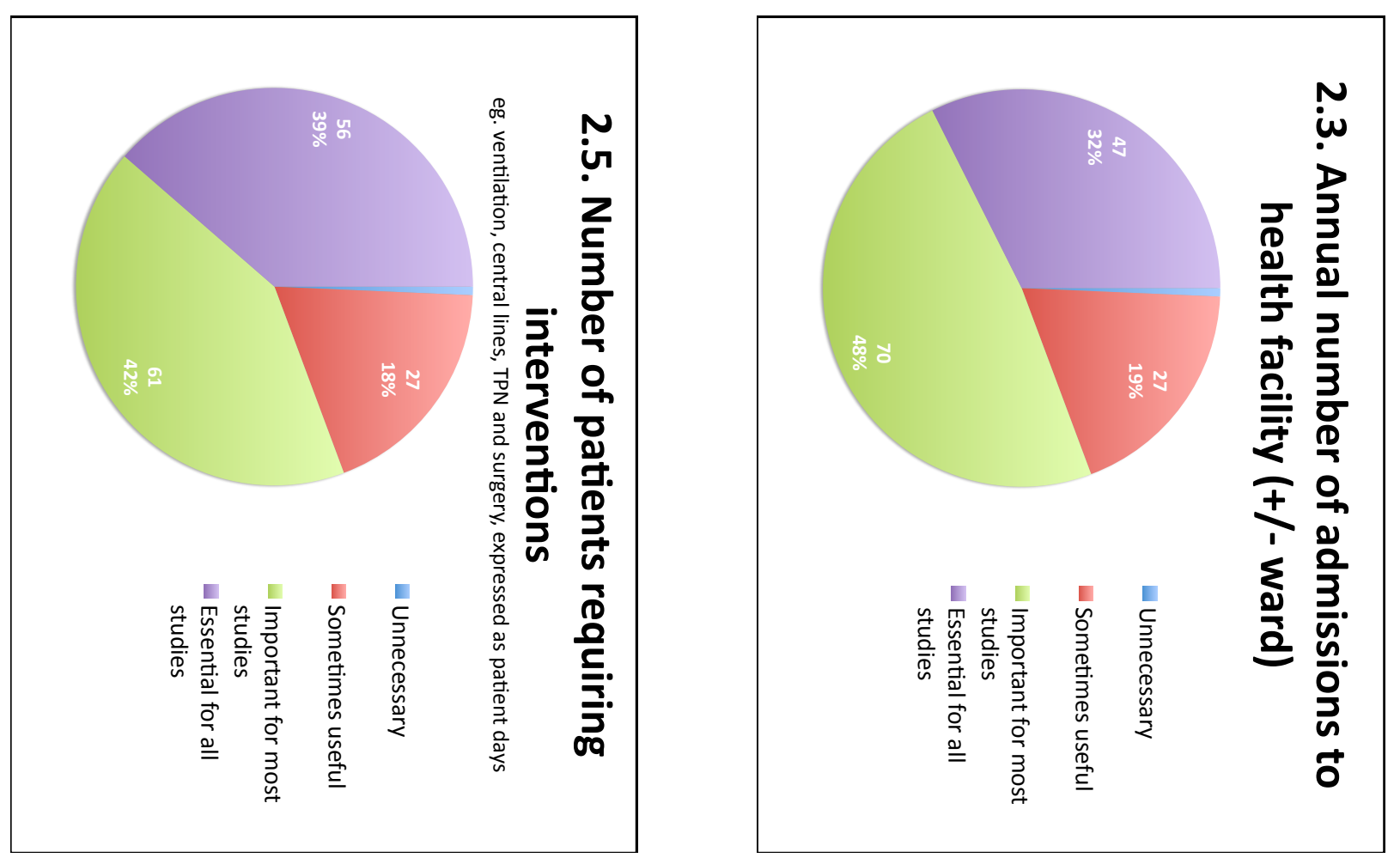

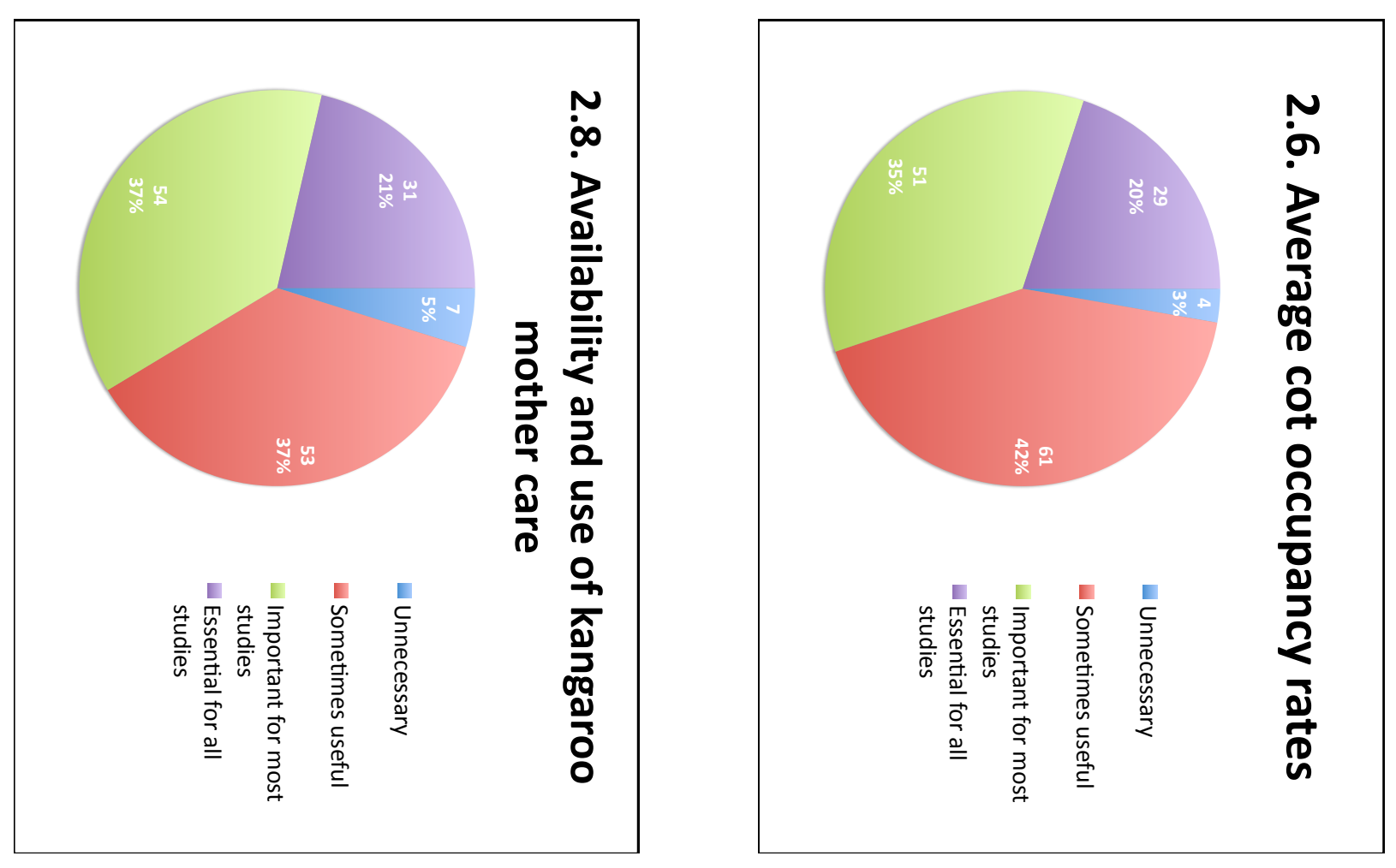

$\tilde{\sigma}$
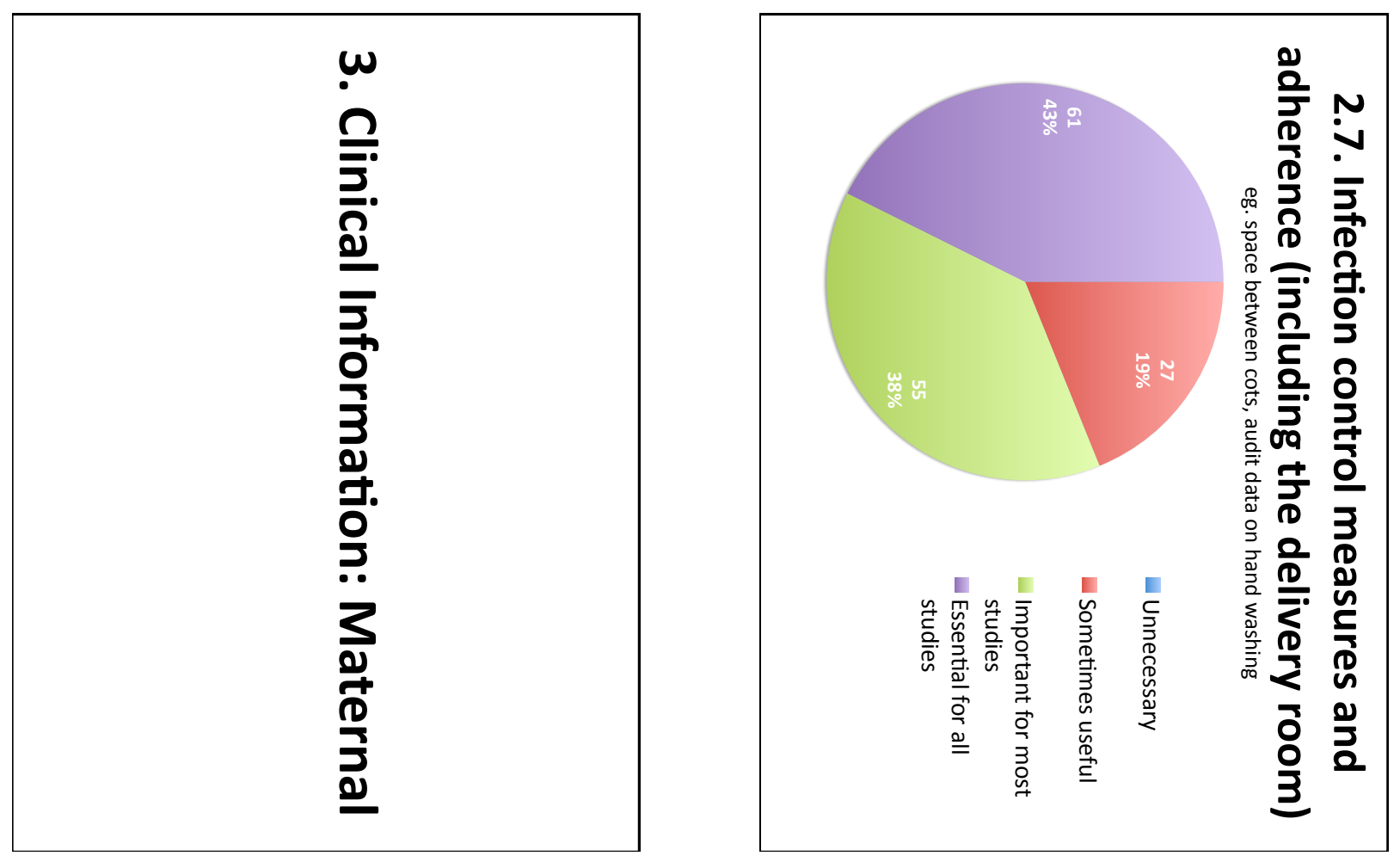

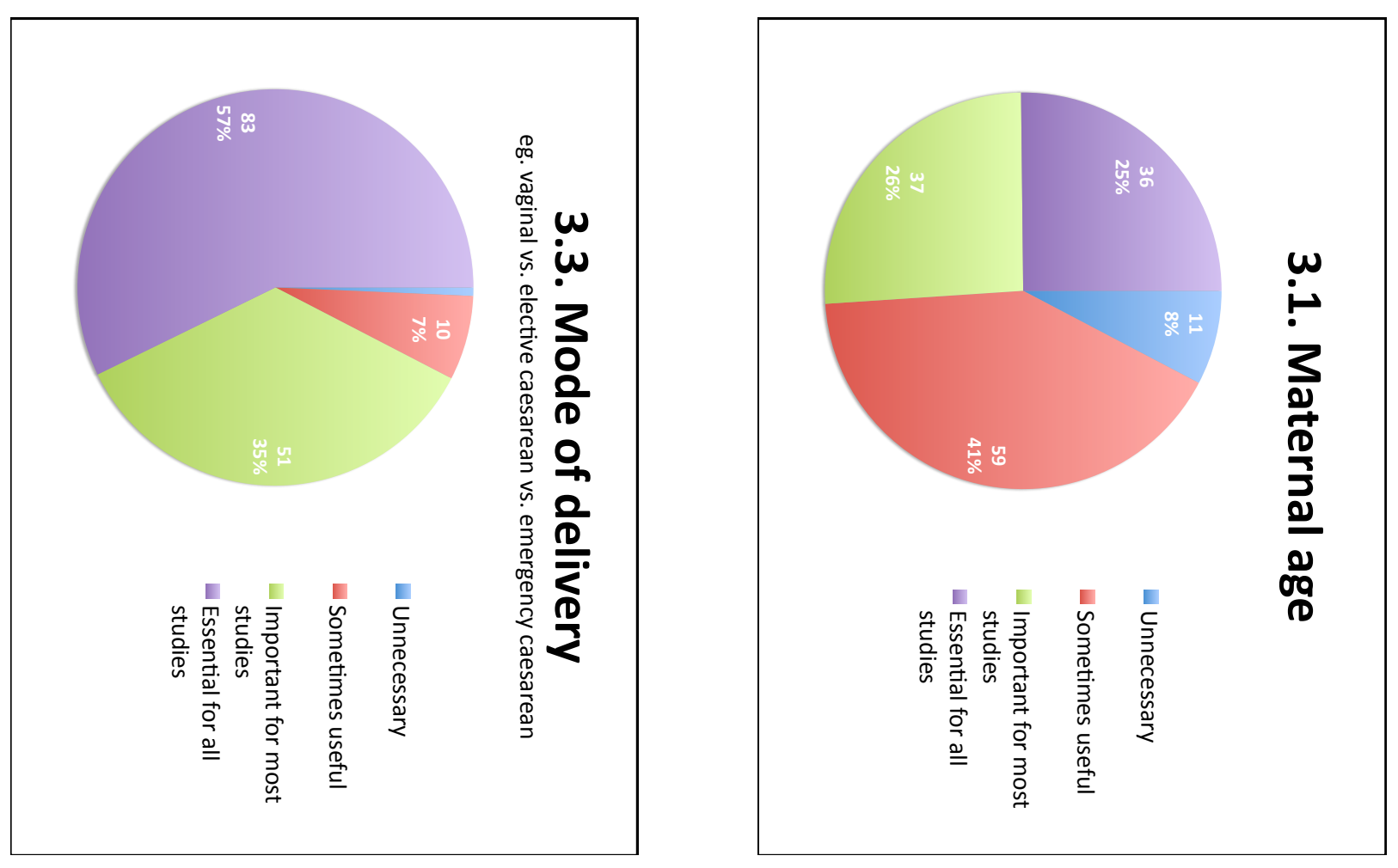

w
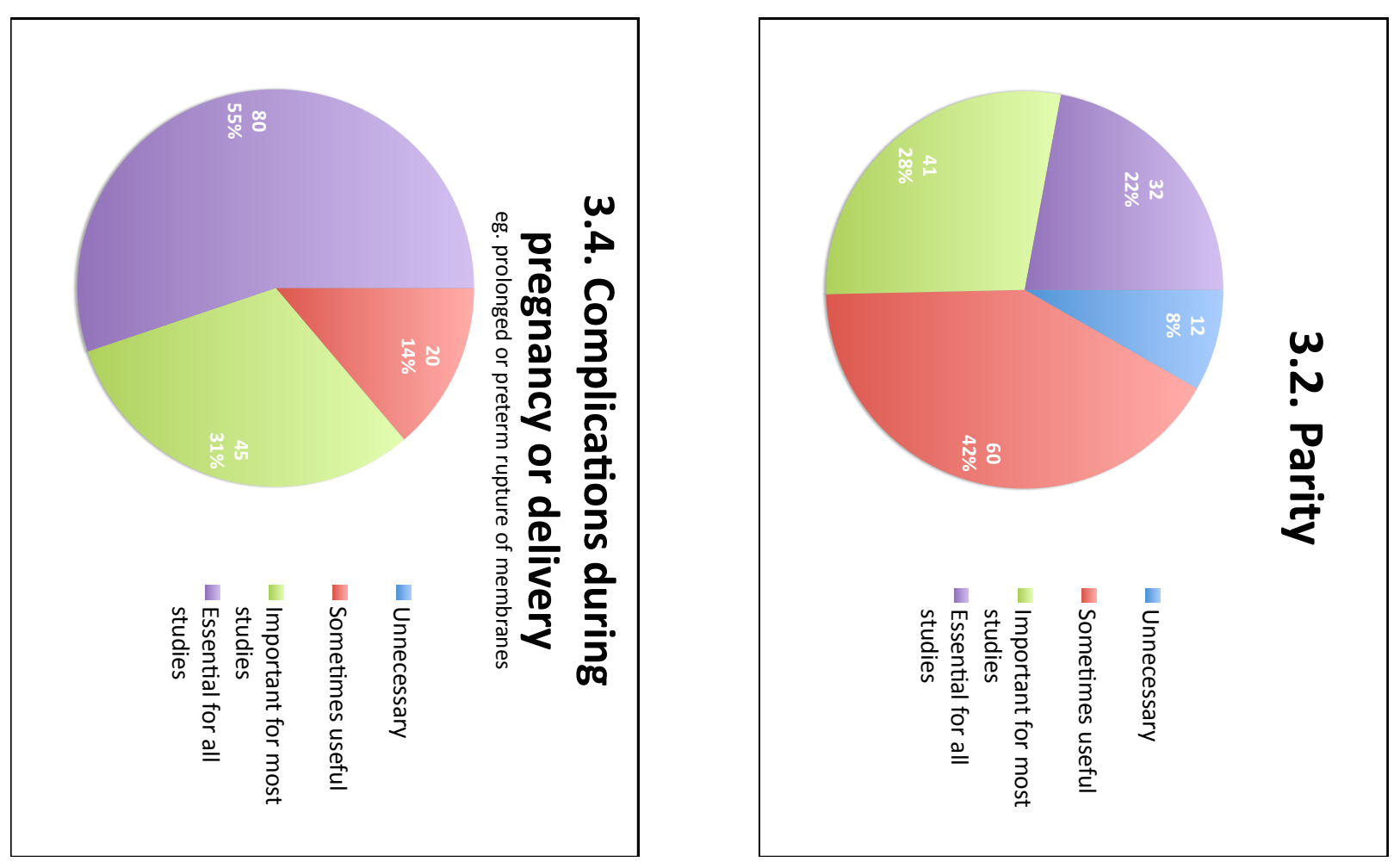

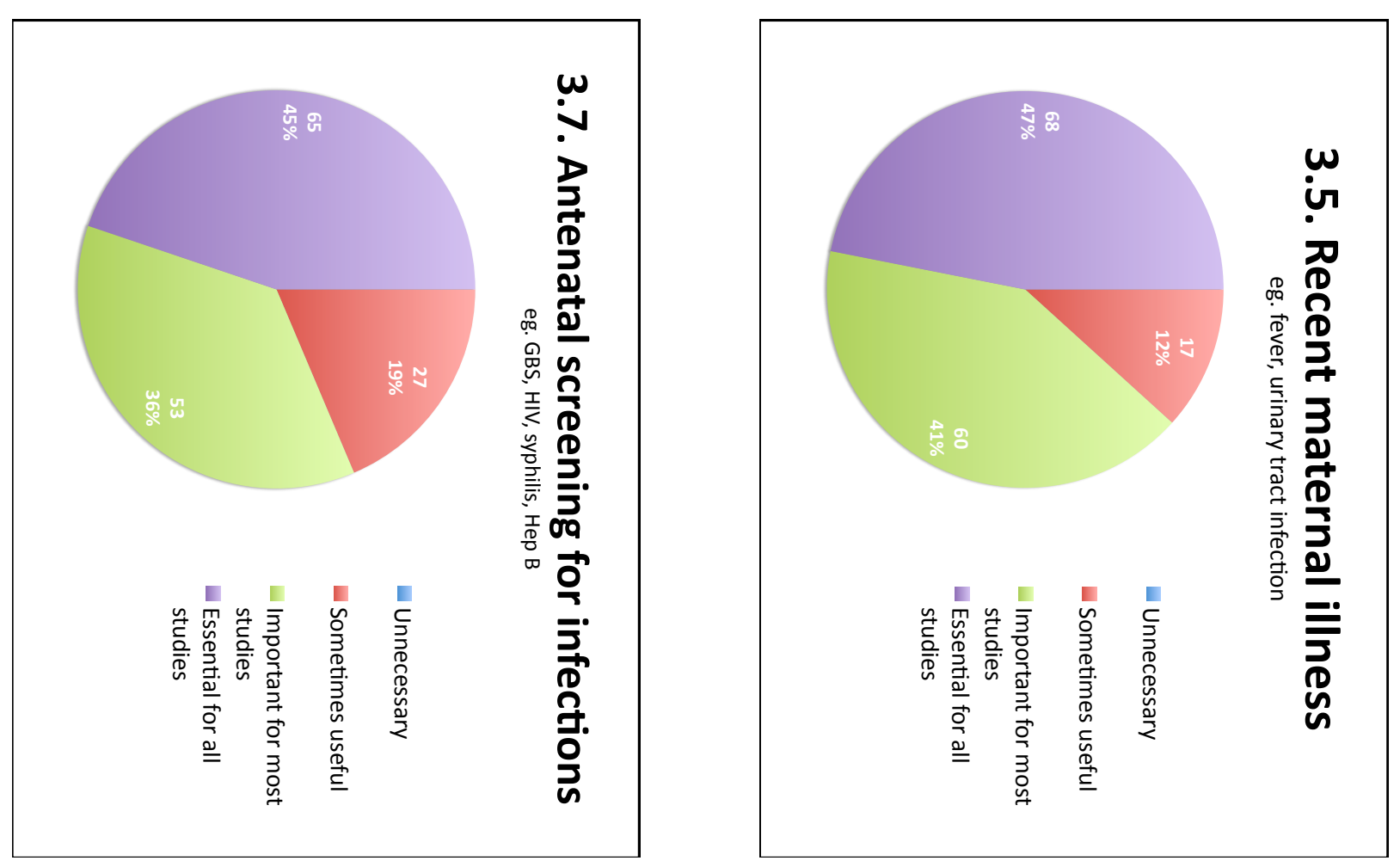

$\stackrel{\omega}{\mapsto}$
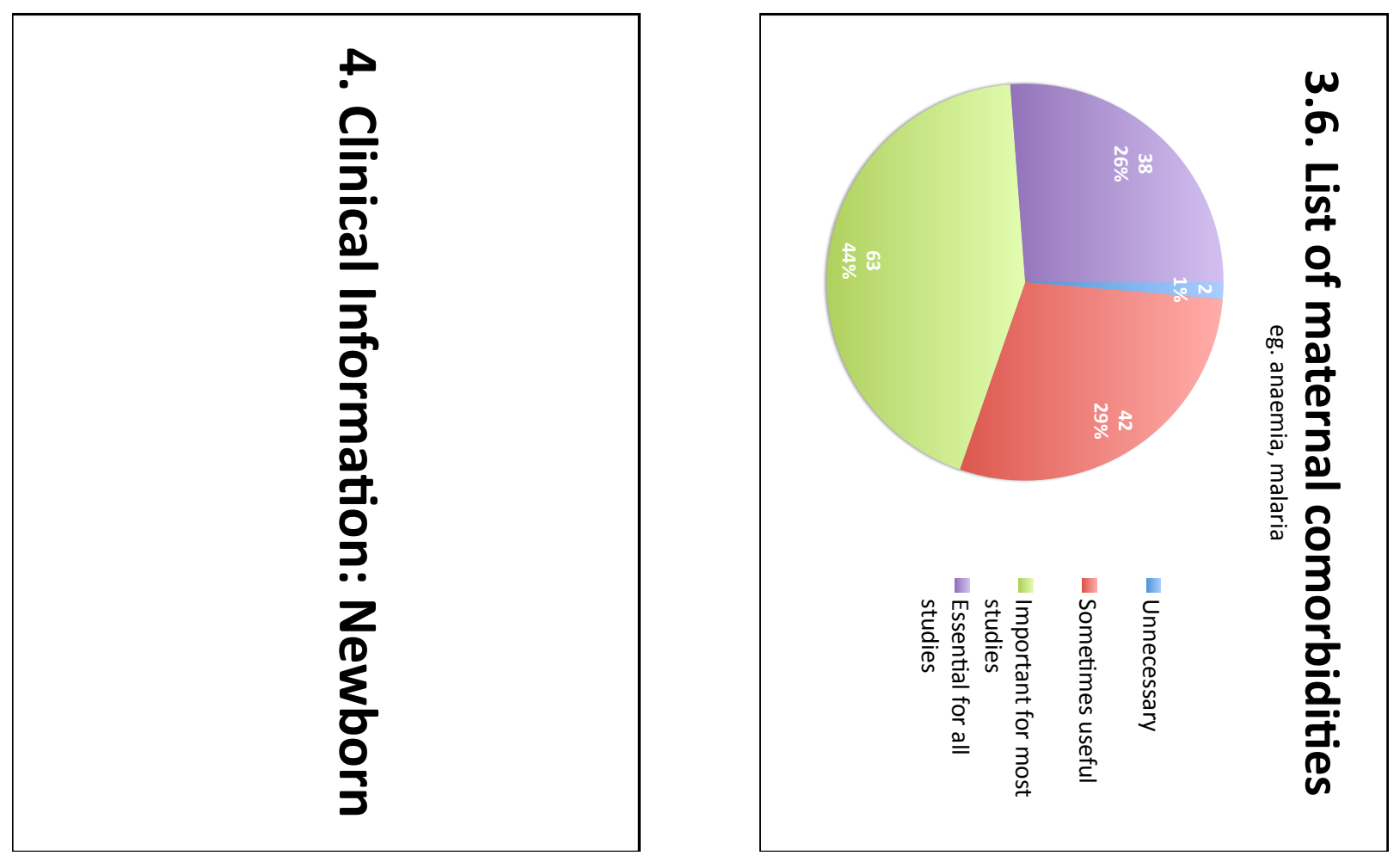

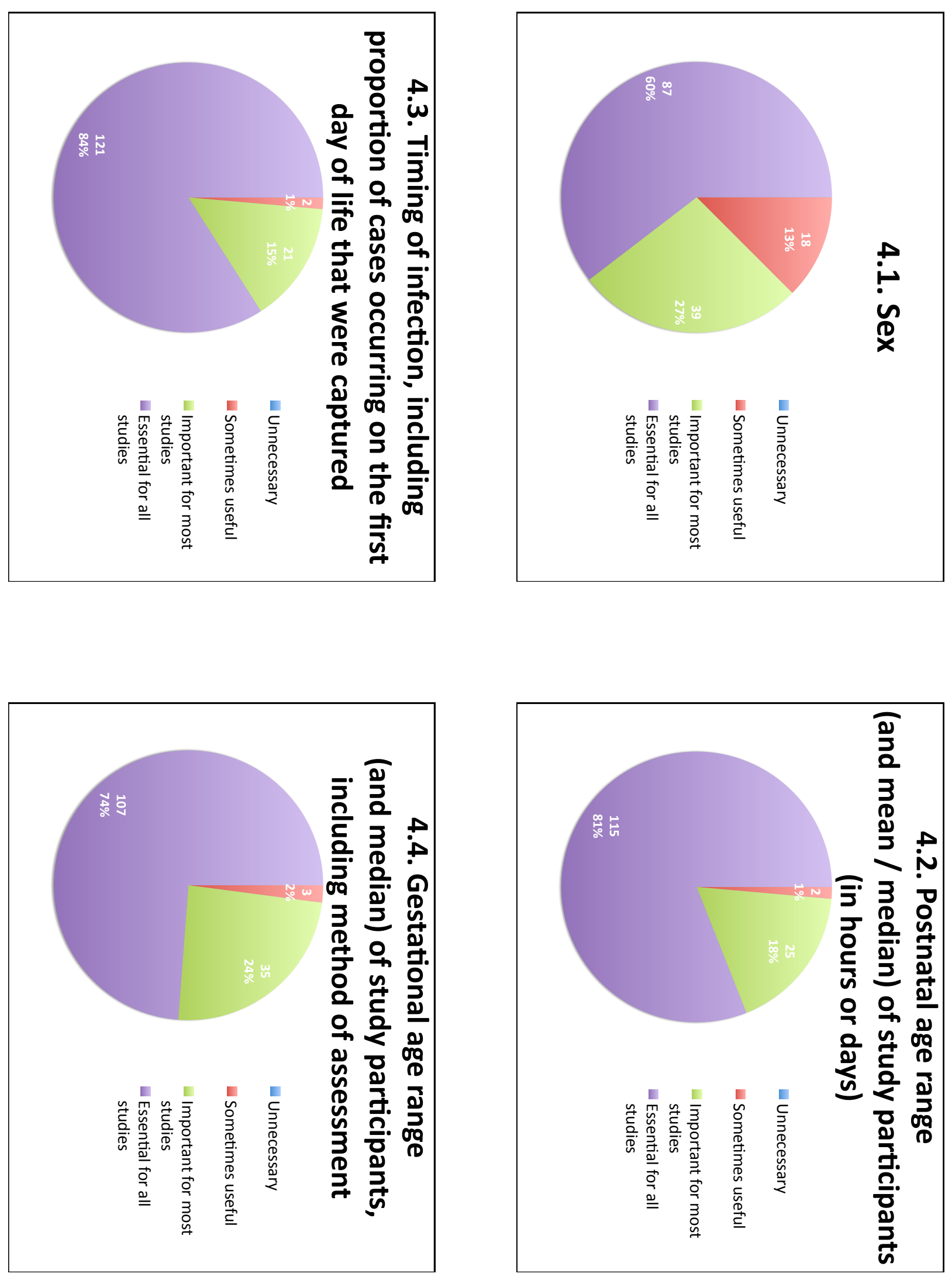

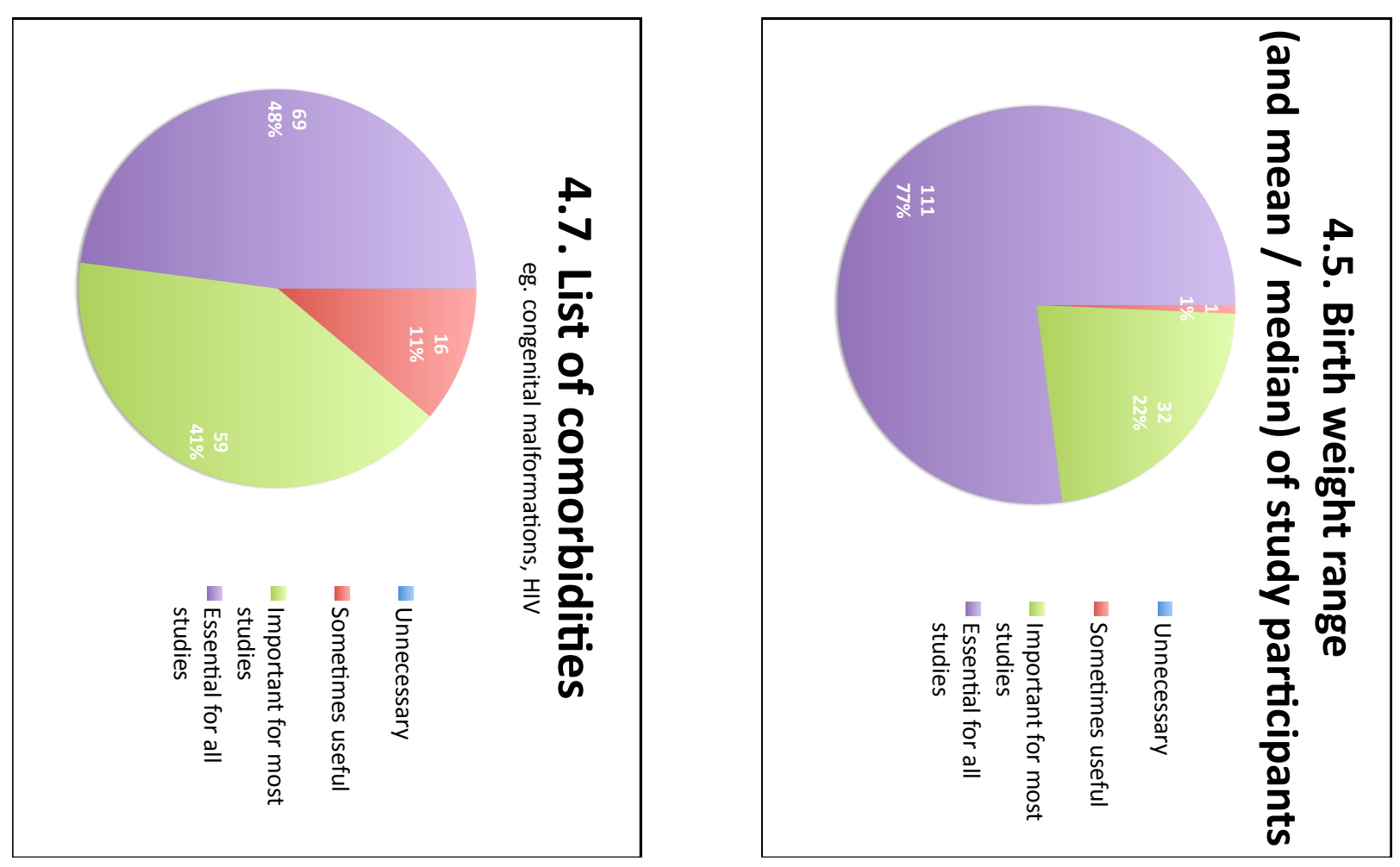

$\underset{\omega}{\omega}$
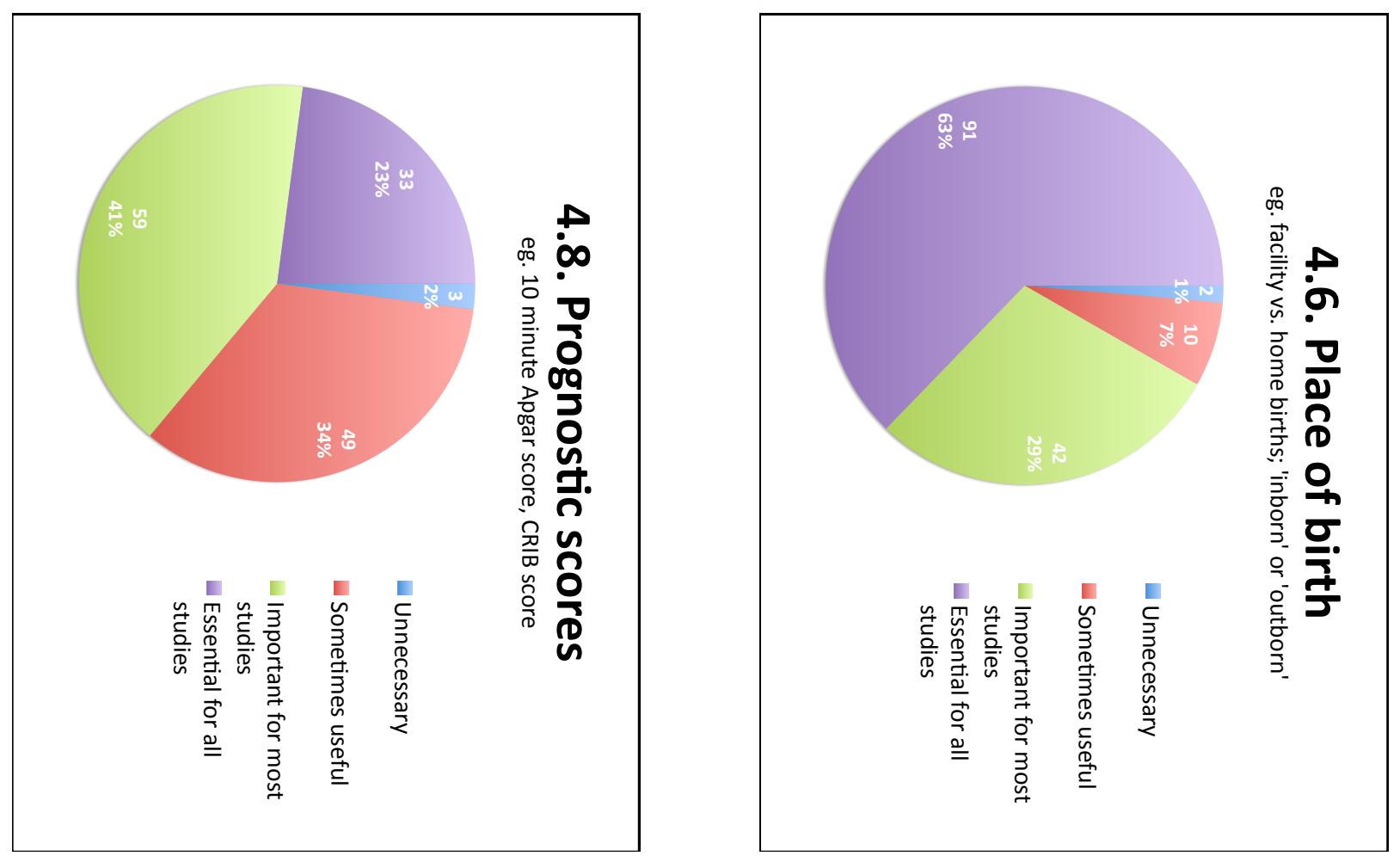

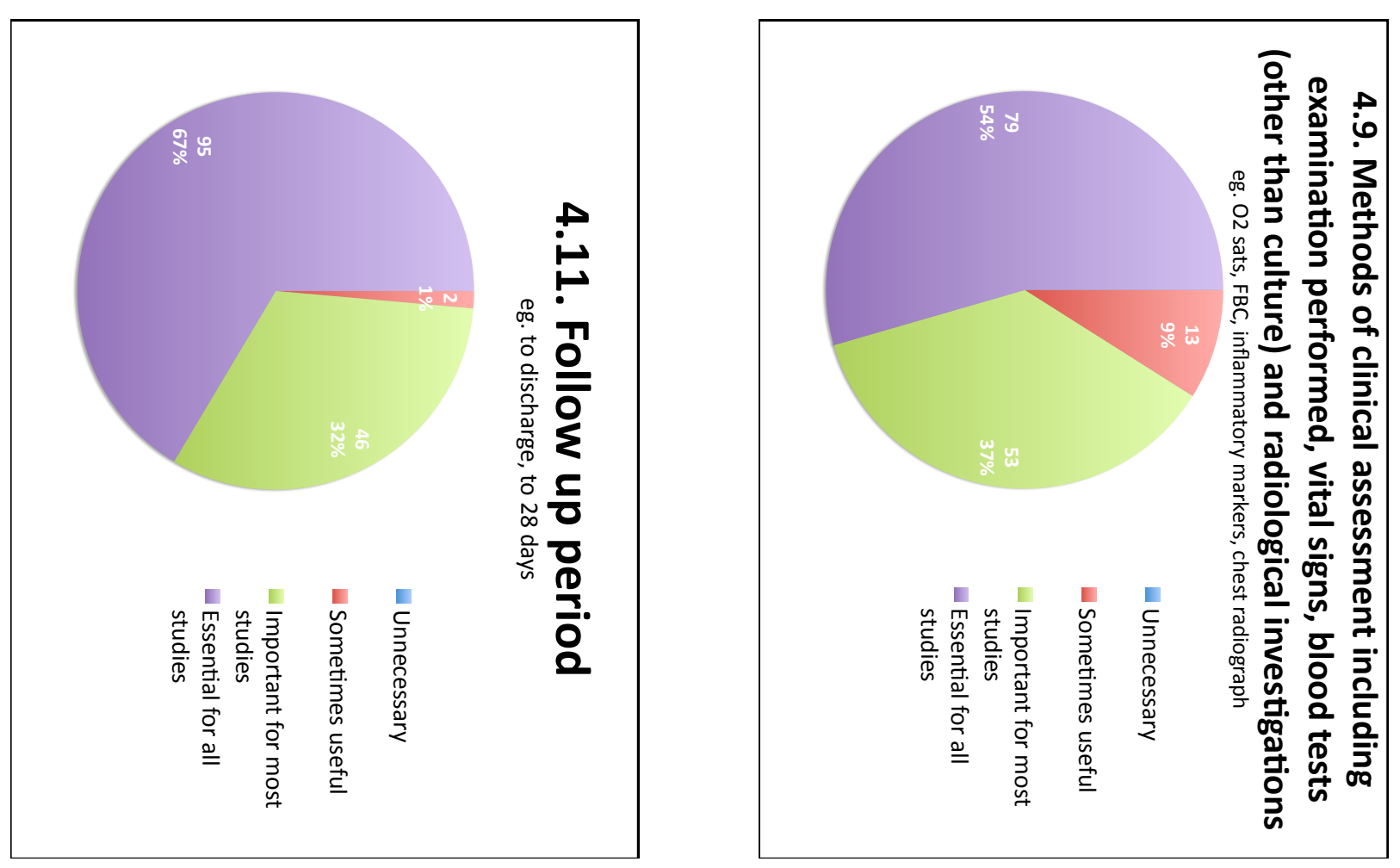

$\underset{\perp}{\omega}$
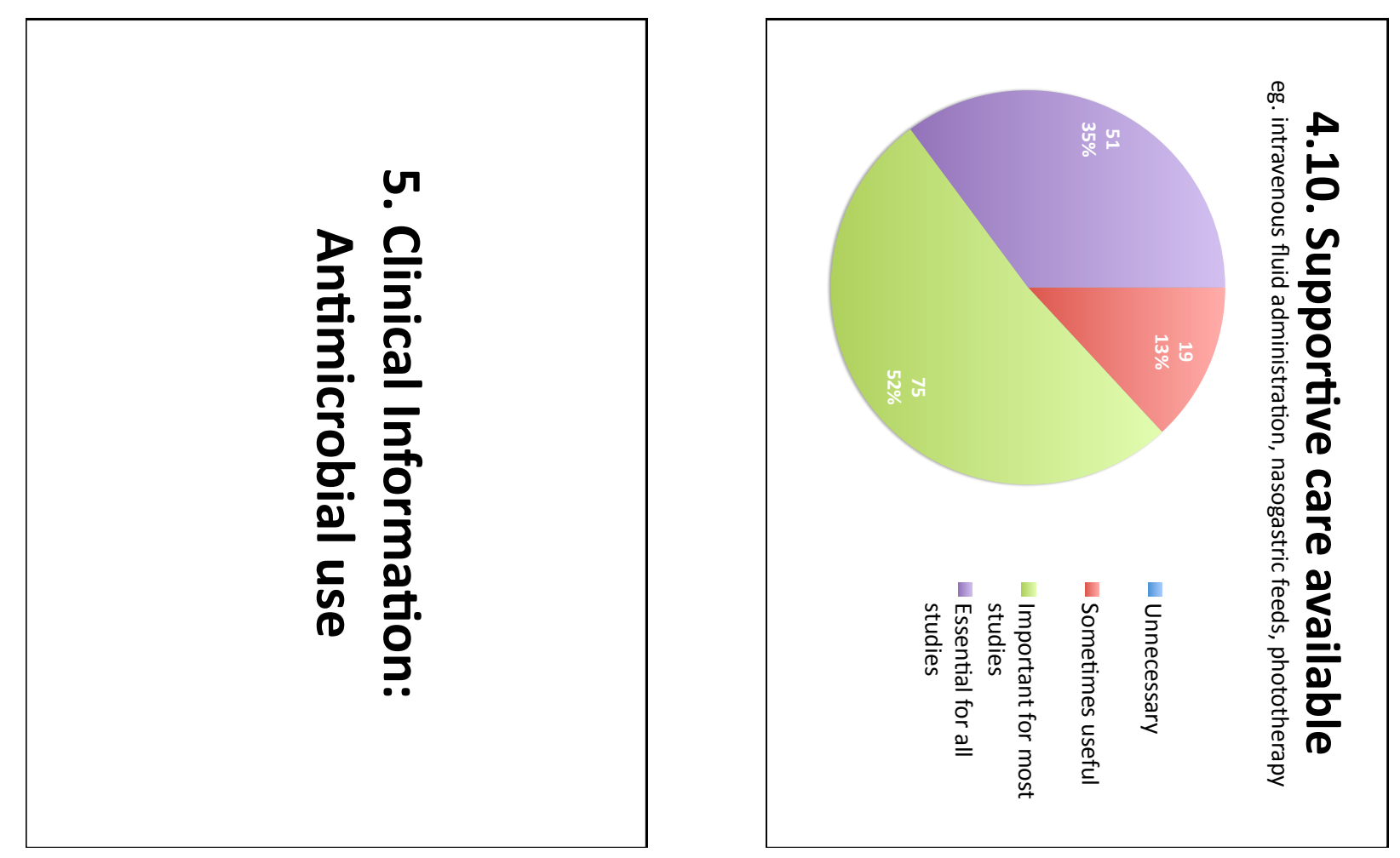

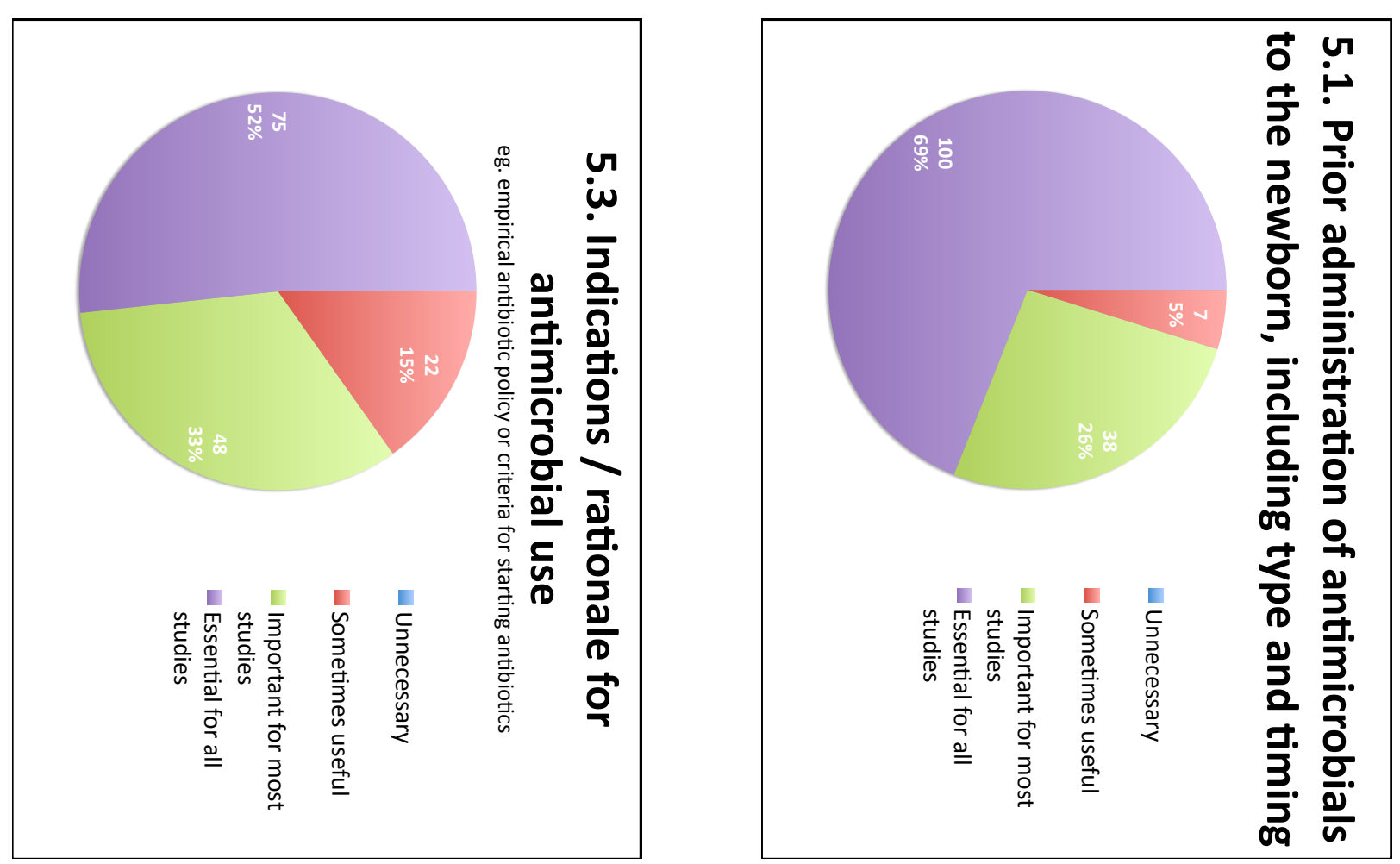

$w_{v}^{w}$
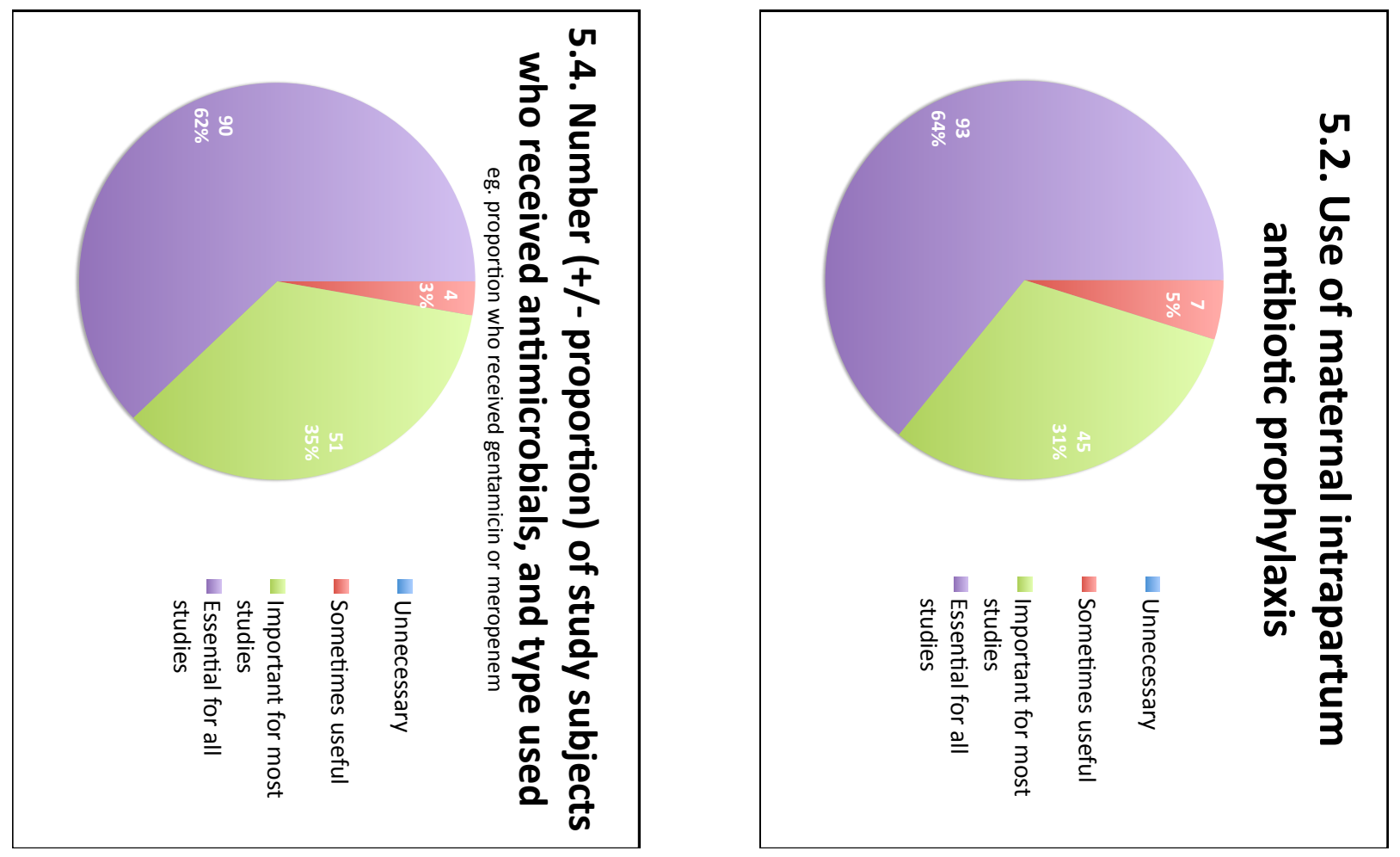

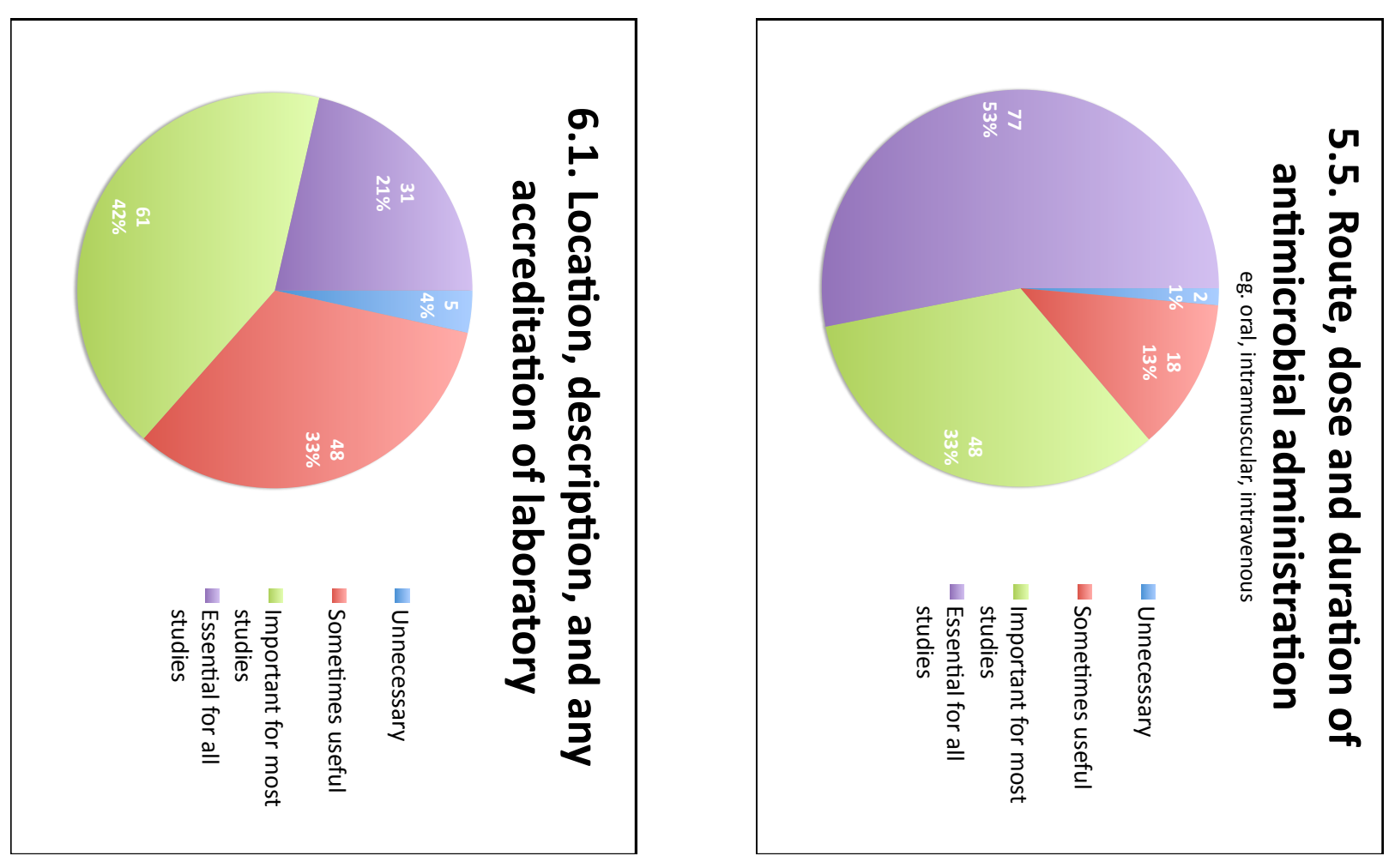

w
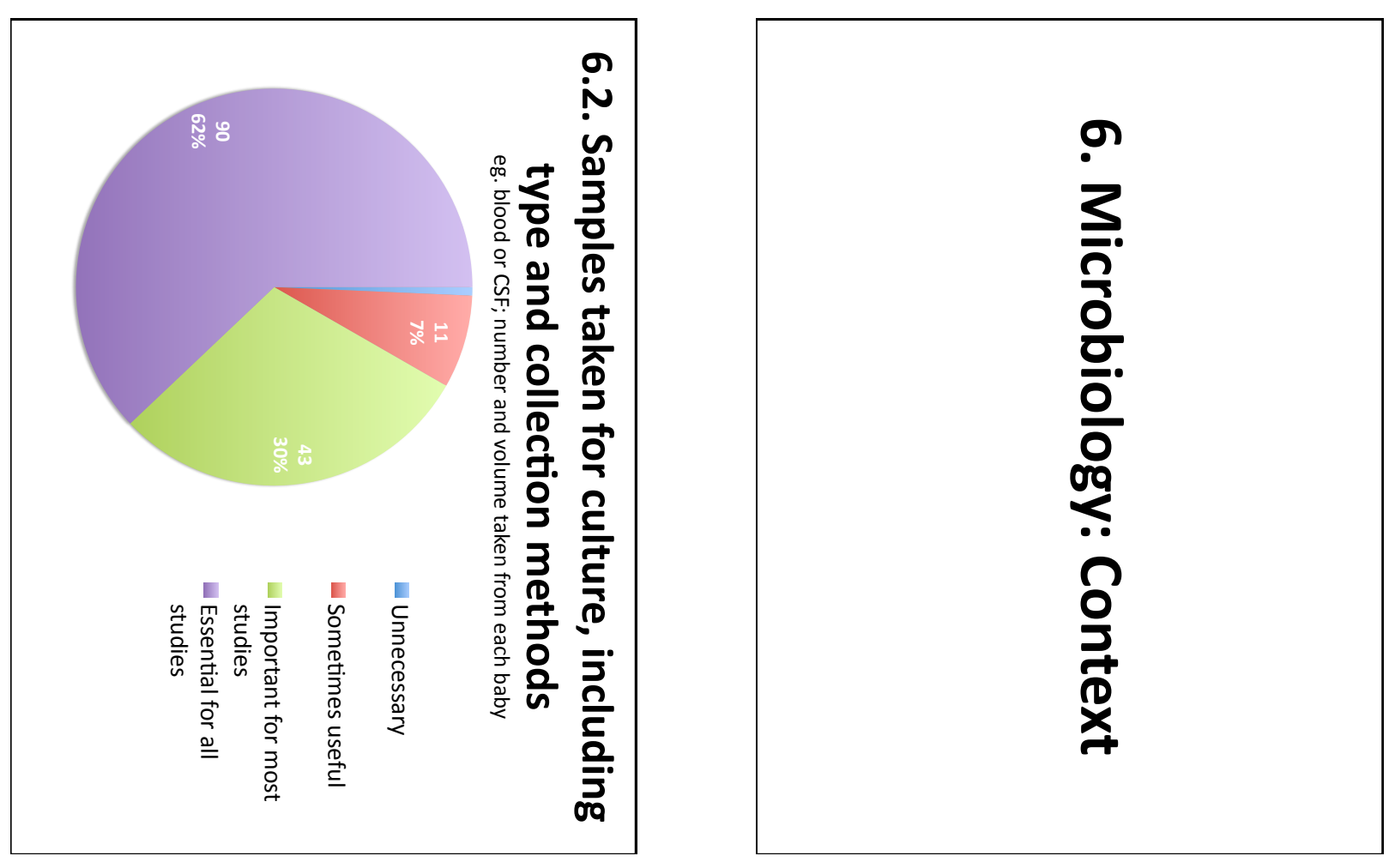

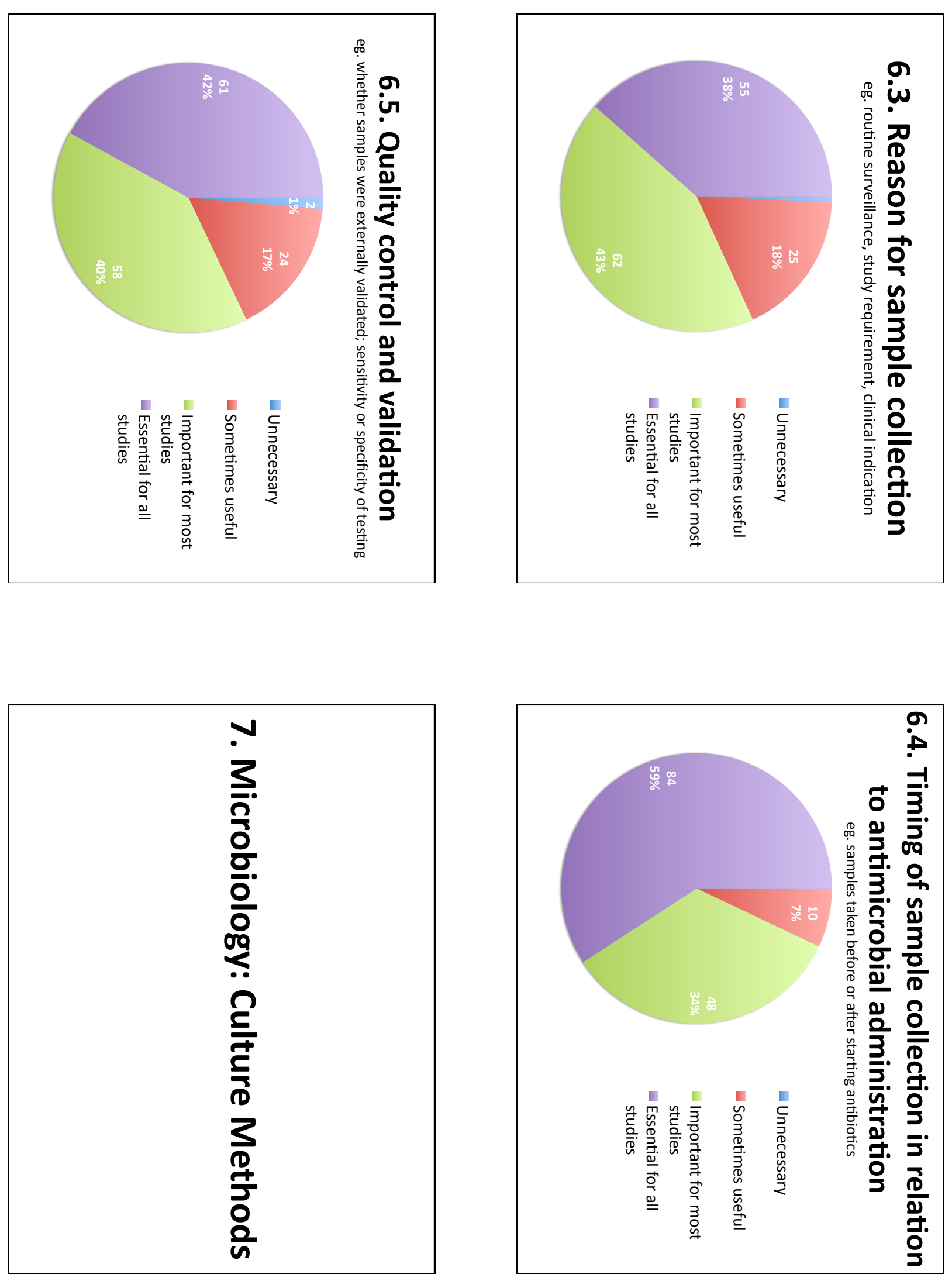

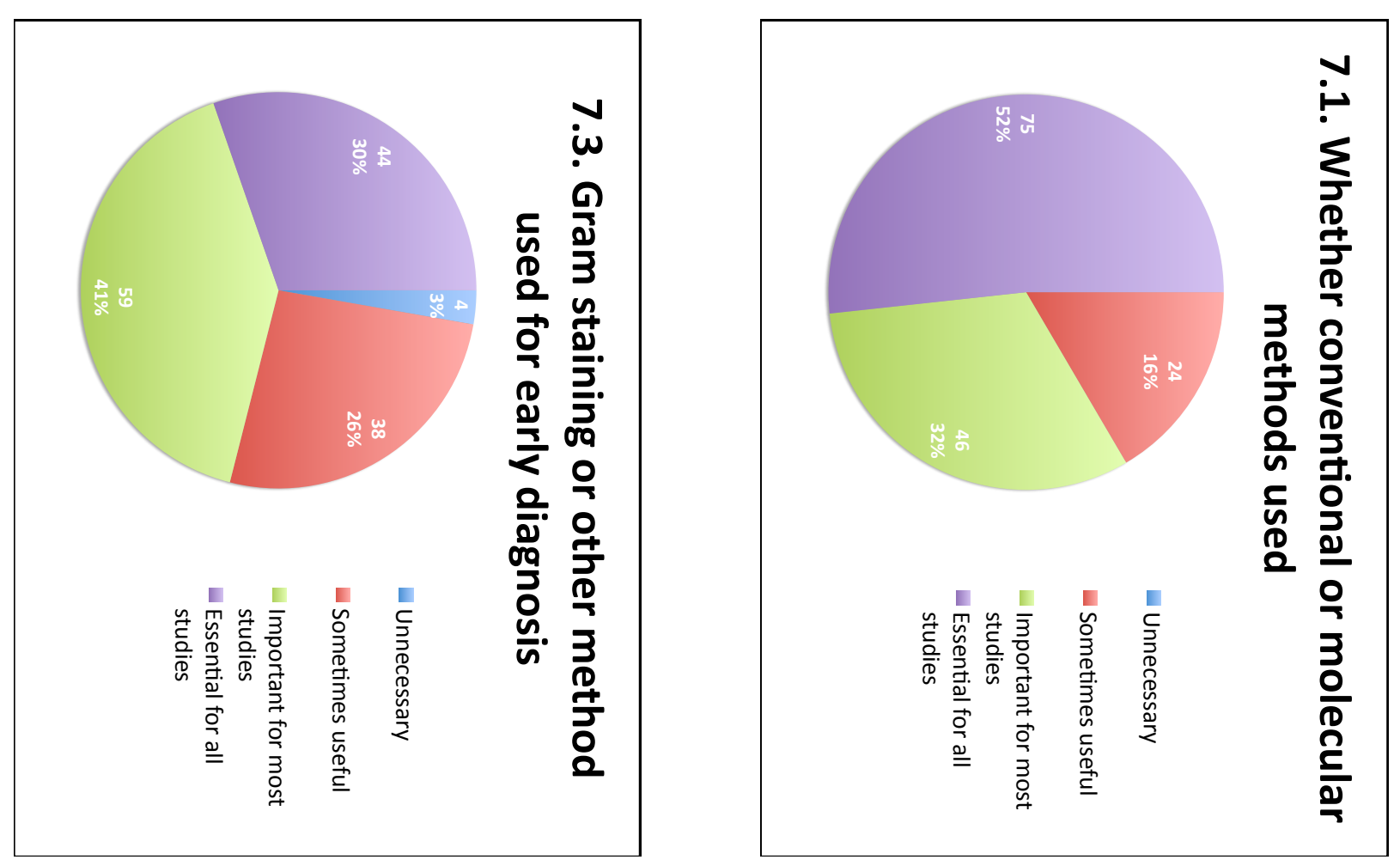

$\underset{\infty}{\omega}$
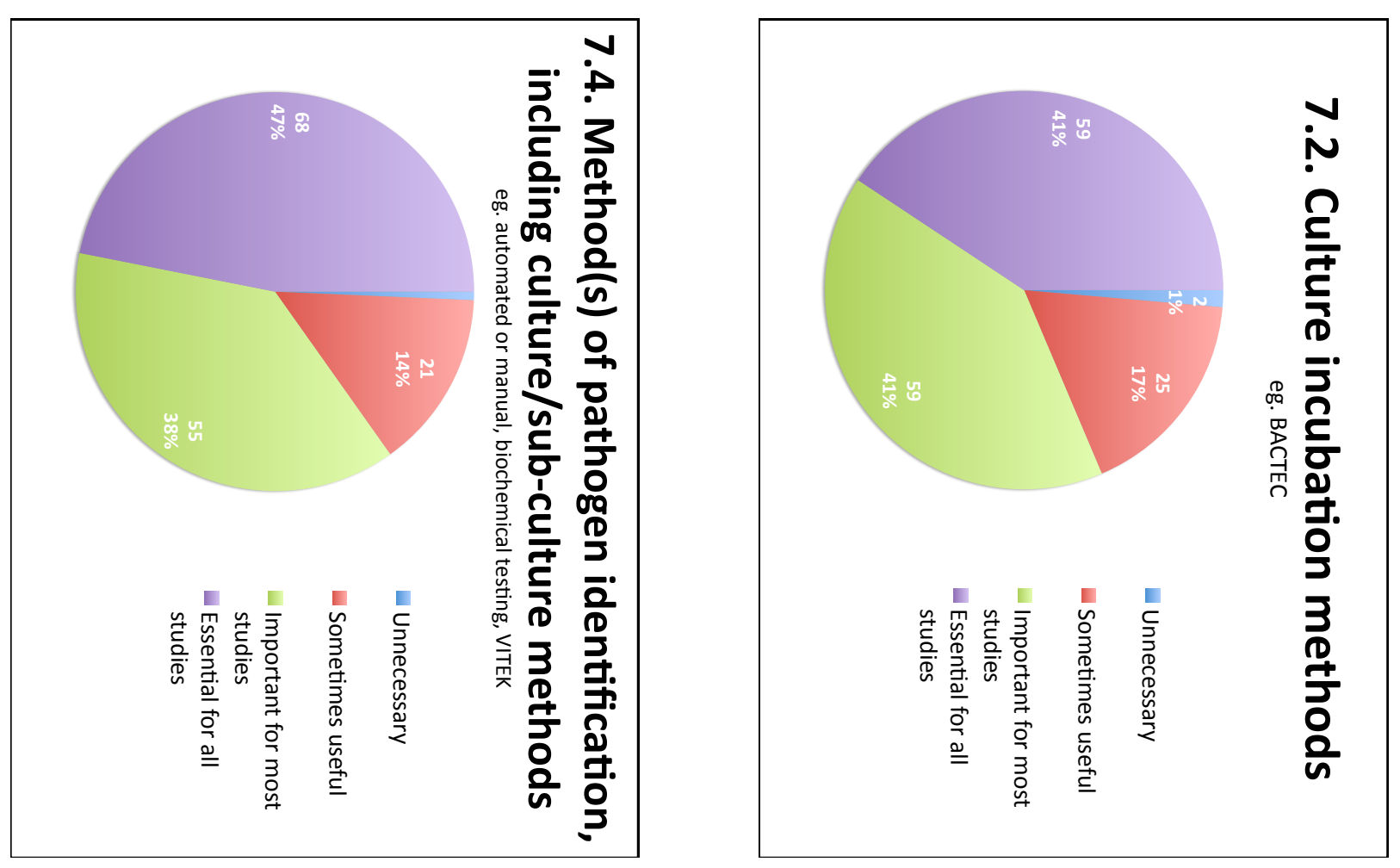

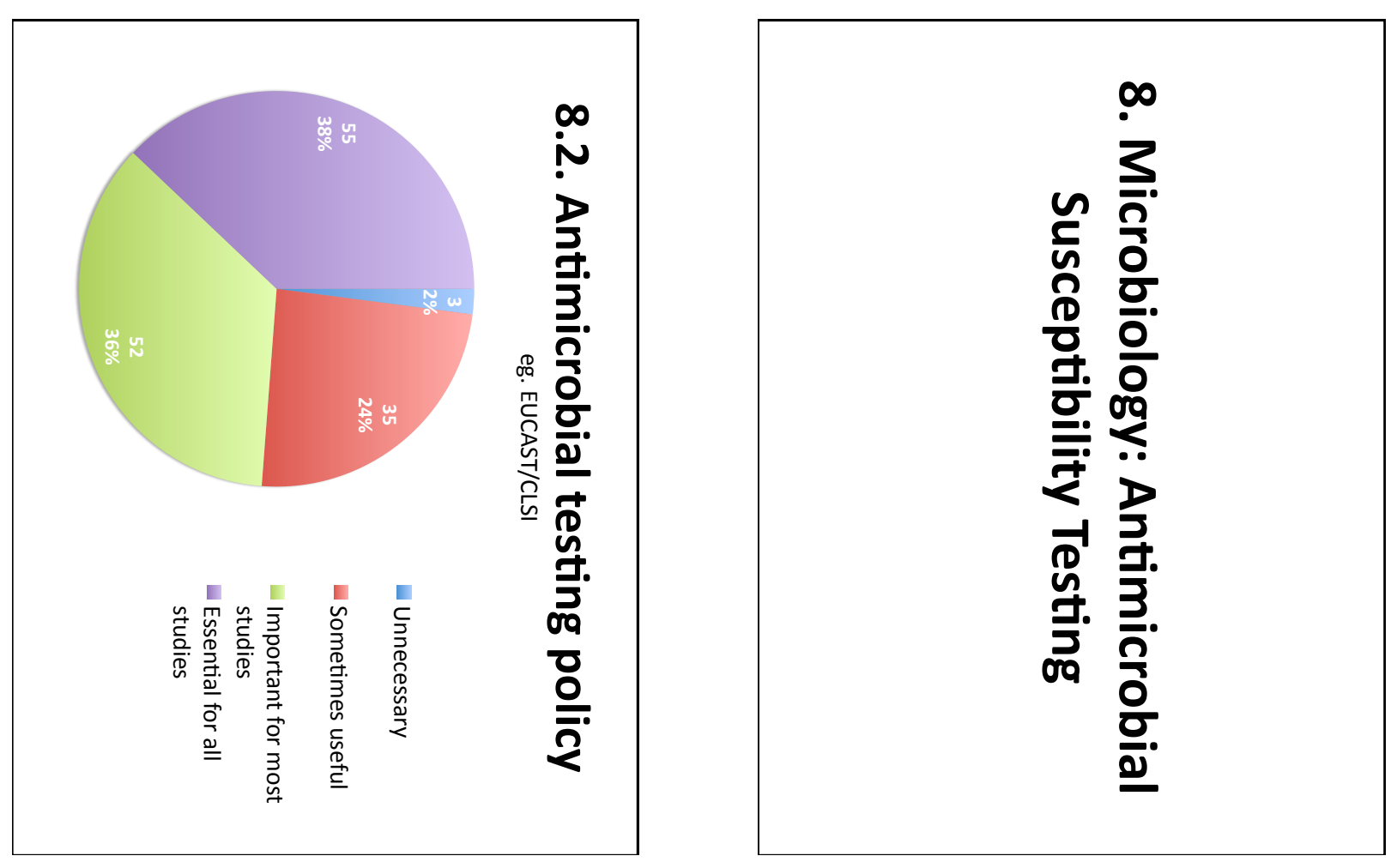

$\omega$
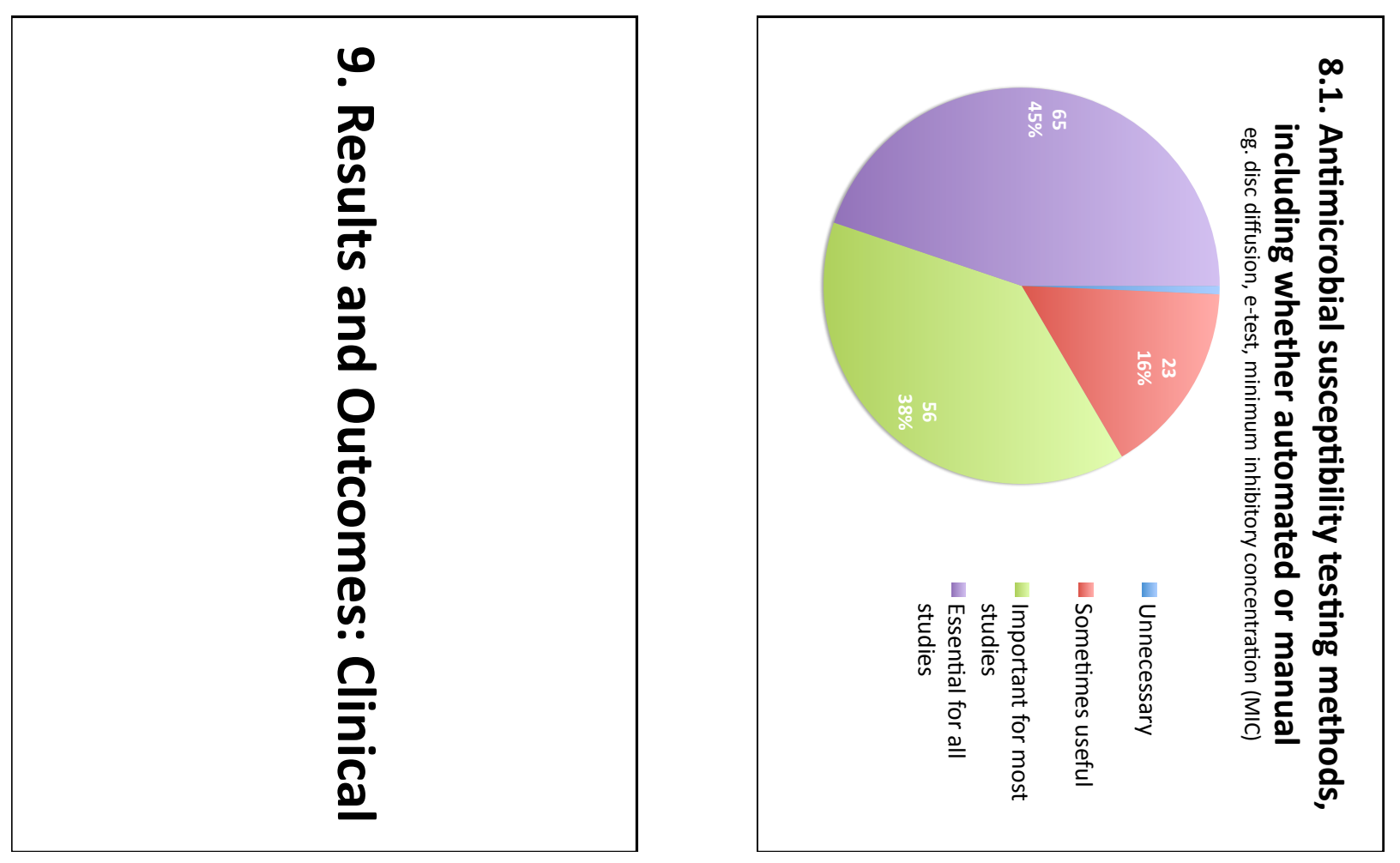

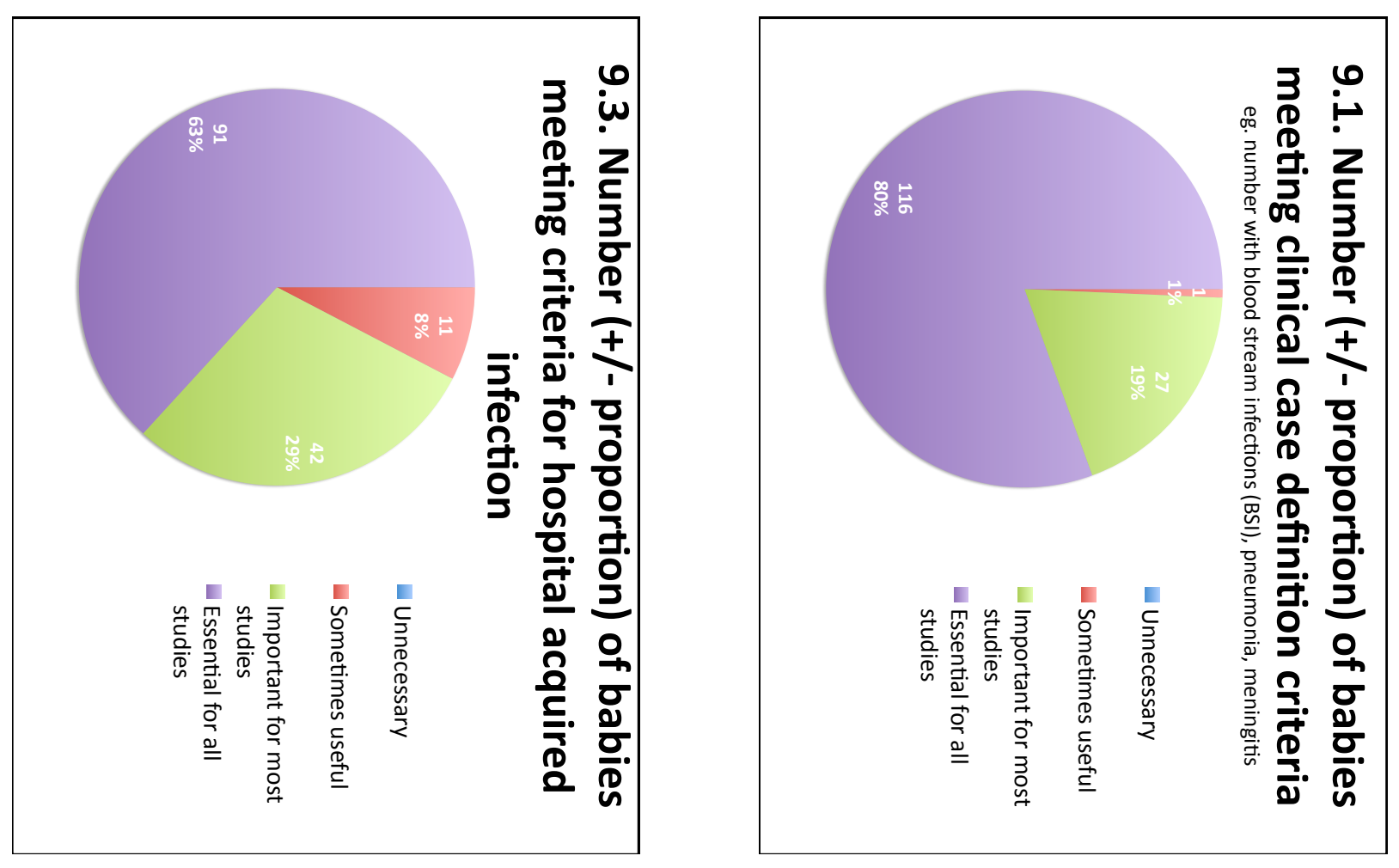

b
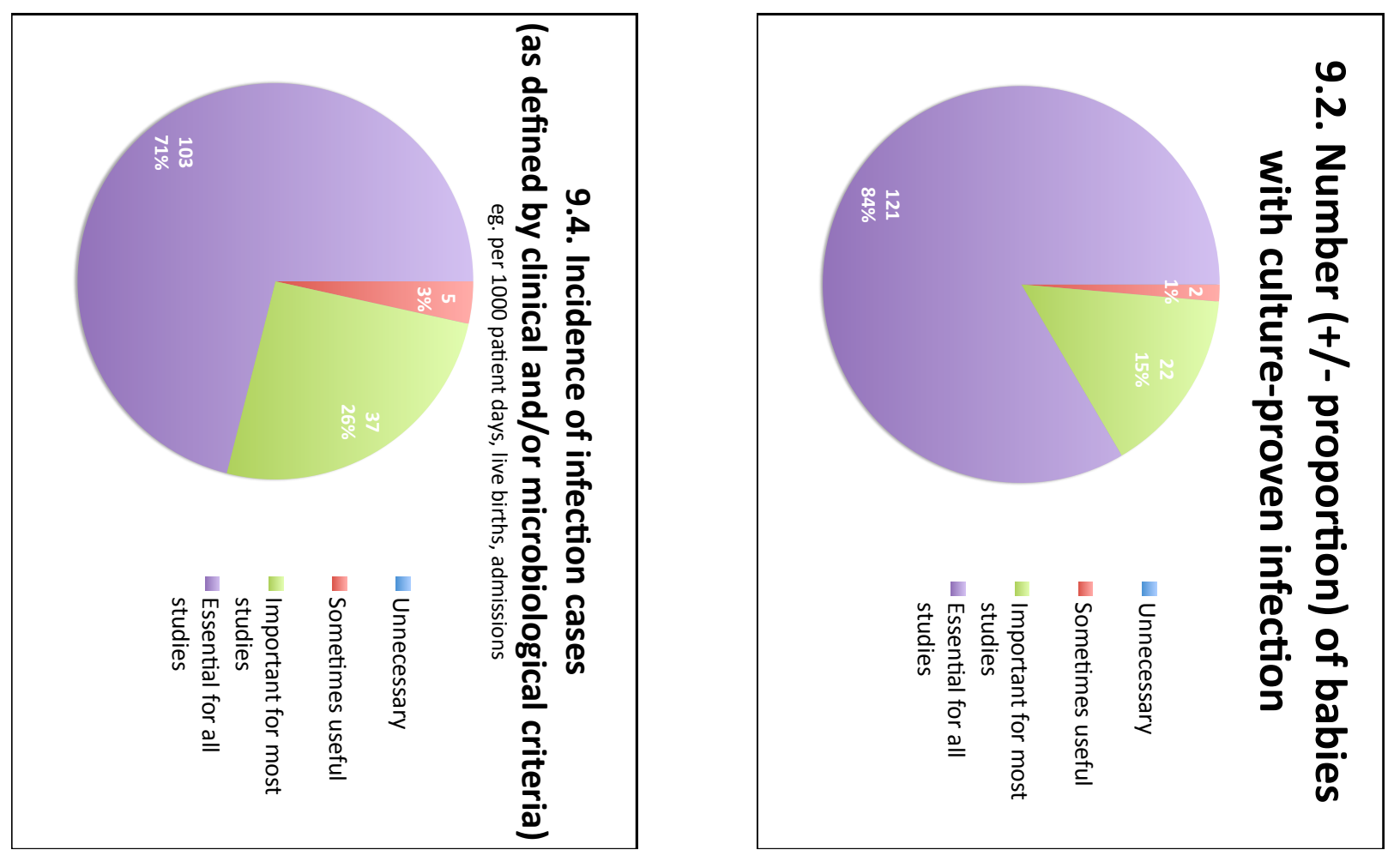

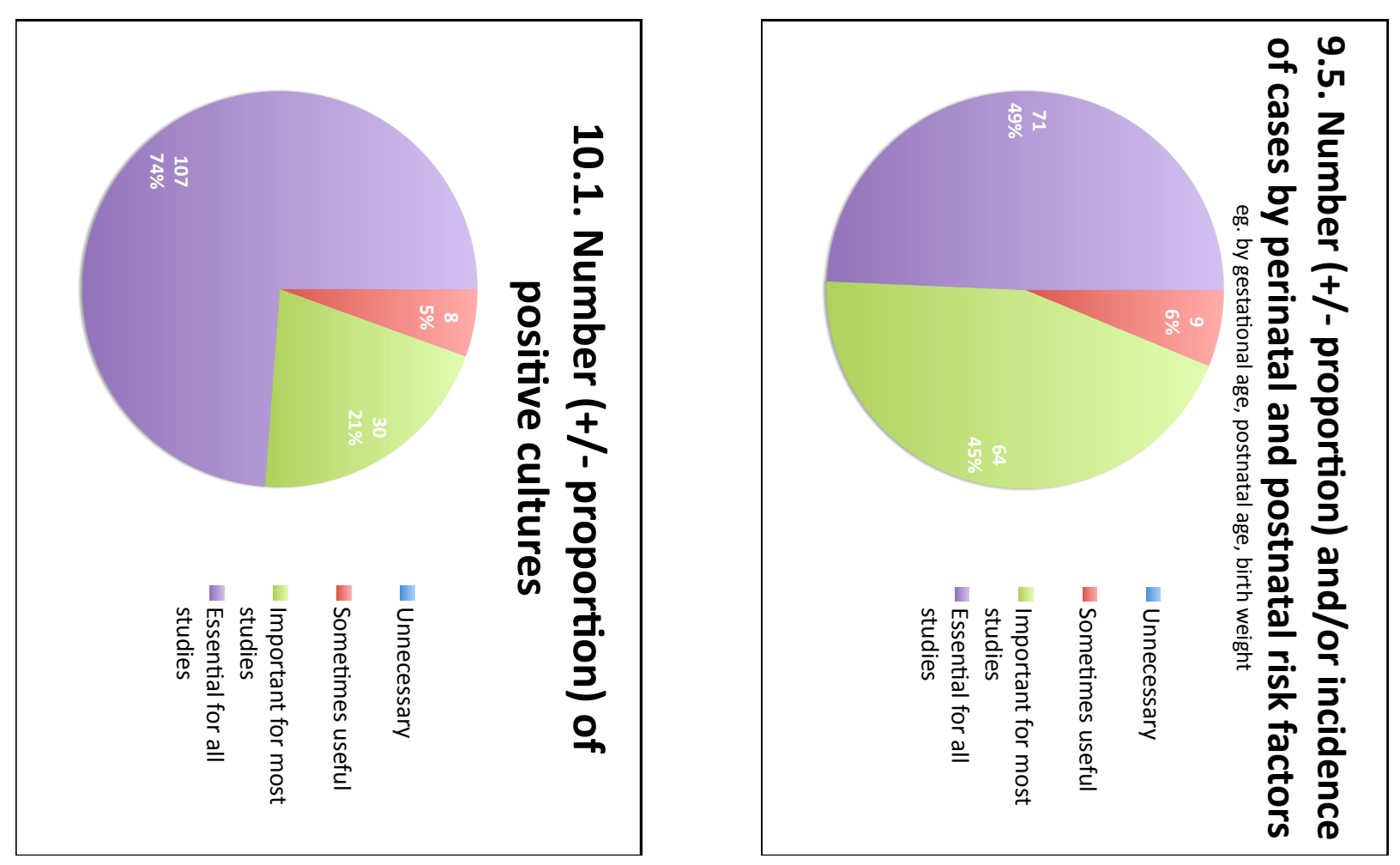

$\stackrel{\mapsto}{\mapsto}$
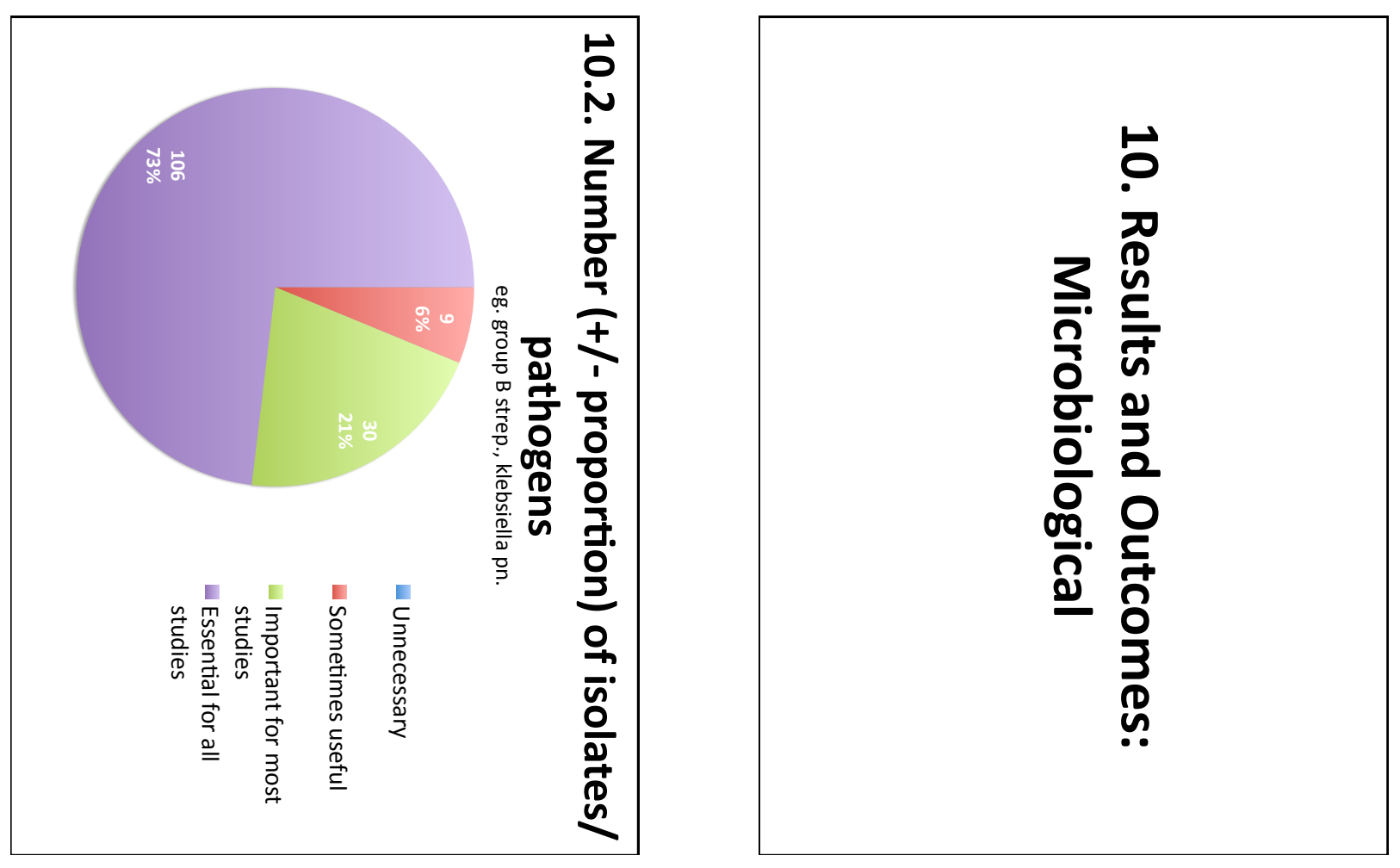

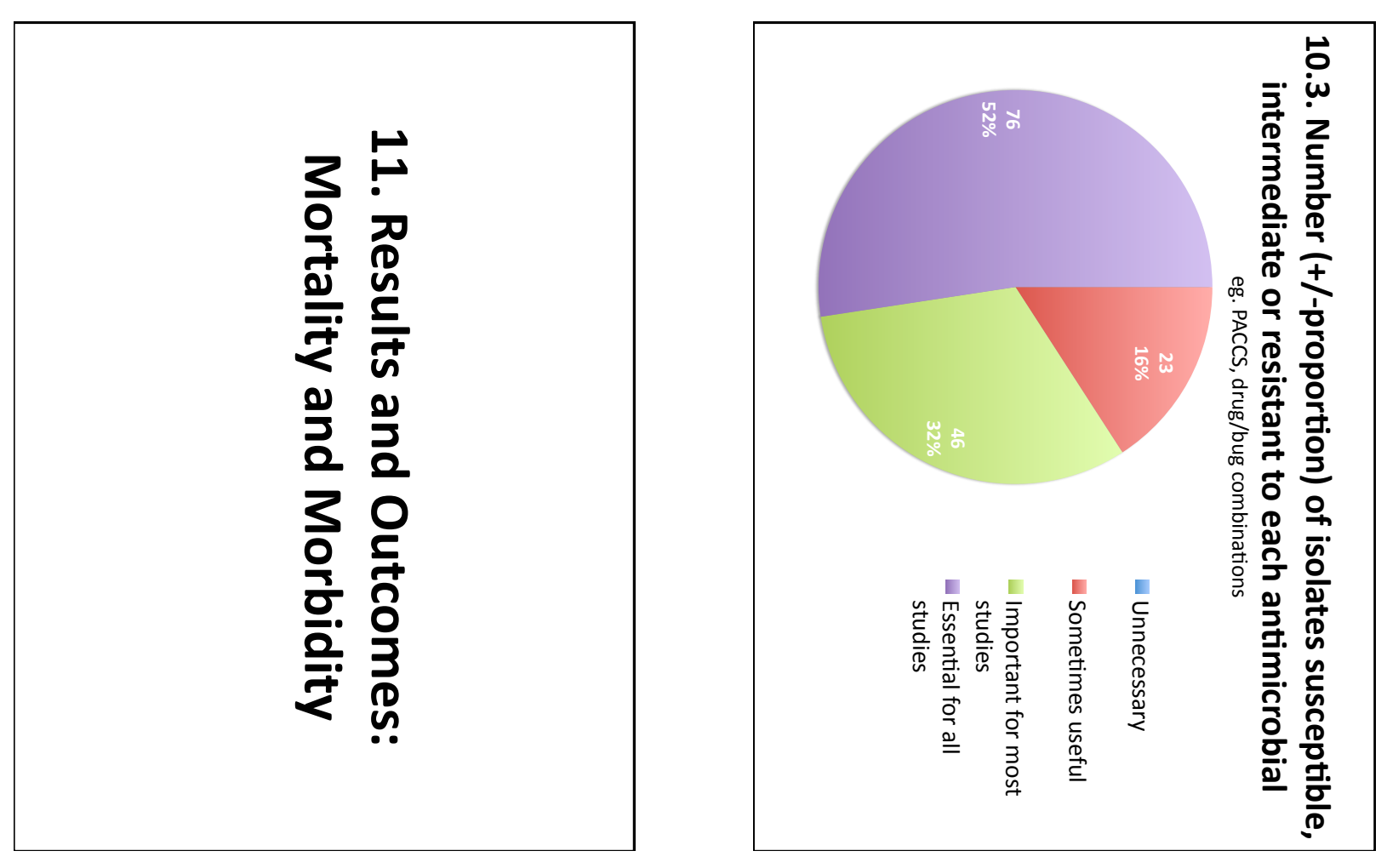

$\stackrel{D}{N}$
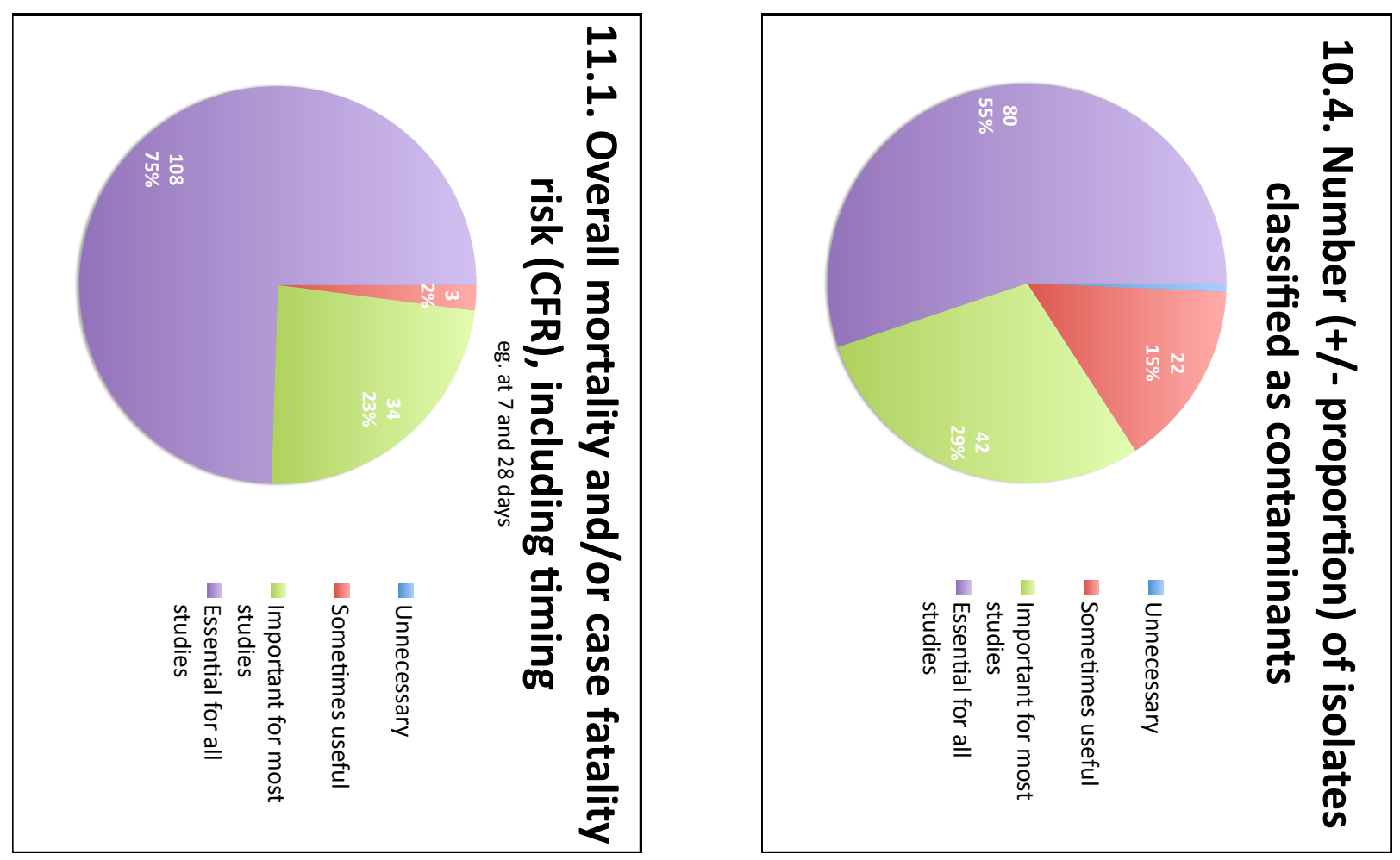

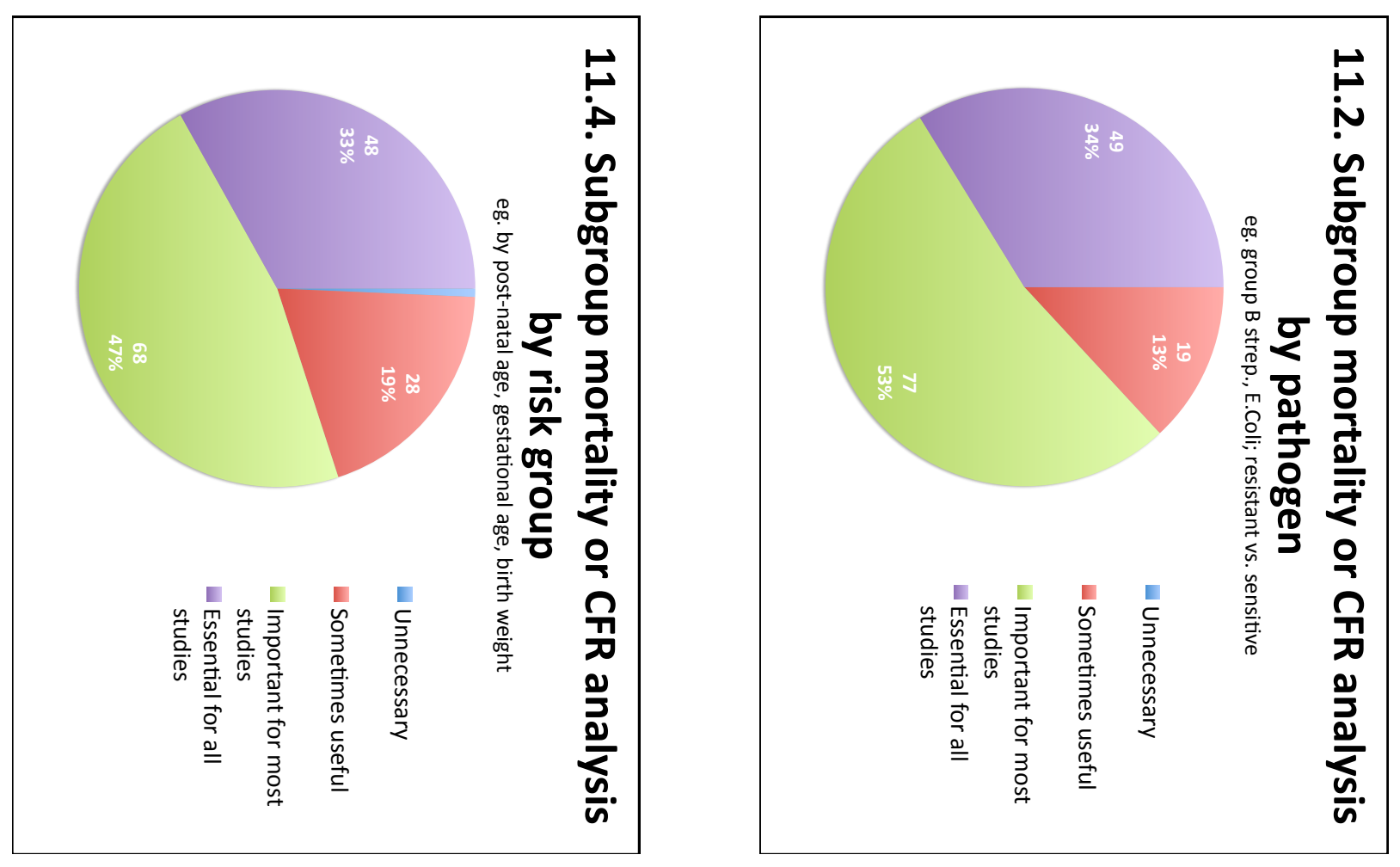

$\stackrel{+}{\omega}$
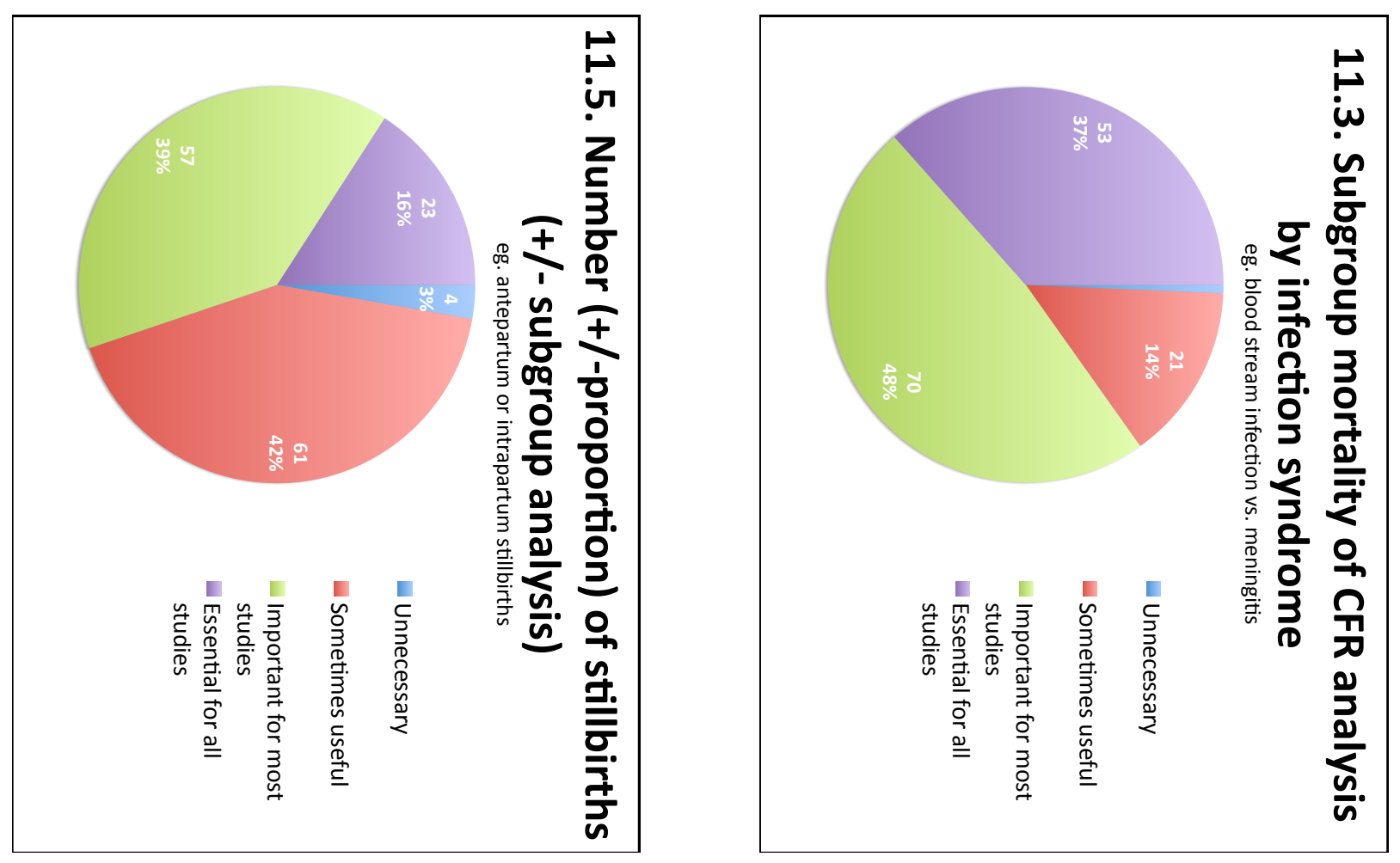

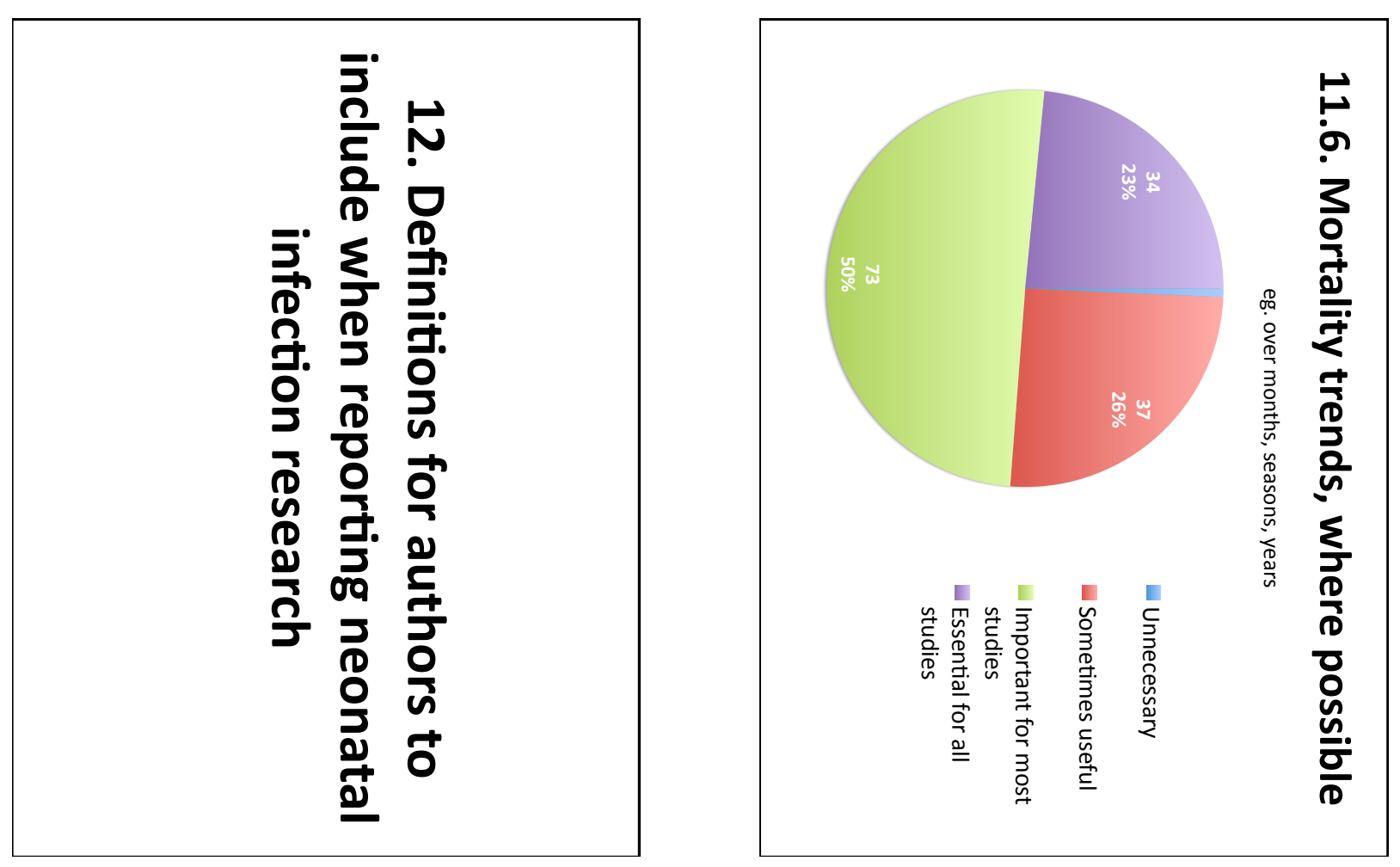

$\stackrel{D}{A}$
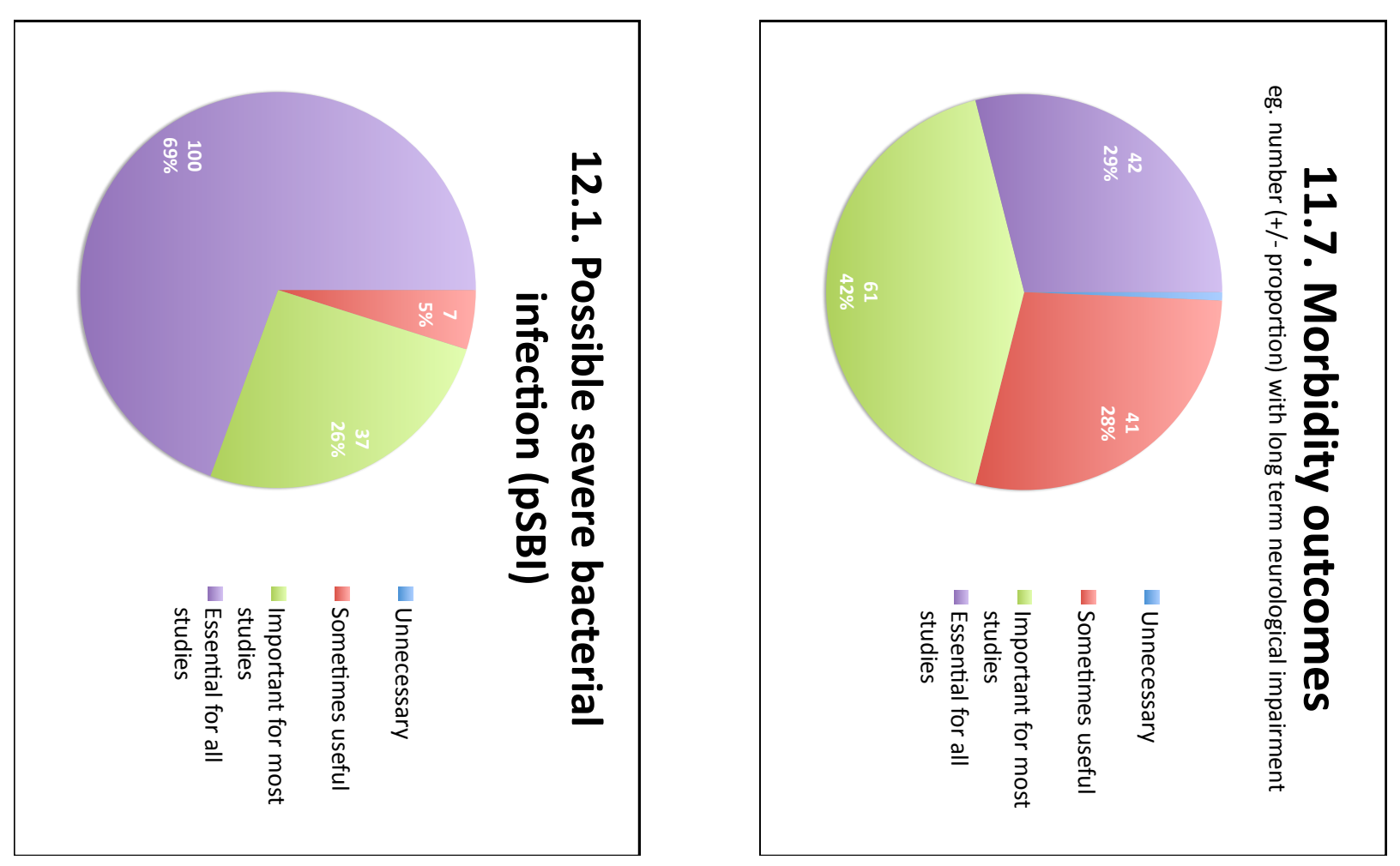

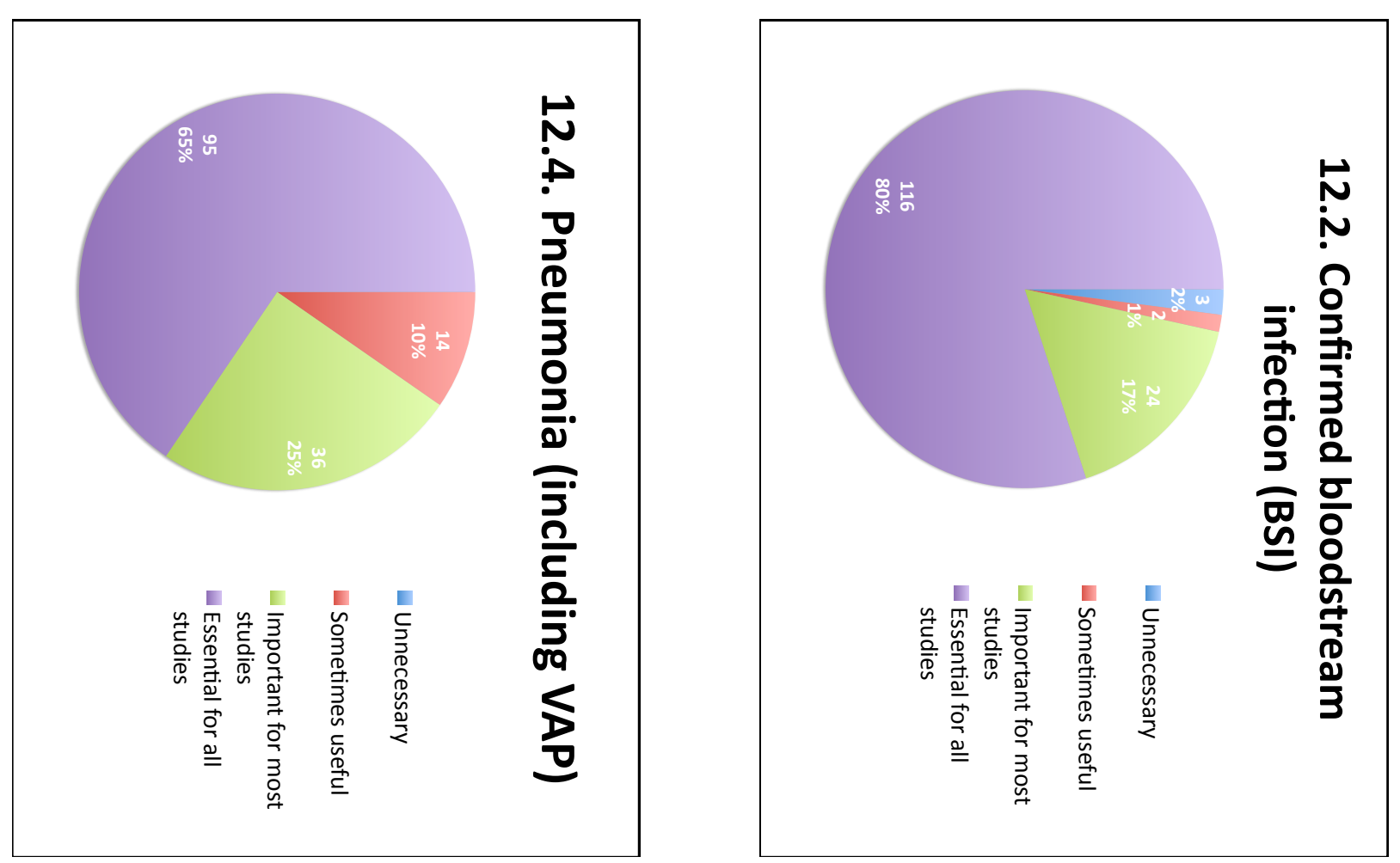

ज
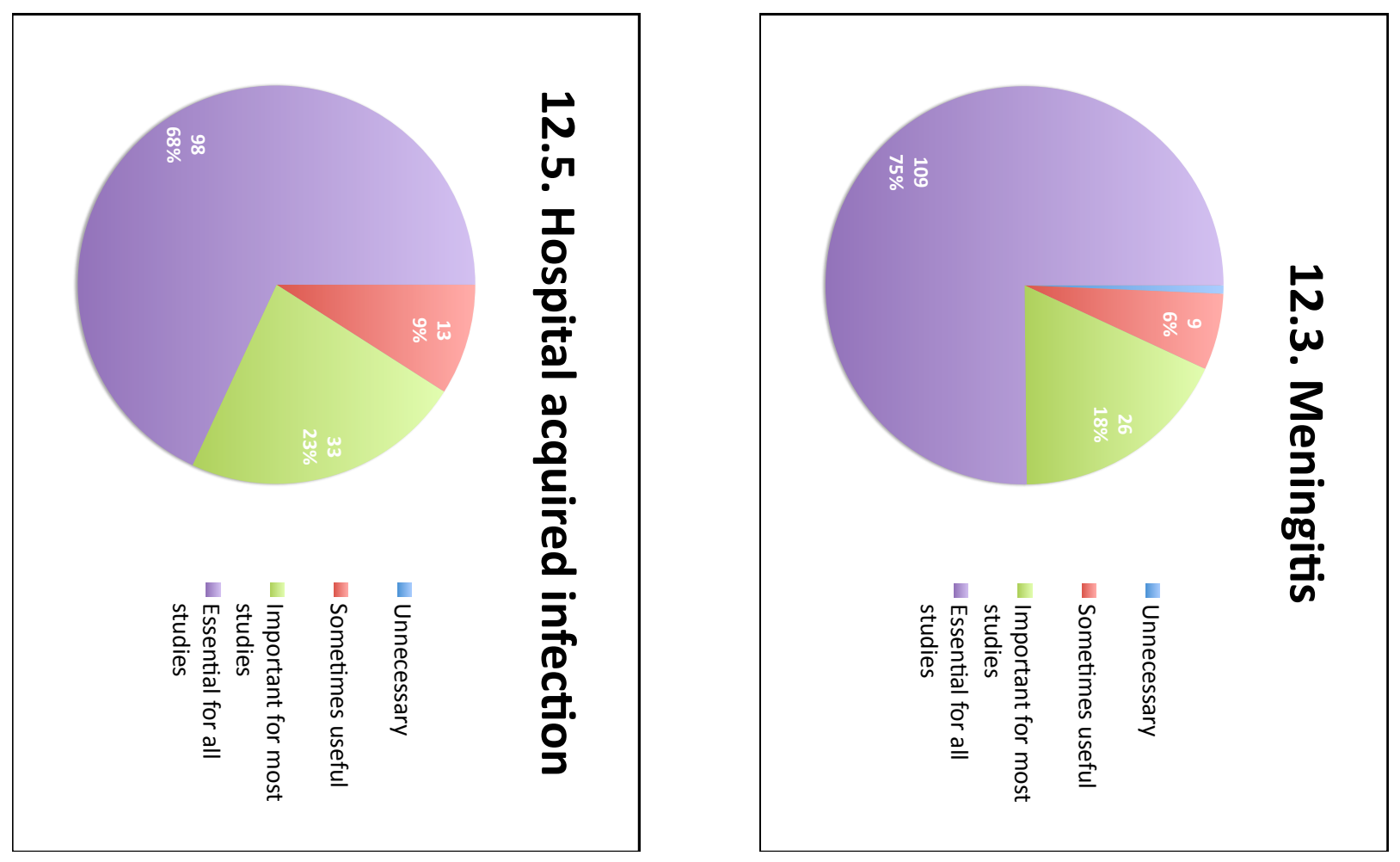

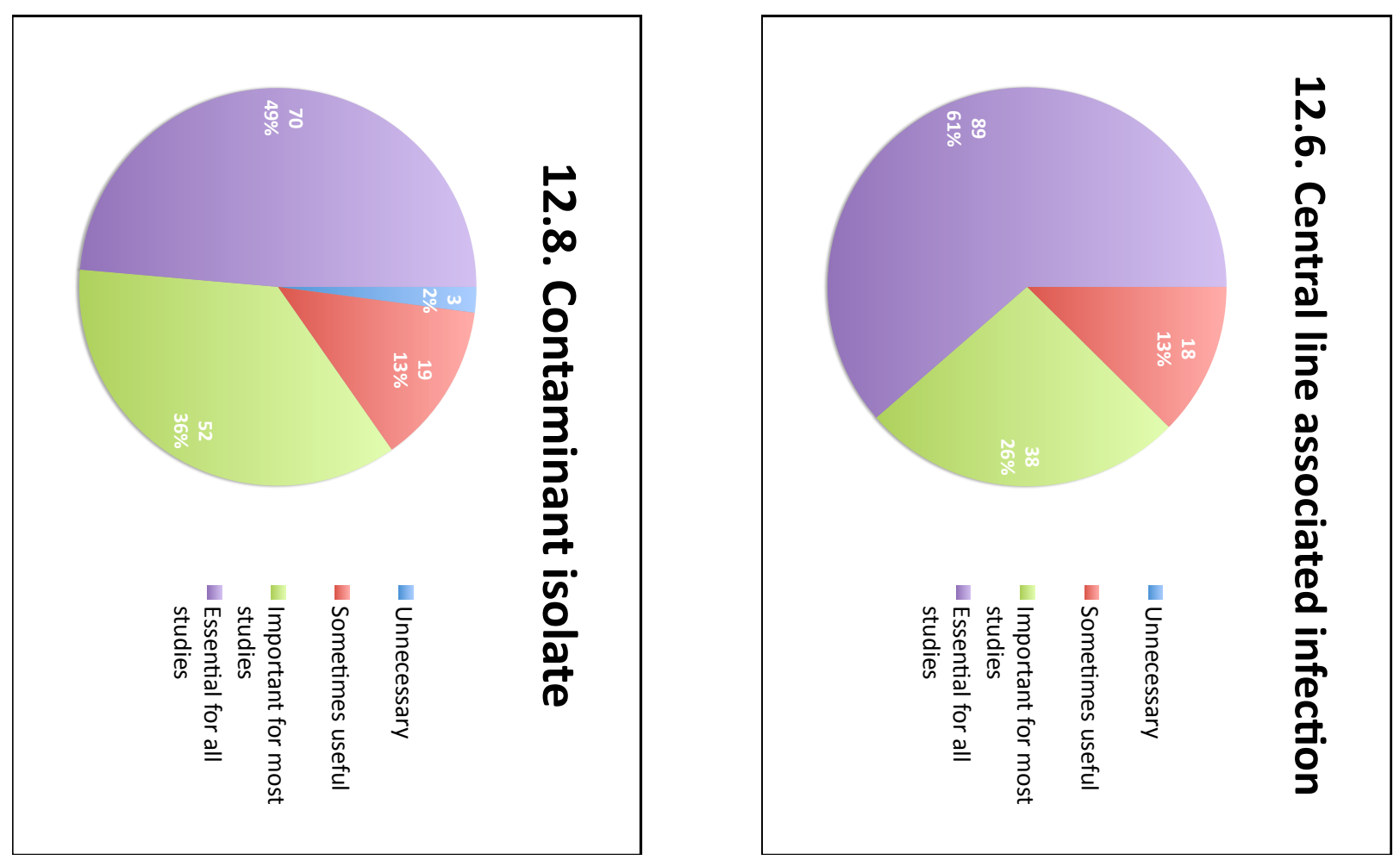

के
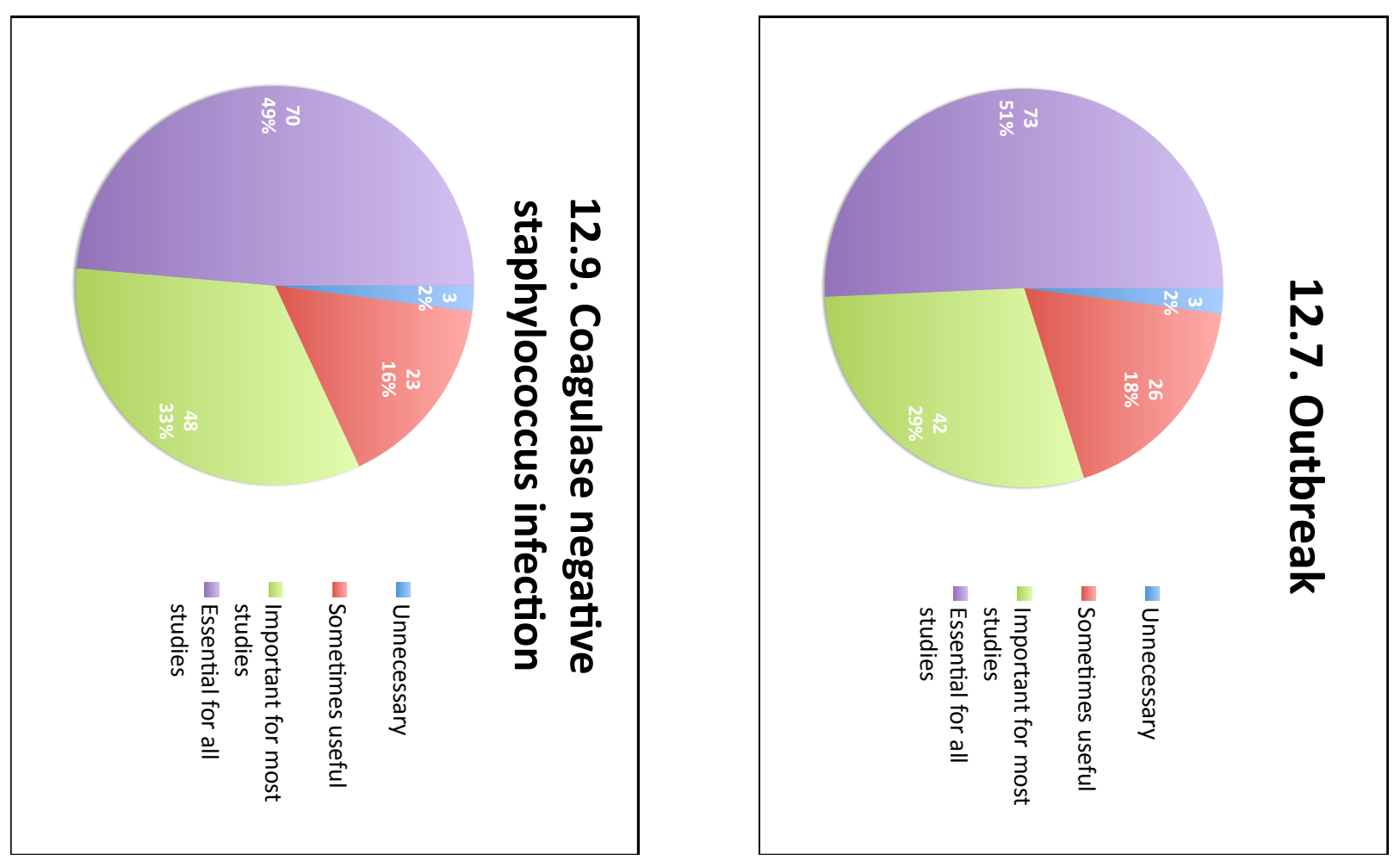

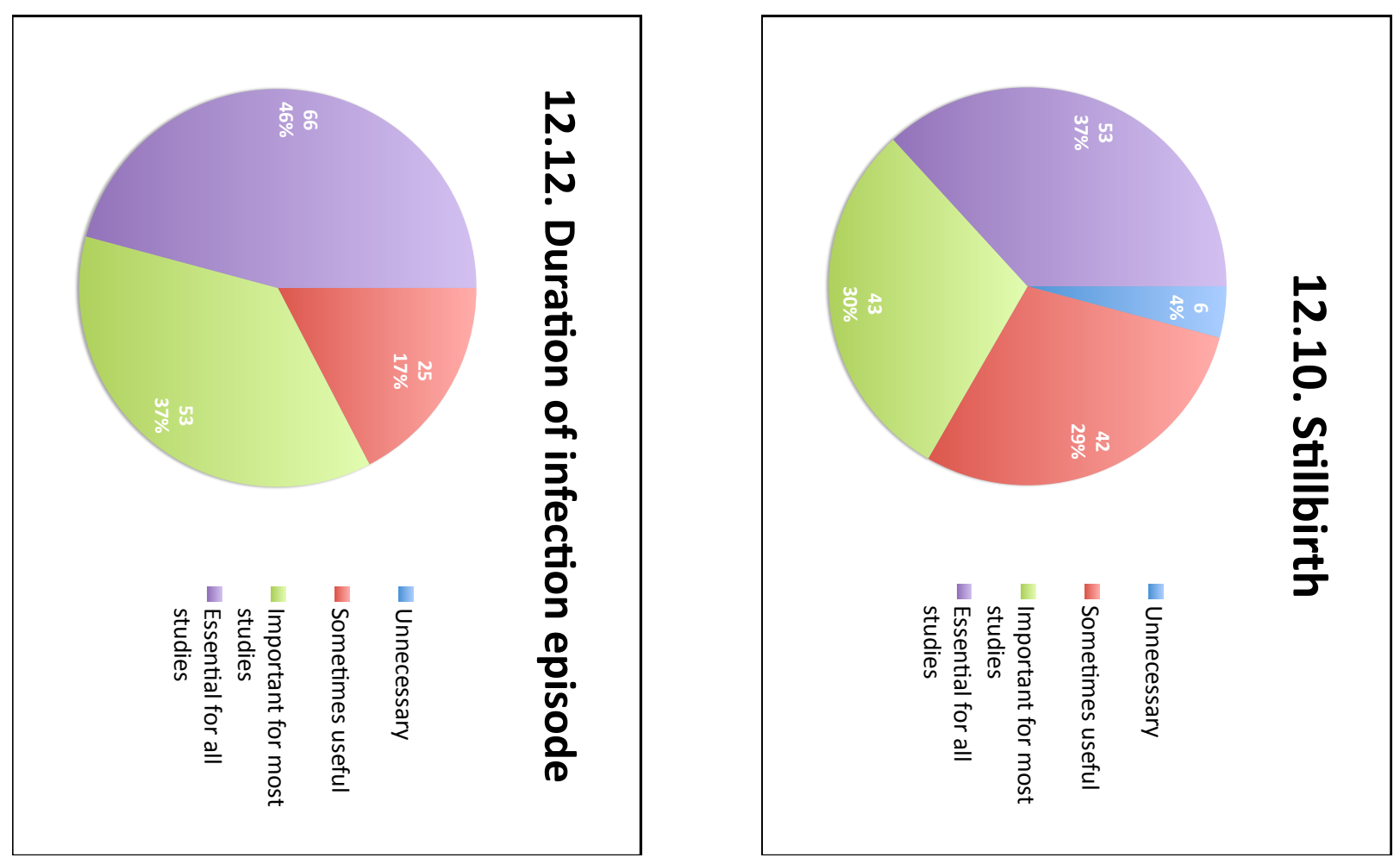

$\pm$
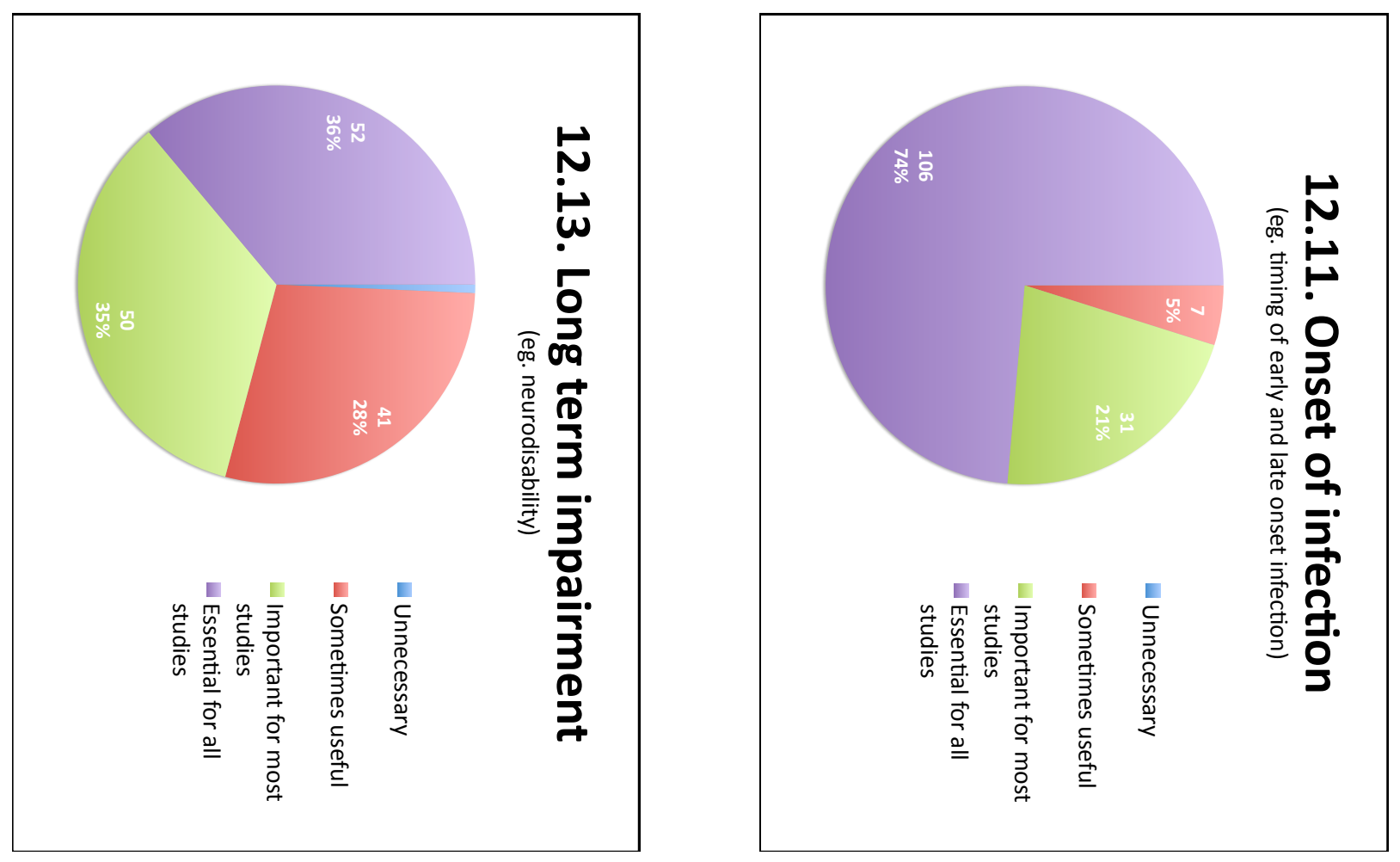

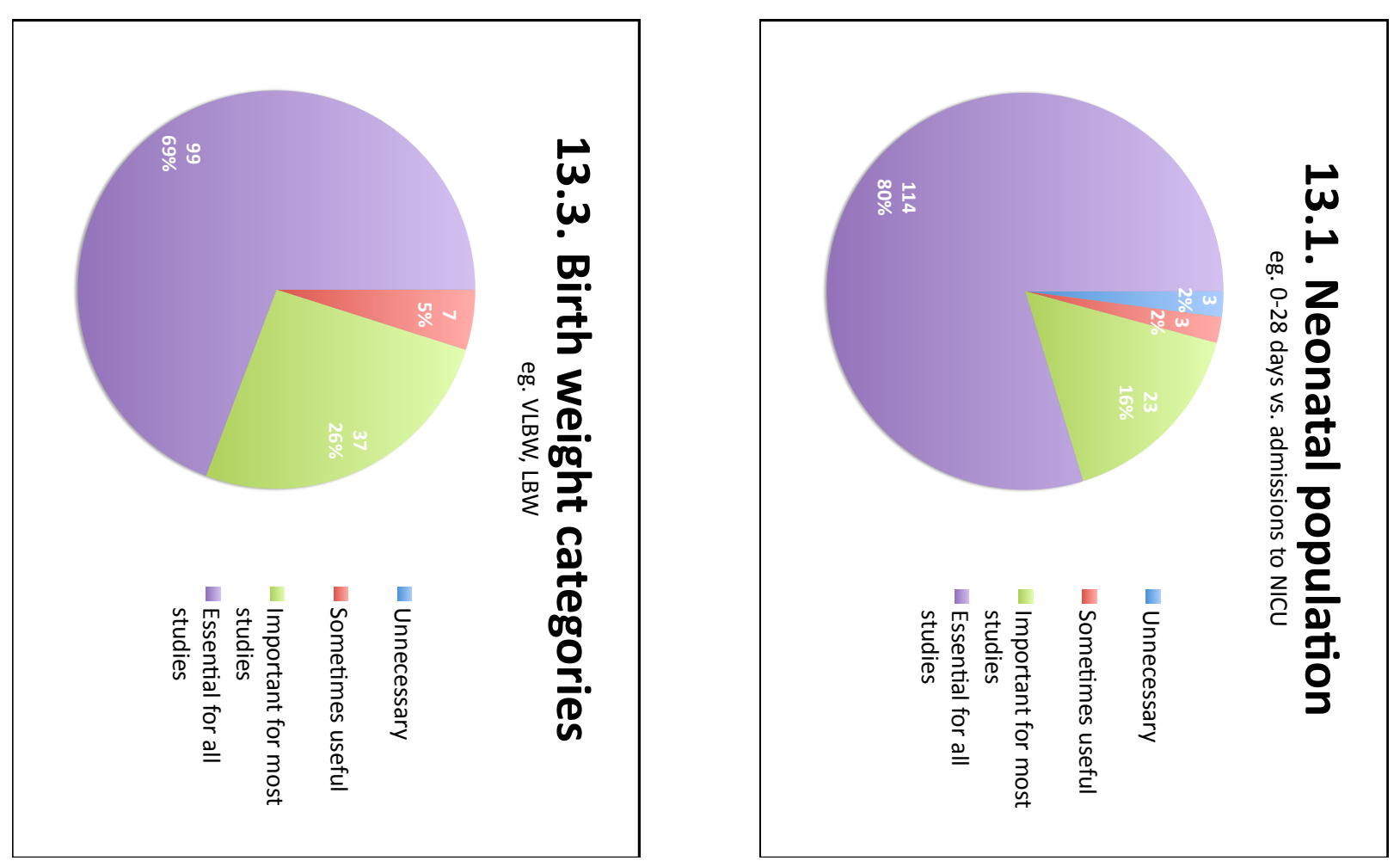

$\stackrel{\infty}{\infty}$
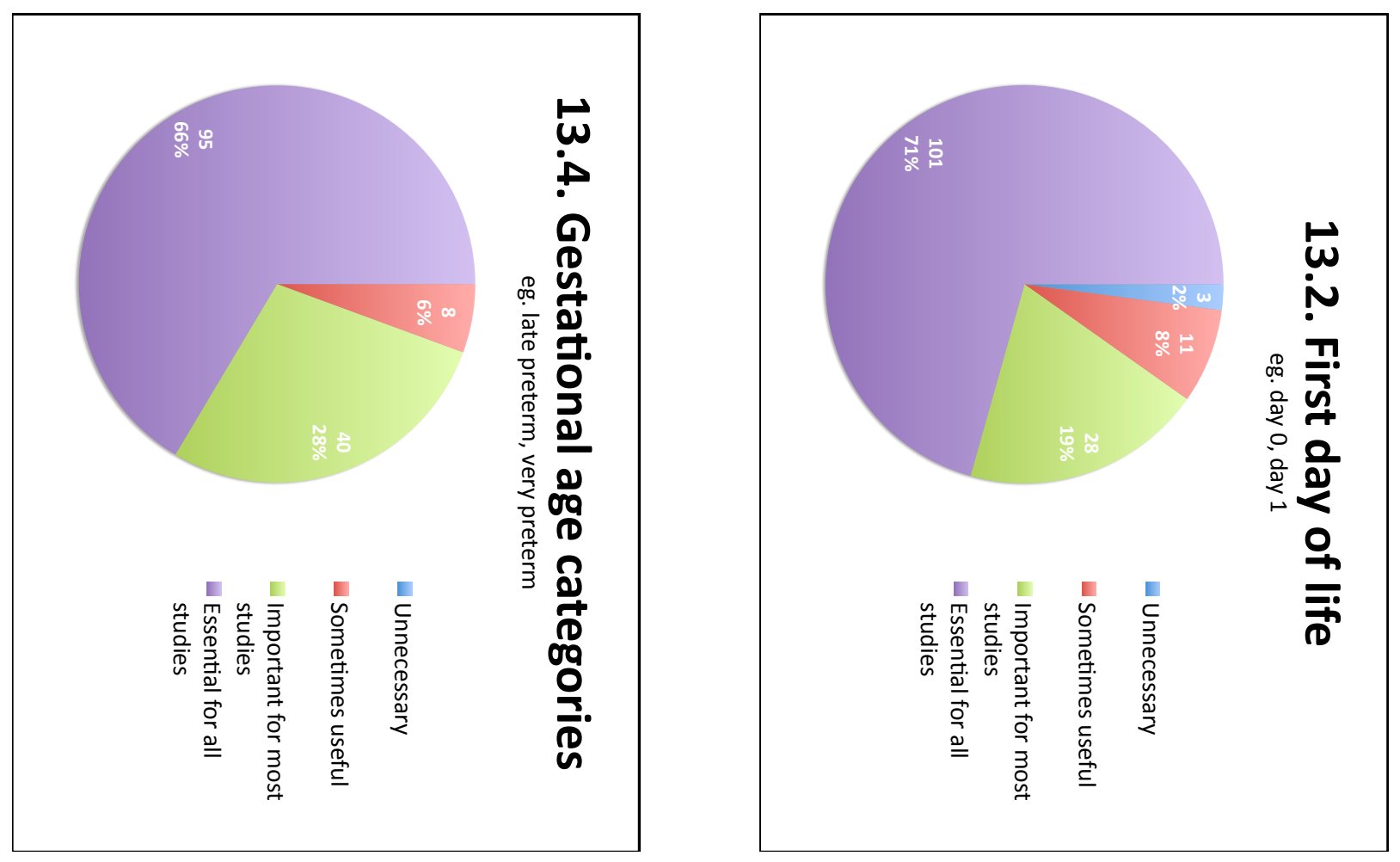

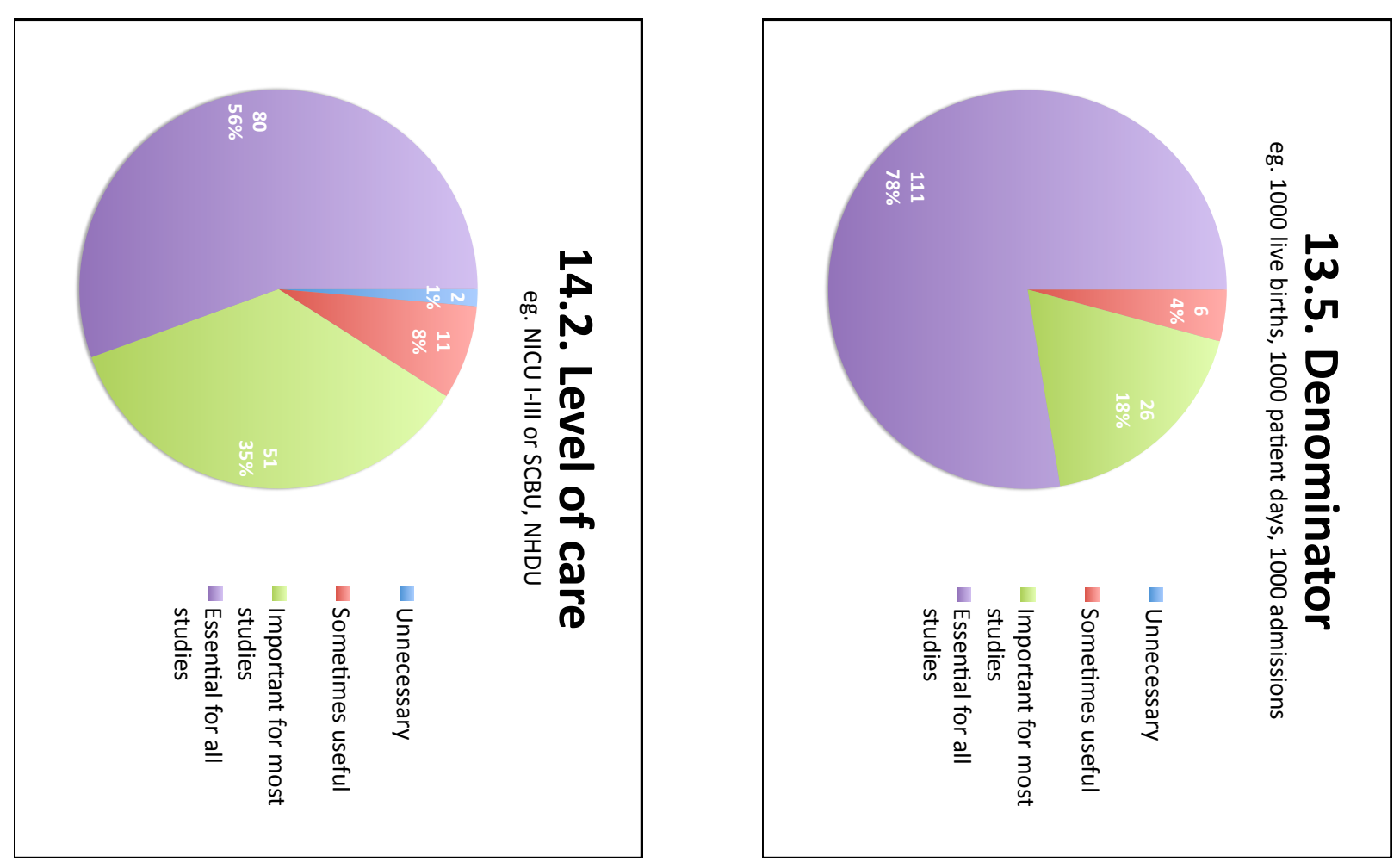

$\overrightarrow{6}$

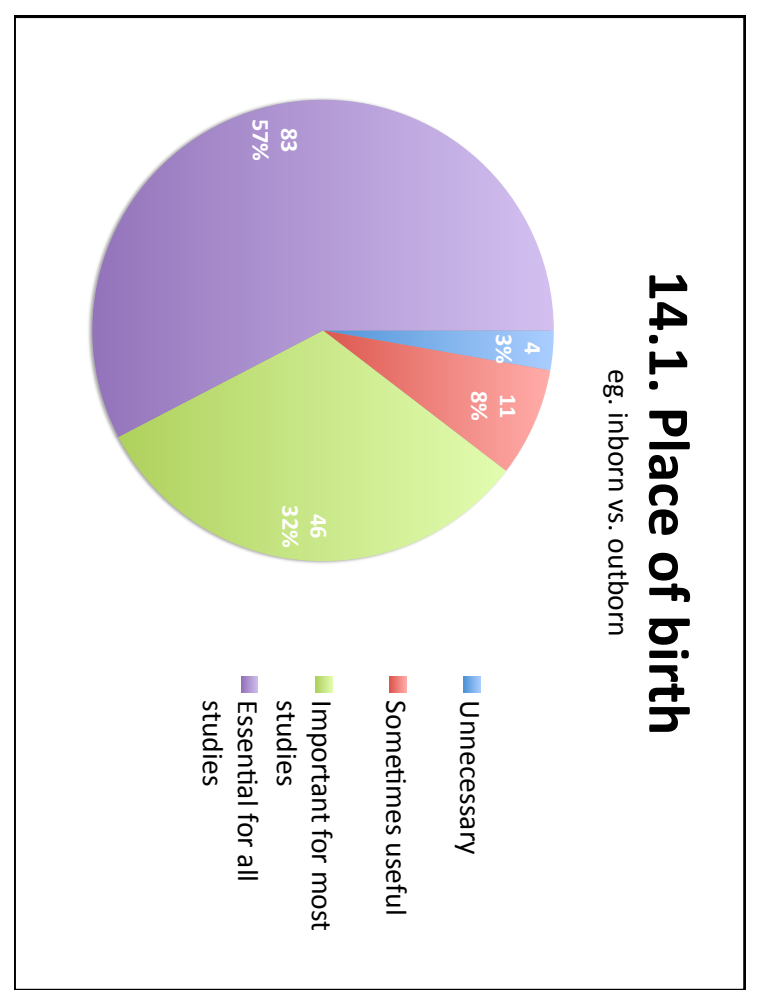


3A. Figure 2b: Graphic showing structural relationship between $\mathrm{STROBE}^{29}, \mathrm{STROME}^{-\mathrm{ID}^{31}}$, and STROBE-NI

\begin{tabular}{|c|c|c|c|c|}
\hline & & STROBE & STROME-ID & STROBE-NI \\
\hline \multirow{2}{*}{ TITLE and ABSTRACT } & & $1(\mathrm{a})$ & STROME-ID 1.1 & \\
\hline & & $1(\mathrm{~b})$ & & \\
\hline \multirow{2}{*}{ INTRODUCTION } & Background/rationale & 2 & STROME-ID 2.1 & \\
\hline & Objectives & 3 & STROME-ID 3.1 & \\
\hline \multirow{31}{*}{ METHODS } & \multirow{12}{*}{ Study design } & 4 & STROME-ID 4.1 & \\
\hline & & & STROME-ID 4.2 & \\
\hline & & & STROME-ID 4.3 & \\
\hline & & & & STROBE-NI-4.1 \\
\hline & & & & STROBE-NI-4.2 \\
\hline & & & & STROBE-NI-4.3 \\
\hline & & & & STROBE-NI-4.4 \\
\hline & & & STROME-ID 4.4 & STROBE-NI-4.5 \\
\hline & & & & STROBE-NI-4.6 \\
\hline & & & & STROBE-NI-4.7 \\
\hline & & & & STROBE-NI-4.8 \\
\hline & & 5 & STROME-ID 5.1 & \\
\hline & \multirow{6}{*}{ Setting } & & & STROBE-NI-5.1 \\
\hline & & & & STROBE-NI-5.2 \\
\hline & & & & STROBE-NI-5.3 \\
\hline & & & & STROBE-NI-5.4 \\
\hline & & & & STROBE-NI-5.5 \\
\hline & & & & STROBE-NI-5.6 \\
\hline & \multirow{3}{*}{ Participants } & $6(a)$ & STROME-ID 6.1 & \\
\hline & & $6(\mathrm{~b})$ & & \\
\hline & & & & STROBE-NI-6.1 \\
\hline & Variables & 7 & & STROBE-NI-7.1 \\
\hline & Data source/measurement & 8 & STROME-ID 8.1 & \\
\hline & Bias & 9 & STROME-ID 9.1 & \\
\hline & Study size & 10 & STROME-ID 10.1 & \\
\hline & Quantitative variables & 11 & & \\
\hline & & $12(a)$ & STROME-ID 12.1 & \\
\hline & & $12(b)$ & STROME-ID 12.2 & \\
\hline & Statistical methods & $12(c)$ & & \\
\hline & & $12(d)$ & & \\
\hline & & $12(\mathrm{e})$ & & \\
\hline \multirow{17}{*}{ RESULTS } & \multirow{9}{*}{ Descriptive data } & 13(a) & STROME-ID 13.1 & \\
\hline & & $13(b)$ & STROME-ID 13.2 & \\
\hline & & $13(c)$ & & STROBE-NI-13.1 \\
\hline & & 14(a) & STROME-ID 14.1 & STROBE-NI-14.1 \\
\hline & & & & STROBE-NI-14.2 \\
\hline & & & & STROBE-NI-14.3 \\
\hline & & & & STROBE-NI-14.4 \\
\hline & & $14(b)$ & & \\
\hline & & $14(c)$ & & \\
\hline & \multirow{4}{*}{ Outcome data } & 15 & & STROBE-NI-15.1 \\
\hline & & & & STROBE-NI-15.2 \\
\hline & & & & STROBE-NI-15.3 \\
\hline & & & & STROBE-NI-15.4 \\
\hline & \multirow{3}{*}{ Main results } & $16(a)$ & STROME-ID 16.1 & STROBE-NI-16.1 \\
\hline & & $16(b)$ & & \\
\hline & & $16(c)$ & & \\
\hline & Other analyses & 17 & & \\
\hline \multirow{4}{*}{ DISCUSSION } & Key results & 18 & & \\
\hline & Limitations & 19 & STROME-ID 19.1 & STROBE-NI-19.1 \\
\hline & Interpretation & 20 & & \\
\hline & Generalisability & 21 & & \\
\hline \multirow{2}{*}{ OTHER INFORMATION } & Funding & 22 & & \\
\hline & Ethics & & STROME-ID 23.1 & STROBE-NI-23.1 \\
\hline
\end{tabular}

